\title{
REVENGE REMIX:
}

TERROR NULLIUS (2018) AND THE POLITICS OF SAMPLE FILMMAKING

by

Caitlin Lynch

A Thesis Submitted for the Degree of Master of Arts

to the Film Studies Programme at

Victoria University of Wellington - Te Herenga Waka

April 2020 


\section{ACKNOWLEDGEMENTS}

Thank you to my supervisors, Dr. Missy Molloy and Dr. Alfio Leotta for their generous guidance, feedback and encouragement.

Thank you also to Soda_Jerk for their communication and support throughout my research. 


\begin{abstract}
TERROR NULLIUS (Soda_Jerk, 2018) is an experimental sample film that remixes Australian cinema, television and news media into a "political revenge fable" (soda_jerk.co.au). While TERROR NULLIUS is overtly political in tone, understanding its specific messages requires unpacking its form, content and cultural references. This thesis investigates the multiple layers of TERROR NULLIUS' politics, thereby highlighting the political strategies and capacities of sample filmmaking. Employing a historical methodology, this research contextualises TERROR NULLIUS within a tradition of sampling and other subversive modes of filmmaking, including Soviet cinema, Surrealism, avant-garde found-footage films, fan remix videos, and Australian archival art films. This comparative analysis highlights how Soda_Jerk utilise and advance formal strategies of subversive appropriation, fair use, dialectical editing and digital compositing to interrogate the relationship between media and culture. It also argues that TERROR NULLIUS employs postmodern and postcolonial approaches to archives and history to undermine positivist, linear historical constructions and colonial mythologies. Building on these formal and theoretical foundations, this thesis also closely reads TERROR NULLIUS to scrutinise the accessibility of its arguments for Australian and international audiences: one reading utilises Donna Haraway's cyberfeminist theory to interpret TERROR NULLIUS' progressive identity politics, and the second explores the cultural and historical references imbedded in TERROR NULLIUS' samples to unpack its commentary on contemporary debates in Australian politics (particularly regarding refugee detention and white nationalism). Ultimately, this multifaceted analysis of TERROR NULLIUS' form, content and references highlights the complexity of sample films' political messages, which are radically open to diverse interpretations.
\end{abstract}




\section{TABLE OF CONTENTS}

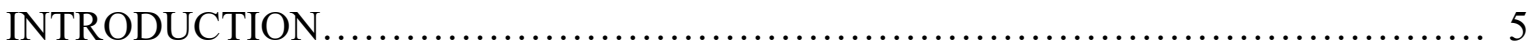

TERROR NULLIUS Unmixed................................................ 10

CHAPTER ONE: A History of Sample Filmmaking: Compilation,

Found-Footage and Remix ........................................................ 11

Sample Filmmaking Definitions...................................... 11

From Early Innovators to the Post-War Avant-Garde........................ 15

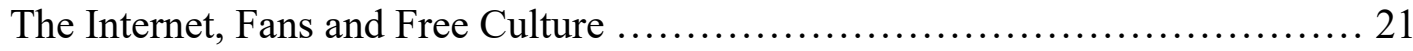

CHAPTER TWO: "From the Same Raw Material as History":

Historical Discourse and Archive Sampling ....................................... 30

Esfir Shub's Modernist Histories ............................................. 32

Histore(s) du Cinéma's Postmodern Constellations ............................. 37

Australian Postcolonial Sampling ...................................... 42

CHAPTER THREE: "Not Shot but Built": TERROR NULLIUS'

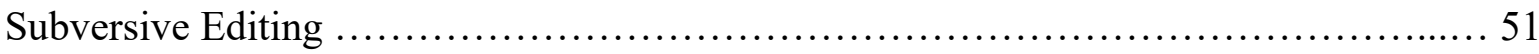

Dialectical Montage.................................................... 52

Uncanny Continuity................................................... 56

Collage Compositing ....................................................... 60

CHAPTER FOUR: A Harawayan Reading of TERROR NULLIUS ..................... 66

Overcoming Problematic Origins........................................ 68

Affinities and Accompliceship........................................... 73

Unresolved Ironies...................................................... 78

CHAPTER FIVE: Australian Interventions: TERROR NULLIUS

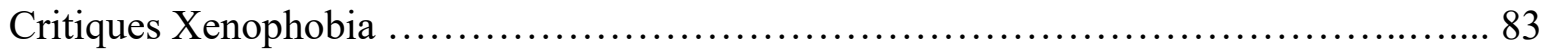

Historical Overview of Australian Immigration ............................ 85

TERROR NULLIUS' Refugee Narrative....................................... 89

Antipodean Camp in Postcolonial Politics.................................... 99

CONCLUSION: Between Political Ambitions and Activist Praxis..................... 104

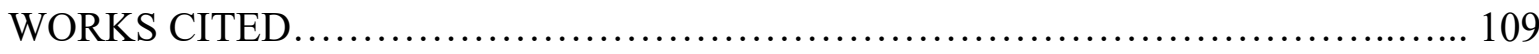




\section{INTRODUCTION}

TERROR NULLIUS, a 2018 sample film by two-person art collective Soda_Jerk, has a reputation for being highly political. Described by the filmmakers as "part political satire, eco-horror and road movie," TERROR NULLIUS samples 174 films, television shows, music videos, YouTube clips and news media associated with Australia into a 54-minute remix film that "offers an unwriting of Australian national mythologies." Five days before the film's premiere, its funding body, the Ian Potter Foundation, retracted their association with the project, deeming it "very controversial" and "un-Australian" (Downes; Heller-Nichols). Meanwhile, Australian popular press reviews (Buckmaster; Di Rosso; Juers) and scholarly publications (Heller-Nichols; Harkins-Cross; Barnett; Neumark) praised the film for its "unequivocal political agenda" (Heller-Nichols). Promoted as "a political revenge fable," TERRROR NULLIUS did well in the international film festival and gallery circuit, screening in dozens of cities around the world from Buenos Aires to Helsinki, Taipei to Istanbul. Glasgow Short Film Festival selected TERROR NULLIUS as its opening night feature, stating that the festival committee "welcomed [its] controversy" (Lloyd and Jehoul), while Wellington City Gallery featured the film in its Iconography of Revolt exhibition. Perhaps the strongest testament to TERROR NULLIUS' political aura is one critic's reflection that "simply watching and supporting it feels vaguely like activism" (Juers).

However, while many viewers seem to agree that TERROR NULLIUS is political, ambiguity remains regarding the specifics of its political messages, how they are constructed, and who can access them. The Ian Potter Foundation does not provide any details on exactly which elements of the film offended their political sensibilities. Meanwhile, Australian press reviews generally focus on the film's domestic political commentary, referencing the samples' cultural and historical references. As short form pieces, these reviews tend to skim over both micro-level details (how Soda_Jerk's editing transforms individual references into an argument) and the film's macro-level significance (what TERROR NULLIUS' appropriated form reveals about Australian culture). Additionally, these reviews do not touch on the film's popularity internationally, for audiences who have no, or limited prior knowledge of the Australian media Soda_Jerk sample and the Australian politics they reference. This thesis aims to demystify TERROR NULLIUS' politics by asking: in which senses is the film political, and how does its politics impact its domestic and international receptions? 


\section{METHODOLOGY}

As its reception indicates, TERROR NULLIUS' politics are multi-faceted, so my analysis breaks politics down into three categories: politics of form, politics of identity, and explicit politics. Politics of form asks how a film's aesthetic, technical and structural aspects stimulate a political sensibility. Drawing on theorists such as Guy Debord and Sergei Eisenstein, I examine how TERROR NULLIUS employs subversive strategies affiliated with various twentieth-century avant-gardes to undermine mainstream media and foster critical consciousness. Clarifying the subversive politics imbedded in TERROR NULLIUS' form helps explain its capacity to resonate politically with viewers who lack prior knowledge of the original media and Australian political history that Soda_Jerk draw on. Politics of identity refers to the "interplay between power [and] culture" that constructs social identity categories such as class, race and gender, and the way people utilise such identities to collectively “challenge, subvert or negotiate culture. . . and contest structures of power" (Hill and Wilson 2). Cultural media, including film, is involved in this interplay, both perpetuating and challenging the ideological discourses that inform social identity. A politics of identity framework analyses how Soda_Jerk critique and rework the social representations of the sources they sample, and reads TERROR NULLIUS in relation to debates within contemporary, international social movements. Finally, I propose the concept of 'explicit politics' to refer to institutional forms of politics, including specific policies, politicians, national governance and political histories. Unpacking TERROR NULLIUS' references to explicit political events and figures allows me to detail how and why the film was received politically by those with in-depth prior knowledge of Australian current events, cultural debates, and history. While these three categories identify different aspects of TERROR NULLIUS' politics, they are not mutually exclusive and often overlap or inform one another. Employing this tripartite framework to analyse the film's politics demonstrates the multiple, often interconnected layers of sample cinema's meaning.

Inspired by the hybrid nature of sampling, this thesis combines multiple methodologies, examining TERROR NULLIUS' three forms of politics through historical, formal, conceptual, contextual and creative modes of film analysis. Historical analysis involves situating TERROR NULLIUS within the literature on sampling and other subversive forms of filmmaking. Combining theory with formal analysis, I compare TERROR NULLIUS with a range of political sample films from the last hundred years, outlining how it borrows from, rejects and innovates previous sampling and editing techniques from the cinema that 
precedes it. I then use close reading to investigate how the politics of TERROR NULLIUS' form intersects with its themes and content to produce arguments relevant to identity politics and explicit political debates ongoing in contemporary Australia. I conduct two close readings: one using a conceptual theory, Donna Haraway's cyberfeminist philosophy; the other, contextualising TERROR NULLIUS within Australian politics by detailing the cultural references of its samples. This dual-reading demonstrates how TERROR NULLIUS can be interpreted differently by international and local audiences, in the process clarify the plurality of sample films' politics. In addition to theoretical and textual analysis, this thesis includes a creative, practical component. Video essay theorist Christian Keathley proposes that conducting and presenting film analysis "using the very tools that constitute [the] object of study" generates "critical insights" unique from those of written research (179, 190; also see McWhirter, Martin and Grant). In accordance with this view, I employ audiovisual sampling and editing to create an 'unmix' video that dissects TERROR NULLIUS' composition and cultural references.

\section{CHAPTER OUTLINE}

This thesis begins with the creative component: TERROR NULLIUS Unmixed (link on page 10). This video essay breaks down a three-minute scene from TERROR NULLIUS, highlighting the generic and historical range of the twelve sources it samples (including blockbusters, art films, television shows and news media) and the sophistication of Soda_Jerk's editing. The video uses additional archival news media clips to clarify the historical context of some of the samples, revealing the scene's references to explicit political debates around Australian refugee detention. The scene dissected in TERROR NULLIUS Unmixed is also relevant to Chapter Five, which expands on the historical significance of each sample and provides a detailed interpretation of the scene's explicit political critique. Positioning TERROR NULLIUS Unmixed immediately after this introduction provides an illustration of TERROR NULLIUS' unique form and style, and raises questions about its sampling, editing, and themes that ground the arguments presented in the following chapters.

Chapter One explores TERROR NULLIUS by contextualising it within the history of sample filmmaking, looking at how it maintains, diverges from, and innovates political aspects of prior sample films. Drawing on literature by Jamie Baron, William C. Wees, Jay Leyda and Lawrence Lessig (amongst others), I conduct an overview of sample filmmaking that addresses early twentieth-century compilations, post-war avant-garde found-footage films and internet-age remixes. This history clarifies how TERROR NULLIUS utilises and 
adapts various formal strategies employed by previous political filmmakers, including sampling news media, subverting the original meaning of samples, and testing the boundaries of fair use and copyright. While the history of sample filmmaking shows that techniques and theoretical attitudes have changed over time, it also attests to the fact that sampling has always been a subversive form of filmmaking, which those with limited resources can practice to challenge mainstream systems of media production and consumption.

Chapter Two maintains this historical approach, looking specifically at how sample films have engaged with different historical discourses and approaches to audiovisual archives. Using Esfir Shub's The Fall of the Romanov Dynasty (Padenie Dinastii Romanovykh 1927), Jean Luc Godard's Histoire(s) du Cinéma (1998), and various Australian sample films, including Ross Gibson's Camera Natura (1985) and Tracey Moffatt's The White Ship Sailed In (2017), this chapter compares modern, postmodern and postcolonial approaches to archival sampling. This comparison clarifies TERROR NULLIUS' use of sampling to present a revisionist history, which informs its explicit and identity-based political commentary.

Chapter Three canvasses three subversive forms of editing-dialectical montage, uncanny continuity and collage composition - to explain how TERROR NULLIUS combines them in a novel way. Films from Soviet cinema, Third Cinema and Surrealism, and theories proposed by Eisenstein, Masahiro Mori, Lev Manovich, and Robert Burgoyne help explain how this editing inspires critical consciousness. These first three chapters aim to contextualise TERROR NULLIUS within a wider historical framework to illustrate the politics of its sampled form. The broad range of case studies, theories and analytical strategies I employ make these chapters particularly relevant to other scholarship on sample filmmaking.

The final two chapters focus more exclusively on TERROR NULLIUS, contrasting a conceptual reading with a contextual reading to highlight the different ways the film invites audiences to interpret its politics. Chapter Four analyses TERROR NULLIUS through the lens of Haraway’s cyberfeminist theory, “A Cyborg Manifesto: Science, Technology and Socialist-Feminism in the Late Twentieth Century" (1984). TERROR NULLIUS' formal strategies, outlined in the first three chapters, promote particular values associated with cyborg identity politics: radical transformation, intersectional collaboration and ironic pluralism. I argue that these cyborg values are relevant to contemporary debates around identity politics and suggest that, because they are expressed through form and narrative, they 
are accessible to those without prior knowledge of TERROR NULLIUS' source material or its Australian cultural references.

Meanwhile, Chapter Five conducts a thorough contextual analysis, unpacking TERROR NULLIUS' references to specific Australian cultural phenomena, historical events, and political figures and how they relate to contemporary debates on refugee detention, xenophobia, indigenous land rights and LGBTQ discrimination. This contextual reading thus clarifies TERROR NULLIUS' explicit politics: its proposal of close (albeit non-homogenous) relationships between national cinema, cultural fictions, and political power. Drawing on literature on Australian national cinema, history and contemporary politics, this contextual reading indicates why Australian audiences, from the Ian Potter Foundation to art press reviewers, found the film highly political. Together, the cyborg conceptual reading and the Australian contextual reading prove that TERROR NULLIUS is open to diverse, yet ultimately progressive political interpretations. 


\section{TERROR NULLIUS UNMIXED ${ }^{1}$}

Link: vimeo.com/394066249

Password: TNvideoessay

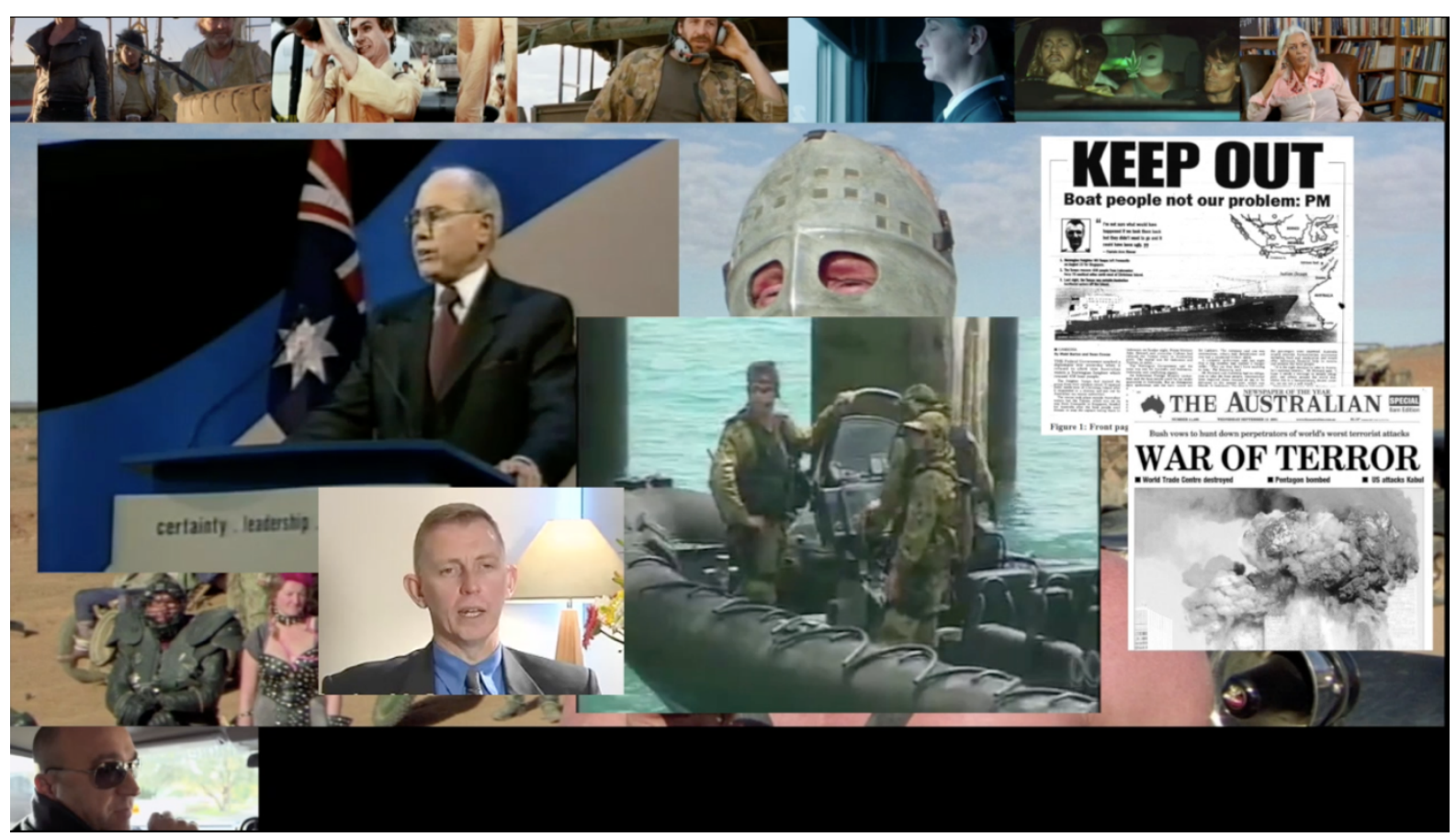

Fig. 1: TERROR NULLIUS Unmixed, Caitlin Lynch, 2020.

\footnotetext{
${ }^{1}$ TERROR NULLIUS Unmixed is scheduled be published in [in]Transition: Journal of Videographic Film and Moving Image Studies, vol. 7, no. 3 in December 2020, and was selected to screen in the 'Thinking Images' section at the Tel Aviv International Student Film Festival, also in September 2020.
} 


\section{CHAPTER ONE \\ A HISTORY OF SAMPLE FILMMAKING: COMPILATION, FOUND-FOOTAGE AND \\ REMIX}

To understand TERROR NULLIUS' political dimensions, it is essential to define sampling and unpack how it produces meaning. A historical overview of sample filmmaking identifies the key tendencies of the form and indicates the technical and conceptual circumstances that have motivated aesthetic variations in sampling over time. Comparing TERROR NULLIUS with previous sample films emphasises its significance within the sampling tradition and reveals the politics of its form. The literature on sampling is broad and terminology is often inconsistent, so this chapter begins by clarifying a definition of sampling and its various formations, categorised as compilation, found-footage and remix. These categories map onto specific historical contexts: compilations emerged with the start of cinema in the late nineteenth century, found-footage is associated with the post-war avantgarde and remix is a distinctly digital, internet-based phenomenon. For early compilation filmmakers, such as Esfir Shub, sampling was a solution to resource limitations and allowed them to engage in political discourses of the time. From the 1950s, avant-garde found-footage films, such as Bruce Coner's A Movie (1956) and Craig Baldwin's Stolen Movie (1976), pushed sampling in new, postmodern directions, using it as a counter-cultural tool to address the mass-commodification of visual media. Since the 1990s, developments in digital technology have made sampling accessible to fans and other non-professional creators, who incorporate sampling into their processes of media consumption and redistribution. By reworking films, television shows and news, often emphasising alternative politics or perspectives, remixes like Jonathan McIntosh's Buffy vs Edward: Twilight Remixed (2009) disrupt the static, whole nature of audiovisual media and hierarchal control of representation. Another key component of sample filmmaking's politics, especially in the digital era, is the ethical and legal debate around copyright (Lessig;Vaidhyanathan). Remix artists, including Soda_Jerk, are proponents of the free culture movement that advocates common rather than corporate ownership of information and cultural media. Laying out key aesthetic and theoretical developments in sample filmmaking demonstrates its political nature and provides a foundation for close analysis of TERROR NULLIUS.

\section{SAMPLE FILMMAKING DEFINITIONS}

The body of literature on sampling and sample filmmaking is broad and multidisciplinary. Media studies scholars have done significant conceptual and technological research on 
sampling, drawing links and comparisons across a range of media including music, visual art, coding and television, as well as cinema. Lev Manovich's The Language of New Media, Eduardo Navas's Remix Theory: The Aesthetics of Sampling and David Laderman and Laurel Westrup's edited collection demonstrate the rigour of scholarship on sampling in twentyfirst-century media studies. Lawrence Lessig's work also approaches media sampling but from a legal perspective, addressing questions around intellectual property, copyright and free culture. Monographs by Jay Leyda, Films Beget Films: Compilation Films from Propaganda to Drama, and Jaimie Baron, The Archive Effect: Found-footage and Audiovisual Experience of History, look explicitly at sampling within film studies, asking how and why particular films use pre-existing footage in relation to themes of authenticity, history and manipulation. The is also a considerable amount of literature at the intersection of film studies and art analysis that look at experimental found-footage film. William Wees' Recycled Images: The Art and Politics of Found-Footage Films analyses found-footage video art and interviews filmmakers like Bruce Conner, Craig Baldwin and Chick Strand. Introductions to art books on found-footage films, such as those by Rob Yeo and Jaap Gauldemond, also offer valuable perspectives on sampling. Though non-scholarly, two documentaries made during the boom in remix culture in the 2000s, Good Copy, Bad Copy (2007) and RiP!: A Remix Manifesto (2008), provide useful insight into sampling culture through interviews with remix musicians and theorists (such as Lessig). This list is far from exhaustive - many scholars engage with sampling in music and computer coding, which are outside the remit of this thesis. The scholarship discussed in this chapter provides a solid theoretical grounding, a historical and technological overview, and a wide range of contextspecific examples relevant to my interpretation of TERROR NULLIUS.

One challenging aspect of the diverse literature on sampling is that authors use different terminology for films that use pre-existing footage: remix, compilation, foundfootage, archival footage, appropriation, montage, collage, bricolage, cut-up and mash-up are among the most common. The usage of these kindred terms is blurry; they can be employed as synonyms, and their distinctions are often contested (Laderman and Westrup 3). This inconsistency is testament to the multidisciplinary scholarly interest in sample filmmaking and the non-institutionalised, eclectic nature of sampling itself. Without necessarily claiming to resolve terminological inconsistencies apparent in the scholarship, this thesis defines sampling, compilation, found-footage, remix, montage and collage in relation to specific historical contexts and technical or aesthetic qualities. 
Sample filmmaking is a useful umbrella term for the range of terms for films that use preexisting footage. Navas defines a sample as a "piece of a bigger whole" and describes sampling as the "the act of taking not from the world but from an archive of representations of the world" (12). Laderman and Westrup articulate sampling in similar terms, as a "specific technical and aesthetic practice" of "taking" (4). Navas and Laderman and Westrup explain sampling as the preliminary step to remix, but do not conflate the two, allowing for sampling to be used as its own, more broadly applicable term $(4,12)$. This thesis uses sample as a noun to refer to a clip of pre-existing audiovisual footage and as a verb to refer to the act of copying and reusing part of a pre-existing text. Sample films/filmmaking refers collectively to the products and processes of filmmakers working with pre-existing material.

To ground my analysis of political sample filmmaking history, discerning different types of sample filmmaking is helpful. Across the literature, the terms 'compilation', 'foundfootage' and 'remix' tend to be associated with particular eras and styles of sampling but are not posed as distinct categories. The earliest academic work in the field of sample filmmaking, Leyda's 1964 Film Beget Films, defines films that "begin on the cutting table, with already existing film shots" as "compilations" (9). 'Compilation film' works as a term for most early sample films, which (as I discuss in greater depth in Chapter Two) tend to recycle newsreels and present them with the air of historial authenticity, obscuring the editor's authorial influence (Leyda, Films 10). While most strongly associated with early sample filmmaking, this realist, footage-as-evidence approach to sampling remains prominent in the documentary genre (Baron 5). Compilation films are not free from editorial manipulation - as the following chapter shows, their sampling is very carefully constructed but this manipulation is not foregrounded. In Wees' words, “compilation films may reinterpret images... but they do not challenge the[ir] representational nature" (36).

Art and experimental cinema literature on avant-garde sample filmmaking favours the term 'found-footage' (Wees; Yeo; Guldemond; Horwatt). Where compilation films generally aim to naturalistically represent real events, found-footage films are associated with a formalist, conceptual style of sampling wherein bringing "different connotations" to the samples is essential (Guldemond 10). Found-footage films foreground the process of locating samples, emphasising the random chance of stumbling across odd-and-ends of used film stock and confronting traditional notions of art authorship (Baron 6; Guldemond 10; Gunning 50). 'Found-footage' was the popular term for most sample filmmaking from the 1950 s to the 1980s and is still common within contemporary art contexts (Yeo; Guldemond). However, whether due to 'found-footage's strong associations with the art world or because in the 
digital internet age the act of 'finding' re-usable material is so commonplace, the recent wave of sample filmmaking is more commonly referred to as 'remix'.

'Remix' typically refers to a popular form of sampling associated with the "read/write" or "cut/copy/paste" logic of "new media" (Lessig 28; Navas 74; Manocich 130; Angeloro 20). The term 'remix' is borrowed from music, originating with 1970s Jamaican dub and popularised by 1980 s U.S. hip hop and techno and, since then, extended to sampling in film and other media (Navas 20, 26; Borschke 21). Whereas found-footage exclusively references audiovisual sampling, remix frames sample filmmaking in the wider context of media convergence and circulation. The flexibility afforded by digital files and sophisticated, easily accessible editing software has produced dozens of sub-genres of audiovisual remix, including cut-up, mash-up, vidding, trailer hack, re-dub and slash (which Soda_Jerk's Dan Angeloro provides definitions of in the 2006 article "Thoughtware: Contemporary Online Remix Culture"). Remixes are generally characterised by their electronic aesthetics (primarily digital, but also video), fan ethos, sense of humour, internet distribution and popular appeal (Angeloro; Russo and Coppa). Like found-footage films, remixes are distinct from compilations in that they foreground their "transformative logic" (Russo and Coppa) but attribute this transformation to the editor's creative choices rather than the circumstantial chance of finding material. 'Montage' and 'collage' are also used inconsistently across sampling literature, sometimes interchangeably as general synonyms for sample films (Warner 5; Etgar 4), at other times to refer to a certain style of sampling (Wees 32) or a specific technique (Manovich, Language 155). This thesis aligns with the latter, using montage and collage to describe specific editing strategies, which are outlined in detail in Chapter Three.

TERROR NULLIUS is best described as a remix film that employs montage and collage editing techniques. Soda_Jerk's overt authorial presence and use of distinctly digital strategies distinguish TERROR NULLIUS from compilation and found-footage films. However, as Laderman and Westrup and this thesis demonstrate, boundaries in sample filmmaking are never concrete (3). There are strong connections between TERROR NULLIUS and compilation and found-footage films, such as explicit politics, use of popular media, and montage editing; therefore, understanding these earlier forms of sampling provides critical insight into how TERROR NULLIUS creates meaning. This chapter unpacks the evolution of sample filmmaking to illustrate that TERROR NULLIUS is a novel iteration of a longstanding filmmaking tradition. 


\section{FROM EARLY INNOVATORS TO THE POST-WAR AVANT-GARDE}

Sample filmmaking is a modern expression of copying, appropriating and adapting traditions that have always existed in "art, literature and even culture itself" (Laderman and Westrup 4; Benjamin 220). Thus the first axiom of Brett Gaylor's RiP!: A Remix Manifesto is “culture always builds on the past," which references the processes of repetition, replication and evolution that define cultural transmission. Marcus Boon's research traces these processes in both Greco-Roman and Buddhist traditions, highlighting the ancient and culturally diverse history of copying. Most arguments for sampling's legal and aesthetic validity begin with the premise that re-use and citation are the building blocks of creative culture (Lessig; Laderman and Westrup; Navas; Gaylor; Russo and Coppa).

Despite its ancient roots, sampling as a technical practice is a distinctly modern phenomenon enabled by mechanical recording and reproductive technologies (Navas 14; Benjamin 220). Sampling relies on direct replication, as opposed to mimicry or recreation which create original objects in aesthetic likeness to another. Nineteenth-century photographic, phonographic and motion picture technologies enabled people to record images and sound and reproduce multiple copies of the recording. According to Walter Benjamin, mass-production reduced the unique value and sanctity of holistic artworks as artists were able to deconstruct and re-use parts of a text without sacrificing the original (222). For filmmakers, duplicating, cutting and rearranging pre-existing footage was far more affordable than re-shooting from scratch. Scholars date the first sample film to 1898 when Francis Doublier (working for the Lumière brothers) combined clips from various, disconnected stock footage with new intertitles to create The Dreyfus Affair (Leyda, Films 13; Yeo 14; Wees 34). In 1927, Esfir Shub bypassed production costs by locating, repairing, copying, archiving and sampling newsreel clips to create the first feature-length compilation film, The Fall of The Romanov Dynasty (Shub 'The first work' 20; Leyda, Films 25). Shub (discussed in-depth in Chapter Two) is a key figure in sampling history, whose techniques have influenced generations of sample filmmakers including Soda_Jerk. Both Doublier and Shub demonstrate a compilation approach to sample filmmaking, assuming "a direct correspondence between images and their profilmic world" rather than a self-reflexive fixation on the process of re-use (Wees 36).

These early compilation films used sampling to engage in contemporary political conversations, thus demonstrate some of the explicit political capacities of sample filmmaking. The Dreyfus Affair was a newsreel recounting the saga of Alfred Dreyfus: a French-Jewish army captain who was framed and jailed for treason in 1894. Dreyfus' 
imprisonment was a divisive political scandal in France and among Europeans Jewish communities throughout the late 1890s, particularly in 1898 when new evidence revealed Dreyfus's innocence (Hoffman 10). At that time, Doublier was touring a programme of Lumière films around North-Eastern Europe and received requests from Jewish audiences for a film on the Dreyfus case (Leyda, Kino 23). Unperturbed by the fact that the 1894 events preceded the invention of cinema, the resourceful Doublier fashioned a film from stock footage, including a clip of the French army, a Parisian street scene and a shot of the Nile Delta, which he presented as authentic recordings of Dreyfus' story and accompanied with verbal commentary (Leyda, Kino 23; Hoberman 14). Though motivated by market forces rather than ideological ones, Doublier used sampling to publicise a politically sympathetic account of Dreyfus' persecution (Holberg 300). Shub's The Fall of the Romanov Dynasty, an anti-Tsarist archival compilation, also uses sampling to political effect. Shub repurposed home video footage of the Tsar in her revisionist history, portraying him in a negative light to rouse socialist sentiment (Nichols 149; Leyda, Films 25). Both Doublier and Shub use sampling to represent events they were unable to film themselves in order to emphasise their films' connection to reality, thereby strengthening their political message. From its origins, sample filmmaking has been used in journalistic and propagandist fashions to engage in explicit political discourse.

Shub is also evidence of the democratising aspects of sampling. As a woman in 1920's Soviet Union, sampling was possibly Shub's only avenue to authorial control. While Shub does not explicitly discuss financial limitations in her writings, the funding she received to compile The Fall of The Romanov Dynasty would have been far less than that granted to her contemporary, Sergei Eisenstein, to pay for the cast, extras, crew, locations, props and equipment needed to shoot Battleship Potemkin (Bronenosets Potyomkin, also made in 1927). Given male directors have historically had privileged access to higher budget productions (Hill 2; Follows and Kreager 20, 120) and women have traditionally found editing one of the more accessible areas of film production (Mahar 21), it is unsurprising that sample filmmaking was initiated by, and has been frequently utilised by women (Dall'Asta and Chiarini 1; Pearlman and Heftberger; Coppa 124). Monica Dall'Asta and Alessandra Chiarini's editorial, "Found Footage: Women Without a Movie Camera," surveys a long list of women filmmakers who have been drawn to sampling - from Shub, Nicole Vedrès and Germaine Dulac in the early twentieth century, to late twentieth-century found-footage filmmakers such as Chick Strand, Abigail Childs, Su Friedrich, Hito Steyerl and Leslie Thornton - and suggests that sample filmmaking is "a field [of cinema] where gender parity 
is close to finally being attained" (3). Coppa's research on 'vidding' indicates that this trend also applies outside art/experimental cinema spheres, with women the dominant creators of popular fan remixes (124). Like the women filmmakers who came before them, the Angeloro sisters (Soda_Jerk) use sampling to bypass some of the barriers that continue to limit women's access to high budget film production (Hunt and Ramón 28; Lauzen 1; Follows and Kreager 7). While methods of sample filmmaking may have changed since Shub's time, the political significance of sampling's accessible nature has not.

Sampling has existed since the beginning of cinema; however, it was the foundfootage filmmakers of the 1950s who really began to explore the form's conceptual politics (Wees 38). Catherine Constable explains that cinema, one of the most theorised media of the twentieth century, has "dual status" as an "icon of modernity and symbol of postmodernism" (43). Sample filmmaking was likewise made possible by the reproductive technologies of industrial modernism but flourished under the conceptual conditions of postmodernity. The post-war period saw a boom in U.S. modern art, including avant-garde found-footage filmmaking (Graf and Scheunemann $x$ ). Over the next few decades, artists such as Bruce Conner, Marie Menken, Hollis Frampton, Arthur Lipsett, Chick Strand, Ken Jacobs, Su Friedrich, Craig Baldwin, and Leslie Thornton located and rearranged footage from a vast range of sources to comment on mass-media, commodification and representation. Their found-footage films illustrate some of the key conceptual strategies TERROR NULLIUS employs, such as combining high and low culture, fragmenting narrative integrity and détournement, and exemplify sample filmmaking's subversive political sensibility.

Where compilation filmmakers mostly sampled newsreels or stock footage, avantgarde found-footage filmmakers were far more eclectic in selecting source materials, breaching traditional distinctions between fact and fiction and elite and popular culture. As "visual culture came to dominate" everyday life throughout the 1950s (Halliwell 189; Foster 18), pop and avant-garde artists came to regard "the shallowest, most ephemeral detritus of popular culture" as valid as newsreels for revealing "the forces that have shaped contemporary society" (Wees 20). Avant-garde found-footage filmmakers sampled blockbusters, B-movies, cartoons, educational videos, advertising and personal film reels found in second-hand shops, camera store bargain bins, library give-away boxes and studio dumpsters (Wees 4). Bruce Conner's A Movie (1958), often cited as the first of the foundfootage wave (Wees 13; Yeo 16; Guldemond 12), is a fast-paced montage of "clichés and horrors" ranging from clips from generic Westerns to a Pathé newsreel of the Hindenburg crash (O’Doherty 239). Conner draws reflexive attention to scopophilic spectatorship, 
accompanying catastrophic crash scenes with upbeat, fair-ground music and cutting from a shot of sailors looking through a periscope to footage of a pin-up model. Arthur Lipsett's $A$ Trip Down Memory Lane (1965) similarly combines found material in a decontextualised, emotionally ambiguous manner, cutting between footage of beauty pageants, fighter-pilots, J. D. Rockafeller, a sword-swallower and Pope Pius XII. Chick Strand's Loose Ends (1979) samples a diverse range of sources-Workers Leaving the Lumière Factory (1895), ethnographic footage from South America, and a scene from a 1947 educational psychology film for teachers - in an effort to replicate the "internalisation of [the] information that bombard[ed]" everyday life (Strand qtd. Leimbacher 133). For influential cultural theorist Fredric Jameson, one of postmodernism's core characteristics is dissolving distinctions between high and low cultural media (112). While a modernist art text might cite or quote popular culture, postmodern works "incorporate them, to the point where the line between high and commercial forms seems increasingly difficult to draw" (122). Found-footage filmmakers used sampling to question cultural and aesthetic hierarchies and call attention to the formal nature of mass-media.

Avant-garde found-footage filmmakers further challenged the status quo of audiovisual representation by fracturing narrative cohesion. Due to its eclectic nature, sampling is inconducive to wholeness and continuity. However, early compilation films tried to retain the illusion of continuity by using samples to illustrate a single, coherent narrative explained via intertitles (or, in the case of The Dreyfus Affair, live verbal commentary). In the latter half of the twentieth century, the postmodern shift in Western philosophy and art sparked a rejection of narrative and unified coherence (Lyotard 37). Found-footage films tend to be more interested in form and theme than narrative and revel in the disruptive nature of sampling. A Movie deliberately undermines traditional narrative structure, opening with the intertitle "End of Part Four" and repeating "The End" intertitle multiple times throughout the film (except, of course, at the end). Craig Baldwin's Stolen Movie (1976) is a ten-minute assemblage of blockbusters and B movies, which Baldwin made by randomly walking in and out of movie theatres and recording with a super eight camera. Stolen Movie undermines narrative cohesion and closure and models an authorship that is sensitive to chance and context, draw attention to alternative ways of reading, making and comprehending media. ${ }^{2}$

\footnotetext{
${ }^{2}$ Baldwin's theatre-hopping practice has precedence in the early avant-garde. In the 1920s, before the invention of hand-held cameras, surrealist artists Andre Breton and Jacques Vache would "wander in and out of cinemas during screenings, paying no attention to the supposed wholeness and integrity of the artworks, sometimes never finding out the titles of the films in question" (Smith 20).
} 
Given that narrative cohesion is so deeply imbedded in culture, from the way people understand shared histories (White, Metahistory 11; Carr 7) to their own psychological experiences (Sarbin 3; Crossley 531), sample films that fragment narrative are radically counter-cultural.

Subversive appropriation, or détournement, is at the heart of avant-garde foundfootage films' politics. Developed by the Situationist International (a 1950s European Avantgarde movement), détournement is a "flexible language of anti-ideology" that "integrat[es] present or past artistic productions into a superior construction of a milieu" to undercut the products' original intentions (Debord, The Society 110; Debord, 'Definitions' 13). Resonating with Jameson's articulation of postmodernism as the rejection of sincere citation (122), Guy Debord defines détournement as "opposite of quotation" (The Society 110). Anticipating the subversive found-footage works to come, Debord and Gil Wolman's “A User's Guide to Détournement" (1956) proposed that détournement would have "greatest effect" in cinema. Détournement is evident in North American 1960s and 1970s found-footage works and is openly cited as a key strategy of the 1980s "culture jamming" movement, which created parody 'subvertisements' (subversive advertisements) to "challenge the cultural influence of corporate commercialism" (Chung and Kirby 36; Lasn 19). Found-footage films typically subvert the textual meanings and commercial functions of the texts they sample. Lipsett's $A$ Trip Down Memory Lane combines a recording of Richard Nixon's televised address from the 1960 presidential campaign with footage of a fairground sword-swallower (fig. 2 and 3). This detournement seems to imply that Nixon too, is a performer, and his presidential campaign is a spectacle with potentially dangerous implications. As explicated in its title, Baldwin's Stolen Movie illegally records and disfigures cinema to "spite the corporate market" (qtd. in Wees 68). Hollis Frampton's Zorn's Lemma (1970) cycles through footage of shop signs in alphabetical order (A, Baby, Cabinet, Daily, Each, Fabric. . .) and gradually replaces each letter with footage of actions such as washing hands, explosions, and ocean waves, stripping the shop signs of all their original commercial signification. ${ }^{3}$ Avant-garde found-footage films demonstrate the radical capacities of sampling in their use of détournement to antagonise, subvert and disarm political and commercial media.

\footnotetext{
${ }^{3}$ Zorn's Lemma uses footage shot by Frampton, however it is still relevant to sample filmmaking because Frampton's footage of signs can be considered samples of pre-existing media in the same way that Baldwin filming live movie is sampling.
} 


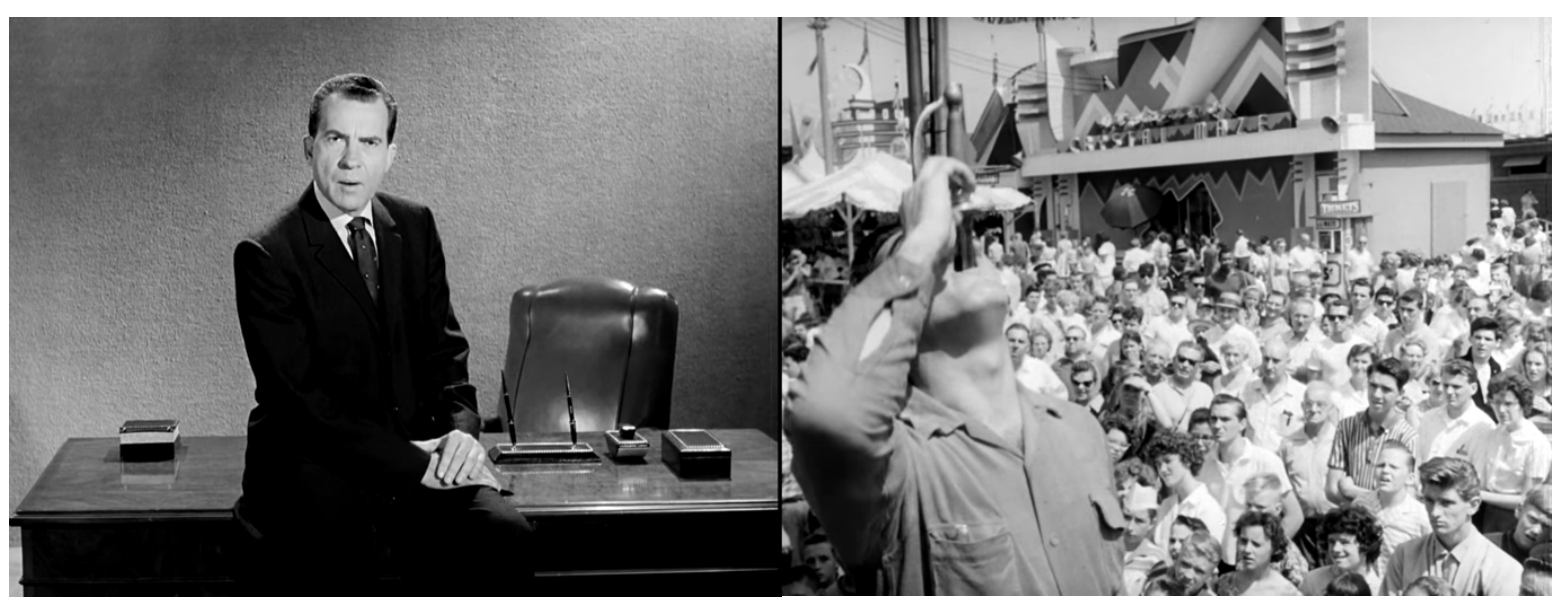

Fig. 2 and fig. 3: Richard Nixon's televised presidential campaign, 1960, and footage of a fairground sword-swallower, from A Trip Down Memory Lane, Arthur Lipsett, 1965.

These found-footage filmmakers' subversive formal strategies provide valuable insight into TERROR NULLIUS' political disposition. Of the three categories of political engagement laid out the introduction - politics of identity, explicit politics and politics of form - avant-garde found-footage films best represent the latter. As evidenced by the case studies above, found-footage films tend to be oblique and ambivalent rather than didactic, so are less likely to provide a clear commentary on specific political debates or overtly promote a certain cultural ideology. Instead, they stimulate critical consciousness through acts of formal subversion, challenging cultural evaluations of high and low media, denying the cohesion and closure offered by narrative logic, and undermining commercial media through détournement. TERROR NULLIUS continues these strategies. Soda_Jerk sample a diverse range of media, blending a broadcast address by Queen Elizabeth (1988), a YouTube video of ex-Prime Minister Bob Hawke sculling beer (2012), the family film Babe (1995) and a splatter-horror Black Sheep (2006) into a single scene. Like Stolen Movie, TERROR NULLIUS operates as a collection of narrative excerpts that defy a singular narrative reading (Soda_Jerk cite Baldwin's "bent documentaries" as a major influence on their practice, qtd. in Maunder). Adopting the logic of détournement, Soda_Jerk take glee in "reprogramming" the original meanings of sample material (such as using the Queen's address to critique colonialism) and undermining commercial copyright ownership (qtd. in Sharp and Juers). The following chapters will continue to return to these formalist strategies of avant-garde found-footage filmmakers to unpack TERROR NULLIUS' subversive politics in greater detail. 


\section{THE INTERNET, FANS AND FREE CULTURE}

Since the 1990s, digital technologies, Web 2.0 and social media have radically transformed the culture of media production and consumption (Manovich, Language 27; Meikle 7). Henry Jenkins' work on "spreadable media" shows that "shaping, sharing, reframing and remixing" are now core tenants of media consumption (2). The convergence of political, cultural and social spheres on sites like Facebook, Tumblr, YouTube, Twitter, Reddit and 4chan has replaced traditional, top-down media distribution with "hybridised circulation" (Jenkins et al. 1; Meikle 7; Sobande 153). In this circulation model, consumers are not passive receivers but active transformers, who experience media and re-circulate it, often altering it in the process. Transformations vary in degree and method: sharing a \#MeToo campaign video with a new caption; creating an Instagram filter that makes the user look like a character from the latest Star Wars; turning a Brooklyn 99 clip into a reaction GIF; cutting Donald Trump speeches into pop song lyrics; making a meme about the final season of Game of Thrones; or editing a highlights reel of late-night talk-show jokes. Not all transformations constitute remixing, but they do indicate a "networked culture," in which users have a sophisticated ability to recognise, process and interpret sampling (Jenkins et al 12). Recontextualising popular media samples to make jokes and/or socio-political commentary is now a central component of mainstream social discourse (Sobande 153).

Network culture and its corresponding digital technologies have caused a major evolution in sample filmmaking: the rise of the remix (Manovich, Practice 33; Navas 74; Russo and Coppa; Watson; Brøvig-Hanssen and Sinnreich 2). Personal computers, digital files, 'ripping' programs, peer-to-peer sharing platforms, and amateur editing software make it easier and cheaper to duplicate, circulate and transform audiovisual samples than ever before. Where previous sample filmmakers were limited to the film stock and videotapes they could physically find, digital remix filmmakers have access to extensive databases of material and use search functions to find specific clips (hence why remixes tend to be less interested in chance and circumstance than found-footage films). The internet also offered new, resource-minimal, ways for sharing sample films to a mass audience, most notably: YouTube (Burgess 103). Compared to the costs and limited audience of screening a film in a cinema, gallery, or even in an underground community/private setting, or distributing it through physical videotapes, uploading a remix to YouTube is free (bar general internet costs), takes minutes and has a global reach.

Fan culture is one of the most prominent sites of audiovisual remix practice and development. Fans have been making sample films with analogue technologies since the 
1970s, but the late 1990s and 2000s saw a proliferation in fan remix practices like vidding (editing visual samples from television shows or movies to a pop song to emphasise a particular trope, relationship or counter-narrative), trailer hacking (creating a fake movie trailer from sampled footage), redubbing (creating new audio tracks to sampled film/television footage), and mashing-up (editing two or more texts together, often merging narrative worlds) (Coppa 123; Angeloro 21-24). These remixes can reach large audiences: Jonathan McIntosh's mash-up, Buffy vs Edward: Twilight Remixed (2009), for example, has close to 4 million YouTube views and 9,500 comments. Once limited to a small number of avant-garde artists appropriating popular culture, sample filmmaking, in the form of remix, is now part of popular culture.

Writing about remix in 2006, Soda_Jerk's Dan Angeloro notes, “what was once conceived as an attack on commodity culture has, for many, become a commonplace way of consuming culture," suggesting contemporary remixes lack the political intent of prior forms of sampling (25). In a media climate where material is always being transformed (Jenkins et al.2), sampling is not necessarily the "art of defiance" it was for found-footage filmmakers (Baldwin qtd. in Wees 69). Fan remixes might incidentally continue some of the technical elements that made found-footage films so subversive (breaching narrative continuity, producing unintended meanings) but they are primarily driven by a desire to "express... personal identity and shared interest," and often affirmatively participate in, rather than antagonise, mass-media culture (Jenkins et al. 187, 151). However, Angeloro goes on to argue that "the recent explosion of remix culture is not a dilution of the radical logic of [sampling] but rather its ultimate realisation" (25). Regardless of the creator's intentions, remixing is a politically charged act because it democratises creative agency and treats media as a public resource rather than a corporate commodity. Francesca Coppa's research on the dominance of women in fan vidding shows how remix gives power to those who have been excluded from traditional media production. Appropriating mainstream media (which is predominantly directed by men, Lauzen 1; Hunt 28) into their own work, these women make vidding a feminist act (Coppa 124). Sample filmmaking's popularisation may have seen a shift in filmmakers' intentions, but it has not reduced sampling's fundamental subversiveness.

In addition to the anti-hegemonic politics of its form, popular remix sampling also expresses politics in its content, often through parody (Brøvig-Hanssen and Sinnreich 1). The political-speech-remix sub-genre, which combines pop songs with news footage of politicians to produce "hilarious yet biting critiques of politicians and their policies" (McIntosh), is a 
strong example of explicit politics. Ragnhild Brøvig-Hanssen and Aram Sinnreich's survey of Donald Trump speech-remixes, such as Derrick Watts and The Sunday Blues "songified karaoke," Do you Want to Build A Wall? Donald Trump (Frozen Parody), outlines a range of "rhetorical tactics" remixes use to engage with politics $(8,3)$. In a recent Australian example of the speech-remix form, Victor De Meer edits a line from Prime Minister Scott Morrison's 2019 election victory speech, "I have always believed in miracles," to a backing track of Hot Chocolate's "You Sexy Thing." Intertitles list Morrison's policy ambitions, then ask the viewer "Did you vote for miracles?" The remix simultaneous mocks Morrison in a lighthearted way and provides genuine scepticism of his ability to deliver his promised policies. While both found-footage films and remixes sample political imagery, found-footage films tend to do so in a poetic, oblique fashion (e.g. Lipsett's use of Nixon's speech) where remixes are more likely to package their political critique in an entertaining, easily consumable parody.

Other forms of popular remix participate in political conversations around identity and representation. These cultural critiques are often made by "transformative fans" who simultaneously appreciate mainstream media and are frustrated with aspects of its representation (or lack thereof) (Jenkins et al. 150; Coppa 124). In the aforementioned Buffy vs. Edward: Twilight Remixed, self-identified "remix activist" Jonathan McIntosh executes a gender critique of The Twilight Saga. McIntosh selects Edward's creepiest dialogue and Buffy's sassiest rebuttals and uses shot-reverse-shot editing to fabricate a feminist narrative that ends with Buffy slaying Edward. Lierdumoa's How Much is That Geisha in the Window (2008) criticises Firefly's cultural appropriation and Asian erasure by cutting out shots of the non-Asian main cast to focus on the Chinese-inspired set design and Asian extras (Coppa 125). 'Slash' remixes challenge mainstream heteronormativity by creating "queer utopias" that "encourage viewers to gaze through a queer lens [and] identify with queer(ed) characters" (Willis 1; Kreisinger). Chuck 13171's Top Gun Recut interweaves shots of Maverick and Iceman hugging and shots from Maverick and Charlie's sex scene (which are cropped to focus on Maverick's body and obscure Charlie), recoding the heterosexual masculinity of the original film as homoerotic (Kreisinger). None of these examples engages with politics in an explicit sense. Instead, they centre on the politics of identity, producing cultural critiques of misogyny, racism and heterosexism and offering pleasures mainstream media denies.

TERROR NULLIUS has strong similarities with these popular remix videos, in terms of its methods of explicit political commentary and cultural critique. Like Watts and De 
Meer, Soda_Jerk parody politicians by 'mashing-up' their formal speeches with popular media. As shown in TERROR NULLIUS Unmixed, Soda_Jerk overlay a clip of the villain Lord Humungus from Mad Max 2 (1981) with audio of ex-Prime Minister John Howard's 2001 federal election campaign speech. This move, which Chapter Five discusses in greater detail, generates an entertaining yet sharp political critique of Howard's dehumanising approach to refugees and exploitation of public anxieties in the wake of the Tampa crisis and 9/11. In terms of politics of identity, TERROR NULLIUS is rich with examples of mainstream media being reworked to address the concerns and pleasures of minorities. Akin to Lierdumoa's critique of Asian erasure, Soda_Jerk draw attention to the erasure of indigenous people from Australian popular culture, cutting a clip of three Aboriginal men from the film Spear (2015) into a landscape declared "empty" by Sue from Crocodile Dundee (1986) (see Chapter Four for further discussion). Mirroring Chuck 13171's queering techniques, Soda_Jerk sample a clip of Jim (from The Man from Snowy River, 1982) winking suggestively and replace the original female recipient of his sexual advance, with footage of men (Miklós from Teenage Kicks, 2016 and Ennis from Brokeback Mountain, 2005). Though TERROR NULLIUS has circulated in prestigious art cinema spaces rather than on social media platforms, it exhibits many of the political strategies of popular remix.

The rise of popular remix has sparked major ethical and legal debates around copyright, piracy and public domain (Lessig; Vaidhyanathan). Understanding copyright is key to appreciating the politics of TERROR NULLIUS' form. Modern copyright laws emerged in the nineteenth century in response to new photographic, phonographic and print replication technologies (Lessig, Remix 25; Boon 51). Late twentieth-century replication technologies like VCR, CD-ROM and digital files, and globalised sharing strategies like peer-to-peer sharing and streaming sites, have intensified creators' demands for robust copyright law (Lessig, Remix 39; Miller et al. 228). Copyright is based on the economic premise that theft applies to creative and intellectual expressions as well as material property and that without laws protecting the financial rights to ideas, creators will have no incentive to make cultural developments (Vaidhyanathan 20). Nations with large intellectual export industries, like the U.S. and Australia, lobby developing countries that have more to benefit from piracy to create and enforce strict copyright laws. Film studios rely heavily on copyright protections and organisations like the U.S. Motion Picture Association (who represent the copyright holders of many of the films sampled in TERROR NULLIUS) are highly invested in international copyright law (Miller et al. 235). Several widely-subscribed international treaties, like the Berne Convention (1886) and the World Intellectual Property Organisation 
International Treaty (1996), standardise some basic regulations, e.g. motion pictures are protected by copyright for their first 50 years (this has been exteneded to 70 years in many countries) (Vaidhyanathan 25, 160). Though remix is far less of an economic threat to copyright holders than piracy (no one is watching TERROR NULLIUS in lieu of paying to watch Picnic at Hanging Rock or Mad Max 2), it has also been implicated in the crackdown on copyright infringement. Under pressure from copyright holding corporations, content sharing sites have developed increasingly sophisticated technologies for detecting sampling (Collins 97). When YouTube's content ID software identified material copyrighted by Lionsgate in Buffy vs. Edward: Twilight Remixed, the remix was deleted and McIntosh had to undergo numerous legal proceedings to have it restored. In the era of the "copyright wars," sampling filmmaking can be read as an act of defiance against corporate power (Lessig, Remix 34).

In most countries, there are certain instances in which creators can legally breach copyright. In U.S. law, this is called fair use. Fair use is a flexible, case-by-case status that takes into account the purpose of the use (eg. commercial or non-profit), the nature or significance of the use of the work, the amount of the work used and the commercial effect on the copyright owner (Purvis 28). Australia's equivalent, fair dealings, is more rigid, in that it classifies five acceptable uses: research/study, criticism/review, parody/satire, reporting news, and seeking professional advice (Purvis 27). Soda_Jerk believe TERROR NULLIUS would likely be protected under both fair use and fair dealing, but also speculate that "the real protection is simply that there's not much financial gain... in suing a scrappy artist collective" (qtd. in Sharp and Juers). McIntosh's experience, however, shows that popular remix filmmakers are highly vulnerable. Even though McIntosh could legally defend his work under fair use, YouTube's guilty until proven innocent approach meant keeping his work online required considerable time and energy (Collins 99). As it stands, fair use sampling filmmaking remains vulnerable to anti-piracy practices.

Remix artists, among others, have critiqued the copyright system and the limited definitions of fair use, suggesting counter-strategies which can be generally grouped as reformist, abolitionist and additional. Reformists, including leading copyright scholar Lawrence Lessig and cultural critic Siva Vaidhyanathan, argue some form of "thin" copyright is needed to incentivise original creation but that the corporate war on piracy has gone so far that it prohibits a positive environment of creative adaptation (Lessig, Remix 20; Vaidhyanathan 5). Abolitionists generally come from an anarchic anti-capitalist position, advocating free speech and challenging Western legal frameworks of exclusive ownership. 
Abolitionist movements, like Situationist International, culture jammers, and copyleft intentionally disregard and undermine corporate copyright as a political act (Andersson 10). The third anti-copyright approach does not seek to rewrite copyright law but create new platforms for like-minded creators to freely share their work for others to access and sample (Lessig, Remix 277). Open access, creative commons and public domain databases are alternative models that side-step aspects of the corporate copyright system. All three counterstrategies are based on one or more of three premises: appropriation is necessary for artistic growth, current copyright law protects corporations more than artists and copyright maintains mass-media hegemony.

The first premise of anti-copyright ties back to ideas laid out early in this chapter: the principles which underlie remix sampling - copying, appropriation, adaptation - are present throughout history and are an ordinary, even necessary part of cultural development (Boon). Anti-copyright advocates argue that file-sharing and sampling are simply digital-era articulations of age-old cultural processes. Celebrating RW (read/write) media over RO (read-only) media culture, Lessig describes remix as "literacy in the twenty-first century... writing for a new generation" (R!P Manifesto; Remix 7). Reminiscent of the attitudes of post-war pop artists, found-footage filmmakers and Situationists, D.J. Girl Talk argues that sampling is a logical reaction to media saturation:

Everyone has been bombarded with media now, that I think we're almost forced to use it as an art form. If people were passing out paints for free on the street every day, I'm sure there'd be a lot more painters. (Good Copy, Bad Copy)

In Lessig's view, copyright laws that prohibit adaptation are an obstacle to development and pose substantial cultural problems much larger than individual filmmakers having their remix removed from YouTube (82). Anti-copyright activists believe sampling is an essential way of reading, processing and writing in the contemporary world.

The second common argument against copyright is that it empowers corporations, not artists. In theory, copyright is designed to incentivise and reward creative development, and give creators the power to decide how and by whom their original work is used. In practice, film studios, publishers and record labels own copyrights, and creative works are caught in "repressive circuits of ownership and commodity exchange" (Vaidhyanathan 51; Zeilinger 156). Corporate copyright often requires creators to relinquish their personal rights to a work, meaning they are not able to freely license their work to artists or causes they wish to support (McCourt and Burkhart 338). In Good Copy Bad Copy, Girl Talk claims he would happily 
pay licensing fees equitable to the (minimal) market impact of his usage, but there are no systems set up to enable minor-scale, quick, accessible licensing of mainstream media. Without systems in place to make amateur licencing accessible, D.J.s, fan vidders and remix artists are limited to the grey area between fair use and copyright infringement. Furthermore, some scholars have noted that corporate copyright ownership further exacerbates illegal piracy and sampling because pirates and sample artists feel morally justified 'stealing' from corporate middle-men rather than individual creators (Andersson 111). According to this “digital Robin Hood” ethos, pirates and sample artists perform a social service by redistributing cultural products away from corporations and into the hands of everyday consumers (Lewis 56).

Thirdly, anti-copyright advocates view piracy and sampling as political resistance against mass-media hegemony. Echoing the attitude of the culture jamming movement (Chung and Kirby 36; Lasn 19), remix artist, Negative Space expresses remix as retaliation against advertising and commercial media:

You don't ask us whether I want to have a billboard everywhere I go in my town, you don't ask me if I want to see Nike everywhere I go, you don't ask me if I want to hear YouTube music everywhere I go shopping or when I eat in a restaurant, so why do I need to ask you to take a little bit and make something out of it and make fun of you, critique you. (R!P Manifesto)

Negative Space's statement highlights that, in an age when much of the world's media comes from a few conglomerates (Miller et al. 9), sampling is a form of radical contra-flow. Media theorist Daya K. Thussu articulates contra-flow as media products made in the Global South that interrupt the hegemonic flow of Western media (21). The Technobrega movement in Brazil, for example, pirates and remixes songs from the U.S music industry to create a local sound (Good Copy, Bad Copy). Expanding Thussu's definition beyond the South to include grassroots and counter-cultural media made within Western nations, anti-copyright advocates see sampling as a tool of anti-hegemonic contra-flow and political resistance against bigmedia.

Anti-copyright activism is central to Soda_Jerk's practice. Where the majority of popular remix artists create in spite or ignorance of copyright law, Soda_Jerk intentionally provoke and protest it. Soda_Jerk's HOLLYWOOD BURN (2006) is “an anti-copyright epic constructed entirely from hundreds of samples pirated from the Hollywood archive" (soda_jerk.co.au). The narrative "pits a righteous league of video pirates against the evil tyrant Moses and his copyright commandments:" a blatant, tongue-in-cheek defiance of the 
anti-piracy crackdown of the mid-2000s (soda_jerk.co.au). Though not quite as overt in its anti-copyright stance as HOLLYWOOD BURN, TERROR NULLIUS also functions as "a prob[e] designed to test the parameters of the law" (qtd. in Sharp and Juers). Soda_Jerk did not ask copyright holders' permission or pay licencing fees for any of the media they sample. At a practical level, securing permission to use all 174 sources would be unlikely, and even if received, would be costly to negotiate in time and money. In principle, Soda_Jerk defy copyright to advocate for the creative benefits of read/write media culture, flout corporate copyright and create a contra-flow against media hegemony.

TERROR NULLIUS comes from a long tradition of radical sample filmmaking. This chapter has identified three aesthetically and technically distinct forms of sampling that emerged at different historical moments. Compilation sampling, characterised by a documentary realism, has been around since the early decades of cinema. Found-footage sampling, pioneered by the post-war North American avant-garde, takes a more formalist approach, using found-footage to reflect poetically on the nature of mediation. In the digital era, entertaining yet critical remix videos have become a part of popular culture. Across these three forms, sample films engage with the politics of form, the politics of identity and explicit politics in different ways. TERROR NULLIUS continues many of these techniques: sampling footage of politicians to engage in debates around policy and political history; blurring the lines between high and low culture and fragmenting narrative cohesion; challenging massmedia through détournement; calling attention to problematic representations; offering counter-cultural pleasures; and promoting free culture and fair use. The following chapters expand on these political strategies and provide a more in-depth reading of how they appear in TERROR NULLIUS. In surveying the history of compilation, found-footage and remix filmmaking, it is clear that Soda_Jerk did not invent TERROR NULLIUS in a vacuum, but instead sample the strategies of past political filmmakers. 


\section{CHAPTER TWO}

\section{"FROM THE SAME RAW MATERIAL AS HISTORY" 4: HISTORICAL DISCOURSE AND ARCHIVAL SAMPLING}

One of the reasons sampling is such a political form of filmmaking is that is has a privileged relationship with history (Baron; Leyda). According a liberal (rather than institutional) definition of archives, all sample films use archival material - whether a clip made earlier that same year from an online database like YouTube or a hundred-year-old newsreel from an official archive - and therefore engage, to some degree, with representations from and of the past. However, some sample films, TERROR NULLIUS included, intentionally foreground the 'archivalness' of this footage, using its historical status to participate in historical discourse. Jaimie Baron explains that audiovisual media's relationship to its origins is distinct from that of written media, thus archival sampling produces unique kinds of historical engagements and challenges (4). Utilising the language of semiotic theorist Charles Sanders Pierce, Baron describes audiovisual media as "simultaneously iconic and indexical" (3). Film is iconic in so far as it uses aesthetic devices (e.g. performance, editing, music) to represent events and stories, the abstracting nature of this translation producing an excess of potential meanings. Yet unlike other forms of iconic representative art, film is also indexical in that it directly, physically depends on the material world, reproducing it with "extraordinary fidelity" (Nichols 121). It is this indexicality that sets sample filmmaking apart from written history. In filmmaker Ross Gibson's words, cinema is "both as a window on the existing world and as a canvas on which a created world can be presented," thus it can create manipulated explanations of reality that hold authoritative claims to truth (50).

Like many postmodern scholars, Hayden White frames history in similarly poststructuralist terms: a discourse that uses ideologically loaded language to translate material events into political, social, cultural, and psychological "facts" (Historiography, 1196). Such facts about the past can become powerful, political tools for shaping the present (Barthes 153). In relation to the political schema set out in the introduction, history exists at the cross-road between explicit politics and politics of identity. As an explicit political force, history provides the mythologies that underpin governance, law and policy; for instance, the historical narrative that Australia was a terra nulllius (no one's land) on British arrival was

\footnotetext{
${ }^{4}$ (Godard and Ishaghpour, 87)
} 
used to legalise Aboriginal land theft and, though contested in the 1990s, continues to disenfranchise indigenous peoples (Nanni 60; Collins and Davis 4; Cerwonka 9; Elder 147). The power of history (particularly in democratic societies) largely rests on its influence on cultural identity; because the myth of terra nullius plays a central role in white Australians' senses of belonging, selfhood and community, moves to redress Aboriginal land theft are perceived by many white Australians as threats to their identity (Elder 175; Collins and Davis 4). By using archival footage to engage in historical discourses, sample filmmakers can affirm or critique dominant institutional and identity politics.

Filmmakers have understood the relationship between archival material and history differently over time, which in turn has influenced the aesthetics and political impact of sample filmmaking. As the previous chapter shows, "different methods of [sample filmmaking] relate to different paradigms of artistic practice and cultural theory" (Wees 34). This chapter shifts focus to examine sample films that correspond with paradigms of history associated with modernism, postmodernism and postcolonialism. First, I will present the work of early compilation filmmaker Esfir Shub, particularly The Fall of the Romanov Dynasty (1927), as an illustration of a modernist approach to sampling's historicity. Shub believed newsreels archives could simultaneously "reveal the past" authentically and (under the guise of objectivity) be crafted to promote a particular political world view (First Work 20). Postmodernism rejects positivist claims to reality epitomised by modernism and Shub's cinema. Therefore, this chapter next features Jean-Luc Godard's eight-part remix film Histoire(s) du Cinéma (1998), which ambiguously blends documentary footage and fiction cinema into a conceptual history of twentieth-century culture and philosophy. Postmodern premises, like those apparent in Histoire(s) du Cinéma, have been productively applied to postcolonial contexts to interrogate the role of Western epistemologies and institutions in shaping historical consciousness. This chapter concludes by spotlighting Australian postcolonial cinema, specifically works by Ross Gibson, Grayson Cooke and Tracey Moffatt. Gibson's Camera Natura (1985), Cooke's Outback and Beyond (2012), and Moffatt's A White Ghost Sailed In (2017) sample footage from the Australian national archive to draw attention to biases and silences in dominant narratives of colonisation. This chapter's case studies and the paradigms of historical thought they represent, clarify Soda_Jerk's use of archival sampling to intervene in the historical mythologies that underlie Australia's governance and national cultural identity. 


\section{ESFIR SHUB'S MODERNIST HISTORIES}

White's seminal analysis of historical discourse (written in 1973), shows that in the nineteenth century and early twentieth century, history tended to be regarded as a "scientific" pursuit, based on data and cause-and-effect logic (Metahistory $x i$ ). Despite drawing extensively on literary techniques, nineteenth-century historical narratives were presented as rational and objective $(x i)$. This positivist approach persisted in early twentieth-century modernist historical discourse, merging with philosophies like Karl Marx's, which promoted politicised histories that present "the kind of humanity we would like to believe we represent” (White, Metahistory 283). The philosopher Jean-François Lyotard describes modernist history as one of "grand narratives", in which politicised versions of history were framed as universal truths (Lyotard 37). The notion of objective truth also impacted perceptions of photography and cinema. Early cinema culture developed a binary distinction between "actualities" and "narratives," in which non-staged recordings of live events edited into newsreels were held up as trusted sources of information, and scripted, staged narratives as entertainment (Gunnings 56; Crittenden 1). According to Andreas Huyssen's theory of "the great divide", the rejection of entertainment media as a legitimate source of information is a defining feature of modernism (vii). Drawing on these premises, I identify three characteristics of a modernist historical approach to archival sample filmmaking: faith in photographic media's indexical relationship to reality; a clear-cut distinction between nonfiction and fiction film; and the organisation of samples into a coherent, seemingly objective historical narrative.

Esfir Shub's filmmaking exemplifies this modernist approach. As noted in the previous chapter, Shub is credited as the first person to create a feature-length archival compilation film and to use sampling to produce a sophisticated historical discourse (Leyda, Films 23). Shub, a Soviet editor and filmmaker, contemporary to Eisenstein, Lev Kuleshov, Dziga Vertov or Vsevolod Pudovkin, is less known today than her peers due to "the cultural invisibility of women" in histories of Soviet cinema and film editing (Pearlman and Heftberger). Recently, scholars such as Karen Pearlman, Vlada Petric, Anastasia Kostina, Liubov Dyshlyuk and Alla Gadassik have begun to raise Shub's profile, by researching her compilation films and translating her theoretical writings into English. Their work reveals Shub's modernist historical sensibilities, specifically her belief in archival newsreels' historical authenticity and efforts to construct persuasive socialist narratives by adapting preexisting visual "facts" into politicised "thoughts" (Pearlman, After the Facts). 
Shub began her filmmaking career in 1922 as a censorship editor at the state-owned Goskino Studio. In this role, Shub gave "ideological makeover[s]" to around 300 films (the vast majority of them foreign), which involved adding Russian titles and recutting the films to reflect Bolshevik politics (Shub, "The Work of Montazhnitsy"). Through this process, Shub "learned the power of scissors and cement" for constructing meaning (Leyda 24). In the mid-1920s, the Soviet State commissioned several film projects to commemorate the recent history of the Soviet revolution. Eisenstein approached the task through re-enactment in films such as Strike (Stachka, 1925), Battleship Potemkin (Bronenosets Potyomkin, 1927) and October (Oktyabr, 1928), which are scripted, staged historical dramatisations. Meanwhile, Shub turned to pre-existing material. Despite years of newsreel production, there were no formal film archives for Shub to sample, so she undertook the painstaking task of locating, repairing, making negative copies of and cataloguing neglected footage. "Discovering footage became a kind of sport" for Shub as she salvaged nearly one million metres of footage from film studios, libraries and museums in Moscow and Leningrad, and organised the return of expatriated footage from the U.S. (First Work 19; Petric 430). With the help of her assistant, Tat'iana Kuvshinchikova, Shub edited the vast archive she collected into the first three compilation features, The Fall of the Romanov Dynasty (Padenie Dinastii Romanovykh, 1927), The Great Road (Velikiy Put, 1927), and Lev Tolstoy and the Russia of Nicholas II (Rossiya Nikolaya II $i$ Lev Tolstoy, 1928). The Fall of the Romanov Dynasty - the only one of the three to have survived in full and be translated into English — samples footage from 1913-1917 and (like October) narrates the inciting events of the 1917 Russian Revolution.

The premise that newsreel archives contain historical truth underpins Shub's historical trilogy. Constructivist factography (a socialist art movement that advocated a documentary approach to art) was a major influence on Shub (Dyshlyuk 12; Petric 435). Shub believed newsreels' indexical nature made them the most compelling historical source material: "the viewer is persuaded by the real environment, real people and real events" (First Work 20). Shub drew a firm line between staged and non-staged film, believing that "only original, non-staged documents can, and must, reveal the past," and that to stage reality was to "distort it" (First Work 20; Great Road 21). Research indicates that Shub never considered including old narrative footage in her historical features despite her knowledge and experience of fiction archives (Dyshlyuk). Alongside Vertov, she criticised Eisenstein's staged dramas, arguing that their focus on entertainment hindered their revolutionary, educational capacity (And Again 24; Petric 436). Moreover, unlike the surreal trick 
photography and overtly manipulated footage of Man with a Movie Camera (by Vertov and Elizaveta Svilova, 1929), Shub's trilogy avoids obvious editorial flourishes and tries to maintain the footage in its original form. Shub uses intertitles to establish settings, events and people involved, then lets the footage convey the tone and significance of the moment. For example, The Fall of the Romanov Dynasty opens with the titles "Czarist Russia in the years of the 'black reaction'/The Kremlin of the Romanovs." Next, footage of the Kremlin's iconic spires cuts to a shot of a large canon located outside with soldiers walking in the background. In ten seconds of screen time, Shub thereby establishes the Romanovs as exploitative figures who use military force to retain their luxury lifestyles. Shub utilises the historical legitimacy of archival footage, appearing objective while propagating an anti-Tsarist narrative. Across Shub's writings, the urgency and passion with which she advocates for archival preservation further attest to her belief in newsreels' unrivalled historical value (From My Experience 18). This faith in newsreels' authentic representation of reality is a key feature of modernist archival sampling.

Modernist archival sampling is bound by the contradiction (which postmodernists later highlight) of claims regarding archival footage's faithful representation of history and filmmakers' active constructions of ideologically influenced histories. Despite Shub's criticism of authorial interference in fiction film production, editorial manipulation is at the heart of her filmmaking. Shub's historical trilogy models a modernist, Marxist approach to history, presenting a clear, coherent version of historical events that positions the State's political view as objective and totalising. White describes a Marxist approach to history as "synecdoch[ic]" and "comprehensive," using specific narratives as stand-ins for universal experience (Metahistory 282, 285). Marxist history is also activist, in that it frames the past in a way that promotes class-consciousness (White, Metahistory 284). Shub took advantage of the widespread perception of newsreels as authentic, manipulating documentary footage to construct persuasive socialist narratives; that is, her "goal was not just to show the facts, but also to interpret them from the point of view of the class that won the revolutionary battle" (First Work 20).

The Fall of the Romanov Dynasty uses archival sampling to engage in explicit politics, presenting the past regime in a negative light to bolster support for the current one, and identity politics, narrating a collective past that exemplifies a socialist, revolutionary ethic. Shub's background recutting international films to align with socialist values made her an expert in ideological editing. When constructing The Russia of Nicholas II and Lev Tolstoy, Shub had only 80 metres of footage of Tolstoy to work with, but plenty of footage of 
the Tsar taken by his personal cameraman (And Again 23). In her writings, Shub explains her use of editing to "reverse" the meaning of counter-revolutionary material, even suggesting that footage of the Tsar could potentially be satirically shaped into "a hilarious comedy" (And Again 22, 23). In practice, Shub employed juxtaposition to "transform" the Tsar's "celebratory home movies" into "a condemnation of poverty, exploitation and arrogance" (Nichols 149). Though The Russia of Nicholas II and Lev Tolstoy is now lost, similar techniques are visible in The Fall of the Romanov Dynasty, which repurposes newsreels of the Romanov-era ruling elite. For instance, one sequence includes (1) a shot of women labourers bundling hay (fig. 4); (2) the Governor and Governess of Kaluga drinking tea in the garden with their dog (fig. 5); and (3) a field of cattle. The first cut overtly juxtaposes labour inequality, while the second offers multiple interpretations, including the set-up of an analogy that likens the ruling class to cattle "grazing idly and living off the land" as Sharp suggests (13), or a link established between the labouring women and cows to comment on the inhumane treatment of workers under elite capitalism. The next chapter analyses the politics of this type of dialectical editing in greater detail, but in the context of historical discourse, this sequence exemplifies how Shub subverts the original intentions behind newsreel footage to recast history in a way that "advocate[s] and propog[ates]" socialism (And Again 25). In sum, Shub's films illustrate that modernist archival sampling relies on maintaining the authentic, indexical status of observational footage while manipulating it to provide an ideologically loaded narrative of history.

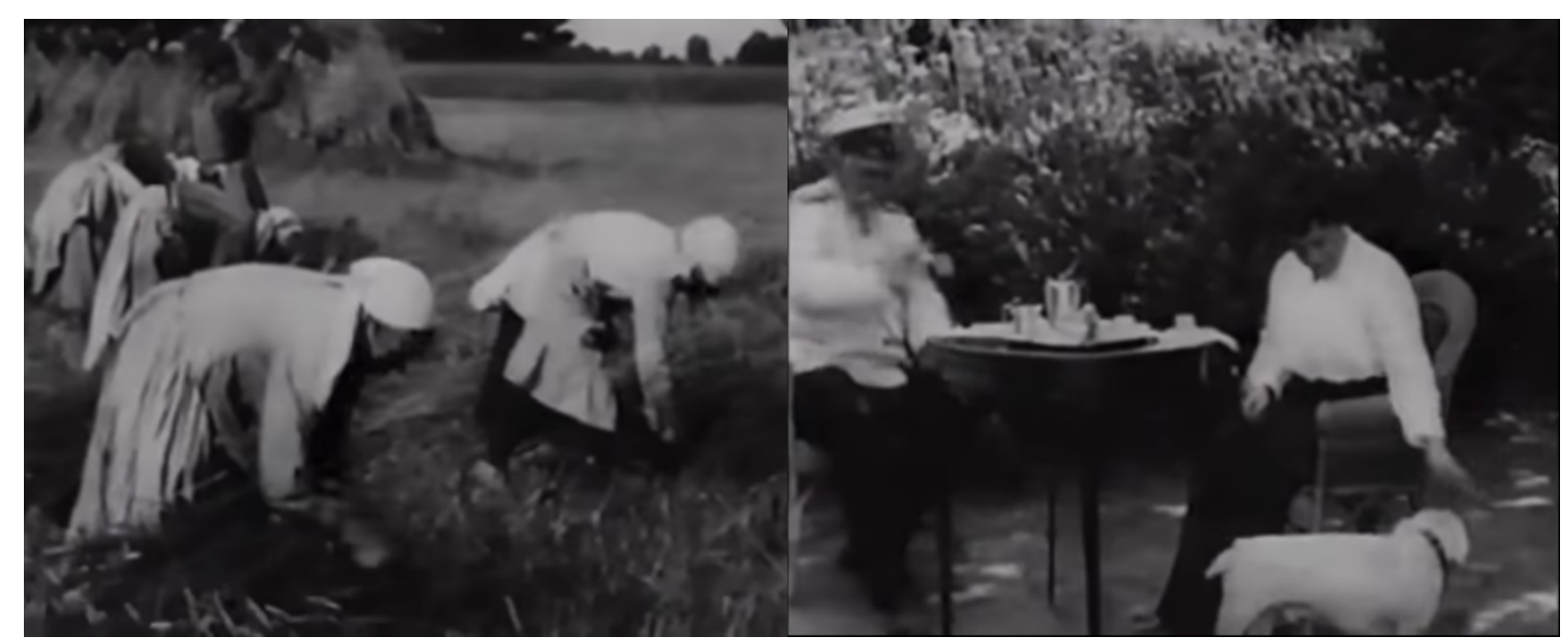

Fig. 4 and fig. 5: Women gathering hay and the Governor and Governess of Kaluga drinking tea, from The Fall of the Romanov Dynasty, Esfir Shub, 1927. 
Aspects of Shub's archival sampling are apparent in TERROR NULLIUS. Like Shub, Soda_Jerk recognise pre-existing footage's emotive and intellectual potency and regard the archive as a reservoir of historical meaning. Also in line with Shub, Soda_Jerk use imagery that was originally taken for purposes counter to their own politics and repurpose it in support of a leftist agenda. With "faith in the tactical power of alternative narratives," Soda_Jerk frame TERROR NULLIUS as a challenge to the lack of "social justice" in the "contemporary national political agenda" (qtd. in Sharp in Juers). Furthermore, TERROR NULLIUS animates multiple socio-political critiques akin to Shub's, including a socialist critique of labour and elite power. In one of the final scenes of Act 3, footage of Queen Elizabeth II's 1988 Bicentenary speech is inserted into a scene from Black Sheep, in which a herd of zombie sheep attach people in suits drinking champagne. Featuring similar iconography (but a very different tone) to the aforementioned scene in The Fall of The Romanov Dynasty, the footage of livestock subverts the original meaning of the Queen's address. That is, just as Shub "reverses" the meaning of the Tsar's home movies, Soda_Jerk co-opt footage intended to uphold and propagate the power of the monarchy to undermine colonial and capitalist cultural values. However, Soda_Jerk do not share Shub's modernist dismissal of fictional footage, nor do they present history as cohesive and universally objective. Where Shub considered her work documentary, Soda_Jerk describe TERROR NULLIUS as a "fable" and "willful narrative space" with a "documentary impulse" (soda_jerk.co.au).

Shub's compilation films are a useful baseline for understanding the dynamic between archival sampling and historical discourse. Her modernist historical approach reflects specific technological, aesthetic, philosophical and political conditions of the late early twentieth century. Faith in photography's indexicality and objectivity, a tendency towards universal grand narratives and the push to politicise history inspired a sampling practice wherein newsreel clips were presented as historical evidence to support a larger ideological narrative. Scholars attribute the emergence of this approach to early cinema, yet emphasise that it persisted through the twentieth century and remains a prominent model for archival sampling in contemporary film, particularly expositional or observational documentaries (Baron 5; Nichols 149-150). Meanwhile, other archival sample films, TERROR NULLIUS included, challenge the realist conventions of modernism. Using Shub's cinema to exemplify modernist archival sampling establishes a foundation for understanding postmodern and postcolonial reactions against modernism. 


\section{HISTOIRE(S) DU CINÉMA'S POSTMODERN CONSTELLATIONS}

Chapter One outlined the emergence of postmodernism and its expression in avant-garde found-footage sampling via three characteristics - the blurring of high and low culture; the dissolution of narrative coherence and totality; and the tendency for subversive appropriation. These characteristics reflect a deep philosophical shift in culture and intellectual thinking that had major implications for how history was understood and communicated. From the late 1960s, structuralist theories by White, Roland Barthes, Michel Foucault and Jacques Derrida stimulated major transformations in historical discourse (Foster vii). As these theories developed over the subsequent two decades, they came to be understood under the umbrella of postmodernism (Lyotard; Jameson; Foster). Sceptical of modernism's allegedly objective, totalising and progressive narratives of 'what really happened,' postmodern historical scholarship shifted focus to metahistories, historical mythologies and plural interpretations (Foucault 7-9; White, Historiography 1196; K. Jenkins 16). In the process, primary sources lost some of their status as objective evidential documents and began to be regarded as discursive texts inscribed with cultural meaning, bias and omission (Foucault 7; Barthes 153). In consequence, official archives, which were previously considered neutral repositories, were reconceptualised as institutions shaped by political and cultural ideologies (Derrida 11; Foucault 129; Manoff 110). Simultaneously, conceptions of what counted as archival expanded beyond the institution, scholars increasingly incorporating popular and personal texts into their historical analyses (Manoff 110). In this discursive context, scholars such as White, Robert Rosenstone and Pierre Sorlin argued that fictional cinema could be as fruitful a historical source as a newsreel, in that it "illuminate[d] the way in which individuals and groups of people understand their own time" (Sorlin 25).

These conceptual shifts in historical discourse are reflected in the way postmodern sample filmmakers engaged with archival sampling. I characterise the postmodern approach to historical sampling as: a lack of distinction between fiction and non-fiction archival texts; a sense of historical plurality and subjectivity; and self-reflexive engagement with violence and trauma. Jean-Luc Godard's 1998 Histoire(s) du Cinéma is a useful illustration of these postmodern characteristics. The 266-minute, eight-part video project compiles film clips, newsreels, images of paintings, philosophical quotations, audio samples and narration by Godard and others into a poetic commentary on twentieth-century Western cinema, history and culture. Using electronic video editing technology, Histoire(s) du Cinéma resizes, slows down, layers, colours, masks and fades between clips to generate "conceptual associations" 
across archives of different genres, period and contexts (Witt 51). Mirroring White's stance that "the historical evidence produced by our epoch is. . . visual," Godard argues that cinema and the twentieth century are inextricably linked and that film, whether fictional or not, is "made from the same raw material as history" (White, Historiography 1196; Godard and Ishaghpour 87). As a remix project that samples a broad range of audiovisual archives to critically analyse cultural history, Histoire(s) du Cinéma is an important precursor to TERROR NULLIUS. Mapping the similarities of the postmodern historical discourses the two films present clarifies TERROR NULLIUS' innovative and subversive politics.

Histoire(s) du Cinéma attributes fiction and non-fiction footage with equal historical significance (thus illustrating the first characteristic of postmodern archival sampling). In contrast to Shub's faith in newsreels' authenticity, Godard argues that the Holocaust “anaesthetised" documentary's function (Witt 127). As a result, Histoire(s) du Cinéma attributes to fictional samples the same historical value as non-fictional ones. In part 1A, 'All the Histories' ('Toutes les Histoires'), footage of Classical Hollywood film stars and producers, such as Irving Thalberg and Howard Hughes, are intercut with clips of Hitler, guns, fighter planes and dead bodies, the sequence crosscutting rapidly between glamorous and horrorifying imagery. "War has broken fiction versus reality. To prove it, the masses like myths. Cinema speaks to the masses," Godard narrates. In part 1B, to represent the myths that culture relies on, Godard makes no distinction between documentary footage of Nazi parades and clips from Charlie Chaplin's The Great Dictator (1940); the section also superimposes a documentary image of train tracks leading into Auschwitz from Night and Fog (Nuit et Brouillard,1956) over a clip of nuns repenting from the narrative film Angels of Sin (Les Anges du Péché, 1943). In blurring images associated with fact and fiction, Godard problematises positivist historical claims and draws the viewer's attention to history's fictional dimension (and vice versa). The audience of Histoire(s) du Cinéma is not presented a clear history of the twentieth century, but an abstract interpretation of significant twentiethcentury cultural shifts apparent in cinema.

As the parenthesised 's' in its title suggests, Histoire(s) du Cinéma presents a pluralist, unstable account of the past that contradicts the grand narratives of modernism. Referencing Walter Benajmin, Godard describes the film as a series of constellations (Godard and Ishaghpour 7). In Benjamin's metaphor, "ideas are to objects as constellations are to 
stars" (The Origin, 34; Krauss 139). ${ }^{5}$ In other words, constellations are a framework for interpreting meaning, based on perceived connections between independent literal events or material evidence. As a historical framework, constellations present non-linear interpretations of the past based on patterns and connections between different moments in time, rather than a rigid, consecutive narrative. Benjamin dismissively likens a positivist, linear approach to history to "telling the sequence of events like the beads of a Rosary," implying it to be doctrinal rather than inquisitive (Illuminations 265). In addition to being non-linear, historical constellations are relative and subjective: just as an observer's view of the stars is unique to their geographic position, a historian's interpretation of the past is influenced by their historical location. A constellation approach to history recognises that a single event or text can contribute to different, and even contradictory, constellations depending on the historian's present subjectivity (Steinberg 92). Benjamin argues that the historian's task is to "grasp the constellation which his own era has formed with another one," highlighting the constellation framework's intentional historical presentism (Illumination 265).

'Constellation' is a useful metaphor for describing how sample films can produce meaning by placing formerly disconnected media into an organised form. Histoire(s) $d u$ Cinéma treats footage as stars (visible projections of light from moments passed) and charts them into constellations of the twentieth century through montage. In some sequences, Godard re-uses the same footage, but in conjunction with different samples, "conveying distinct meanings each time" (Witt 4). The aforementioned clip from Angels of Sin in part 1B appears again in $2 \mathrm{~B}$, but this time alongside clips of femme fatale characters from Classical Hollywood films. In this latter context, the nuns no longer suggest the grief and guilt of the Holocaust; instead, they connote virgins in contrast to cinema's sexualisation of women, which the footage of femme fatales suggests (Aumont, "Mortal Beauty" 107). Godard's constellations frame history as multiple and malleable, pushing the viewer to question historical narratives assumed to be accurate and absolute.

Histoire(s) du Cinéma also demonstrates the subjectivism and presentism of the historical constellation framework. Godard continually foregrounds his presence as the author of the text, including footage of himself at a typewriter and narrating much of the film. Moreover, his subjectivity is evident in the constellations he charts. In part 3A Godard

\footnotetext{
${ }^{5}$ Benjamin's work predates the "postmodern turn" however postmodern theorist like Craig Owens and George L. Ulmer have emphasise his relevance to postmodern theory (Owens The Allegory, 84; Ulmer 97; J. Wong 44) In particular, Benjamin's "posthistoricist" (Habermas 5) notion of histroy as constructed, multiple and subjective closely align with definitions of postmodern history (K. Jenkins 2).
} 
crosscuts between footage of "two very different, unrelated train journeys": footage of French film stars, including Danièle Darrieux, on a train tour of UFA (Nazi propaganda studios) in 1942 and a clip of train from The Ball ( Le Bal, 1931), a film adaption of a text by the Jewish writer Irène Nemirovsky staring Darrieux (Witt 184; Williams, European Culture 123). Nemirovsky was taken to Auschwitz the same year (1942) Darrieux was welcomed in Berlin. By interweaving these clips, Godard produces a historical critique of the French film industry's response to Nazism. The The Ball footage could support a variety of historical arguments about the Holocaust but Godard uses it to express remorse specifically tied to his own national identity (as French-Swiss) and occupation as a filmmaker (Witt 184). In producing history through unexpected combinations rather than a linear timeline, a constellation approach to sampling presents history as constructed rather than set and draws attention to the author and editor's influence.

Postmodern sample cinema's blurring of fiction and non-fiction and rejection of coherent and linear narrative reflect a "crisis in representation" that scholars associate with the traumatic representation of twentieth-century violence (Sobchack 9; Godard and Ishaghpour 129; White, The Modernist Event 22). Referencing holocaust theorists, Thomas Elsaesser explains that traumatic events simultaneously "def[y] representation yet demand it with equal finality" (147). This contradiction is evident in broadcast media's tendency to repeat traumatic images until they promote "obsession and fantasy" rather than provide resolution (Elsaesser 146; Sobchack 4). As the above examples indicate, Histoire(s) $d u$ Cinéma is preoccupied with WWII and the Holocaust (Williams, Histoire(s) 12). Like the avant-garde films A Trip Down Memory Lane and A Movie discussed in Chapter One, WWII newsreel footage of soldiers, guns, planes, bombs, mushroom clouds and victims is intercut throughout Histoire(s) du Cinéma. However, unlike in The Fall of the Romanov Dynasty, wherein scenes of unrest are contextualised to provide a coherent history, in postmodern sample films, violent clips appear without warning and disappear abruptly, denying the viewer time to process and incorporate that violence into a lucid interpretation. For example, the torture scene from Rome Open City (Roma Città Aperata, 1945) appears five times in Histoire(s) du Cinéma, presenting a recurring trauma that never resolves (Witt 148). Sample filmmaking is particularly suited to expressions of violence and unresolved trauma because its technical processes - extracting, fragmenting, cutting — have violent connotations, and its ability to revive and replay scenes from the past mirrors memory patterns associated with trauma.

Like Conner, Lipsett and other postmodern sample filmmakers, Godard utilises an excessive, 
frenetic editing style in conjunction with images associated with WWII to engage historical traumas.

There are strong resonances between TERROR NULLIUS and the postmodern archival sampling Histoire(s) du Cinéma illustrates. Akin to Godard's description of cinema as the "raw material" of history, Soda_Jerk explain fictional media as "historical documents, thoroughly inscribed with concrete traces of their production, circulation and reception" (Godard and Ishaghpour 87; Sharp and Juers). Like Histoire(s) du Cinéma, TERROR NULLIUS primarily samples fictional films and does not signal a distinction between fictional and non-fictional sources. Soda_Jerk also articulate a Benjaminian tension between individual texts, interpretive frameworks and present subjectivities, describing cultural phenomena as "constellations" (qtd. in Maunder) and filmic images as "nodes of energy and matter that migrate across different supports, shaping and affecting people, landscapes, politics and social systems” ('Anarchivist Manifesto' 143). Exemplifying a constellation approach to history, TERROR NULLIUS regard samples as malleable and uses them in multiple ways. In Act One, Amelia from The Babadook (2014) appears in the girl gang that attacks Mad Max/Mel Gibson, striking the match that blows up his car. In Act Two, Amelia appears again, this time trying to exorcise queer apparitions from her house. Soda_Jerk use the same film to chart constellations of two different cultural moments (Mel Gibson domestic violence and Australia's 2017 same-sex marriage postal survey) in a similar way that Godard uses Angels of Sin to explore both the Holocaust and sexual objectification. ${ }^{6}$ The particular constellations Soda_Jerk construct are influenced by their positionality as Australian filmmakers: as Histoire(s) du Cinéma critically reflects on the French film industry's failure to represent Holocaust history, TERROR NULLIUS is interested in the ways Australian cinema has been complicit in (and has challenged) ongoing colonial narratives (Maunder). As a result, trauma is a central theme of TERROR NULLIUS, but in response to colonial, gender and race violence rather than the Holocaust. Chapter Five's close reading of TERROR NULLIUS' treatment of immigration history will demonstrate this postmodern historical discourse in greater detail. Soda_Jerk's approach to history has much in common with Godard's, characterised by the postmodern regard of fiction cinema as historical data, a constellation approach to historical construction, and awareness of historical trauma.

Despite their similarities, TERROR NULLIUS deviates from Histoire(s) du Cinéma in

\footnotetext{
${ }^{6}$ See Chapter Four for a more indepth explanation of the Mel Gibson scene, and Chapter Five for a discussion on links between The Babadok and the same-sex marrage survey.
} 
its approach to source material and its activist attitude. As scholars have criticised of postmodernism more generally, Godard fails to explore implications of postmodernism beyond Eurocentric, ultimately nostalgic and nihilist boundaries (Ashcroft et al. 118; Radhakrishnan 308; Maffettone 503; Yin 193; Williams, Histoires(s) 12). Despite the global implications of its title, Histoire(s) du Cinéma predominantly samples French, Italian, German, Russian or American, critically regarded arthouse or drama films (Witt 141-142). This Eurocentric definition of cinema reinforces the academic canon of film studies (of which Godard is a central figure) (Fletcher 65). By the 1990s, Godard held a highly nostalgia view of cinema, believing the 1960s "avant-garde was in fact arrière garde [rear guard]" (qtd. in Sterritt 181) and that television marked cinema's downfall (Morrey 73; Witt 170). Though Histoire(s) du Cinéma was made in the late 1980s and 1990s, the vast majority of the 384 films it samples were made before 1970 (Witt 136). Contrastingly, TERROR NULLIUS foregrounds itself as a broad study of Australian media, featuring 'ozploitation' films and over thirty television shows alongside prestige drama cinema and including sources from as recent as 2017. Histoire(s) du Cinéma's sense of nihilism has implications for its politics; while the film produces a subversive politics by undermining totalising historic logics, it struggles to offer positive models or an activist sense of agency regarding explicit politics or the politics of identity. As Sebastiano Maffettone argues, "the nihilist consequences of postmodernism make [it] impossible [for discontent to transform] into a basis for reasonable political action" (493). TERROR NULLIUS, meanwhile, has a more optimistic tone and a clear activist agenda. Postmodernism, in the manner Godard demonstrates, is useful but not fully sufficient for understanding TERROR NULLIUS' approach to archival sampling and the politics of history.

\section{AUSTRALIAN POSTCOLONIAL SAMPLING}

Postcolonialism is the most relevant historical discourse for analysing TERROR NULLUS' archival sampling. Heralded by the Franz Fanon's work in the 1960s and Edward Said's seminal 1978 text Orientalism, postcolonial theory rose in prominence throughout the 1980s and by the mid-1990s had a strong body of critical literature (Ashcroft et al.; Iskandar and Rustom 9). Postcolonialism continues the critical epistemological project of postmodernism, but in the context of specific national and transnational histories, encounters, oppressions and archives (Appiah 348; Maffettone 495; Hutchinson 131). Linda Hutchinson argues that while postmodernism and postcolonialism share several key conceptual premises, postcolonialism has "a theory of agency that allows [it] to go beyond the postmodern limits of deconstructing 
existing orthodoxies into the realms of social and political action" (130). For historians, postcolonialism meant re-evaluating whose perspectives were included in and absent from dominant historical narratives and understanding how histories of nationhood maintain or challenge colonial legacies (Ashcroft et al. 355). Official archives came under immense scrutiny, reinterpreted from neutral repositories to institutions which "shape and $\operatorname{direc}[\mathrm{t}]$ historical scholarship, collective memory and national identity" in ways that uphold and legitimise colonial legacies (Schwartz and Cook 2). Postcolonial approaches to history tend to continue many of the strategies of postmodernism - using non-linear structures, focusing on historical constructionism, recognising the impact of violence and trauma - but in a less abstract manner, drawing on concrete discrepancies between settler and indigenous narratives and experiences.

The postcolonial turn in Australian scholarship brought the politics of history into sharp relief (Macintyre). In the 1980s and 1990s, history, law, literature and cultural studies scholars began to look more critically at their country's colonial history, questioning the master narratives of terra nullius and the civilising mission (Verachini). Subsequent backlash scholarship, by the like of Geoffrey Blainey and Keith Windschuttle, criticised postcolonial analysis as "black armband" history (Blainey 11). The "history wars" expanded into public discourse and took on political dimensions, with Paul Keating's Labour government pursuing reconciliation and apology and his Liberal opponent, John Howard, maintaining that "the balance sheet of [Australian] history is one of heroic achievement" (Sir Robert Menzies Lecture; Collins and Davis 6; Macintyre 82). Archives became highly charged spaces, used on both sides of the debate in different ways. For instance, in 1993, the landmark Mabo case used archival government documents to help overturn the doctrine of terra nullius, hailed as a turning point for reconciliation and Aboriginal and Torres Strait Islander land rights (Edler 175; Cerwonka 11). Archives were also used to deny indigenous oppression- Windschuttle used the absence of death records in the Tasmanian archives to claim postcolonial scholars had exaggerated the narrative of Tasmanian genocide. Through these debates, archives "became a contested cultural site of immense potential", malleable to different ideological approaches to history and deeply affecting "understandings of national identity" (Conor and Lydon 140).

Australian filmmakers and artists have utilised archival sampling as a way to engage with political debates around colonial history and its legacies. In a 2011 special issue of Journal of Australian Studies about visual cultures and colonialism, editors Liz Conor and Jane Lydon explain how analysing visual media, in the context of its production and 
circulation, reveals how colonial Australia built racist stereotypes about indigenous people, and reinforced the perception of pre-colonial Australia as an unoccupied terra nullius (138, 141). Conor and Lydon also note "a recent trend in Australian cultural production to reclaim and rework imagery from the colonial archive" (137). TERROR NULLIUS is one of the most recent and complex examples of reclaiming the Australian audiovisual archive through sampling, but it is far from alone. In 1985, Ross Gibson created Camera Natura, a poetic essay film which remixes cinema, documentaries, paintings, written texts, maps and television advertisements into a historical argument about the link between dominant representations of the Australian landscape and white Australia's national identity. Grayson Cooke's archival remix performance, Outback and Beyond (2012) investigates how settlercolonial images of the Australian landscape mirror frontier imagery of American Westerns, and what this indicates about national identity. One of Australia's most prominent visual artist, Tracey Moffatt has recurrently used archival sampling to explore representations of gender, race and history. Moffatt's 2017 Venice Biennale exhibition, My Horizon included two video works, The White Ghost Sailed In and Vigil, which both use archives to explore Australian colonisation and migration politics. Unpacking how Camera Natura, Outback and Beyond and The White Ghost Sailed In engage the Australian audiovisual archive to explore themes of land, time, archival absences and transnationalism, clarifies a postcolonial approach to archival sampling and provides a foundation for understanding TERROR NULLIUS' archival use.

Land and its representation is a primary focus of postcolonial historical discourse (Elder 147; Collins and Davis 75). While colonialism has many impacts, indigenous land loss and the disenfranchisement and trauma it has caused is one of the most significant, and the centre of much indigenous political action in Australia and other postcolonial settler states (Johnson). Meanwhile, postcolonial scholars have noted a tendency in white settler cultural imaginary to subconsciously project the "unbearable weight of [colonial] history" onto the landscape (Collins and David 75; also see Bergland 4; Stadler et al 13). Australian national cinema has a strong aesthetic tradition of gothic, foreboding landscapes, void of people but with their own mysterious sense of energy (Rayner; Stadler; Gibson). Gothic appears at the unresolved intersection of imperialist perceptions of Australia, first as terra incognita (unknown land), then terra nullius (no one's land), with the reality of Aboriginal people's ancient heriage on the continent and their familiarity with landscape (Stadler et al.). Renee Bergland explains that in the colonial imaginary, landscapes often serve as an allegory for indigenous people, with empty landscapes serving as "spectral" reminders of colonial 
violence (4). Meanwhile, Gibson describes settler landscape anxiety as a continuation of terra incognita, stemming from a lack of Western historicisation of the Australian outback:

Every plot of earth, every spike of spinifex hasn't accrued a story, hasn't yet become a sign in the arbitrary system of meaning which is history. To white sensibility, most of Australia is empty space, devoid of inhabitants, architecture and artefacts. (47) In positioning settler culture at odds with the environment, gothic landscapes express a "pervasive unease" about the "origins of white settlement" and emphasise white Australia's migrant (rather than indigenised) identity (Rayner, "Gothic" 96). In denying settler "indigenis[ation]", such representations thereby undermine colonial claims to the land (Elder 147). However, in erasing indigenous presence from the landscape, gothic representations also maintain the terra nullius myth and fail to openly confront colonial history. Cinematic gothic landscapes can, therefore, be understood as latent or unrealised postcolonial critique.

Several Australian sample films repurpose gothic representations of the landscape to confront colonial guilt and emphasise terra nullius as a construction rather than a reality. Camera Natura samples a variety of films, including The Back of Beyond (1954) and Picnic at Hanging Rock (1975), which represent the Australian outback as a mythic site of danger and mystery. One sequence features a clip from The Back of Beyond in which two young girls are lost in the desert - "what became of them isn't known, all that remains is their story" the voice-over narrates. The The Back of Beyond narration overlaps with a sequence from Picnic at Hanging Rock (1975), a canonical Australian gothic period drama about school girls who disappear into the Australian bush (Rayner, "Gothic" 92). In drawing attention to this gothic landscape trope, Gibson emphasises how the notions of terrra nullius permeated the white cultural imaginary (47). Meanwhile, Outback and Beyond make links between the Australian gothic and Western iconography in Australian films from the 1920s-1950s, also including The Back of Beyond. Cooke spotlights archival images of cracked earth, open expanses and ranchers on horseback, evoking familiar Hollywood frontier narratives associated with racial violence. Using luma-keying to make "faces reveal landscapes and landscapes reveal faces," Cooke surfaces colonial allegorical connections between land and indigenous peoples (109).

As its title indicates, TERROR NULLIUS also explicitly engages with gothic landscapes. Soda_Jerk consider Australian gothic films to be "a stealth repository for unspoken cultural anxieties" and use sampling to bring those anxieties to critical attention (qtd. in Sharp and Juers). TERROR NULLIUS opens with a scene from Walkabout (1970) (regarded by Rayner as one of the benchmarks of Australian Gothic, 92), in which the vast desert landscape appears a menacing threat. The scene is followed by a series of gothic 
desert-scapes from The Adventures of Priscilla, Queen of the Desert (1994) and Roadgames (1981), as well as an audio clip proclaiming Australia "the oldest earth on earth" (from the 1988 Australia Live bicentenary T.V. special). Soda_Jerk utilise the gothic tradition to establish themes of postcolonial unease, but where other films leave unease hanging, Soda_Jerk confront it directly. In Act Two, Skippy and Sonny (Skippy the Kangaroo) stumble across the bodies of the girls from Picnic at Hanging Rock. Soda_Jerk subtitle Skippy's clicking: "What if the fate of these four fictional white girls becomes a national obsession? It may very well exacerbate the ongoing obfuscation of our complicity in a colonial history of oppression, dispossession and genocide?" Here, Soda_Jerk directly challenges the indigenous erasure in many gothic films and redirects attention from white settler victimhood to colonial oppression. The film closes with an audio sample from $A$ Secret Country: The First Australians Fight Back (1985) criticising white Australia's colonial amnesia. Detective Zat from Lantana (2001) breaks down in tears as he listens to a tape explaining "massacres as systematic as those practised against the Jews in the twentieth century, were carried out in the name of God, King, anthropology, money and land". In opening with gothic representations of the landscape and ending with a direct critique of the terra nullius myth, TERROR NULLIUS brings the underlying guilt around land in Australian cinema narratives to the fore in a strong postcolonial critique.

According to postcolonial theory, epistemologies of time and territory are closely connected and disrupting linear time can destabilise colonial claims to land (Nanni; Perkins; Martin-Jones). Giordano Nanni explains that colonial notions of chronological, standardised time (cemented by the regulatory demands of industrial capitalism), helped produce the mythology of linear progress from savage to civilised. In the minds of British colonisers, Aboriginal peoples were "timeless," i.e. ahistorical and acultural $(9,60,75)$. Drawing on Maureen Perkin's work, Nanni links the colonial perception that Aboriginal people lacked temporality with the colonial perception that Aborignal people lacked land ownership, arguing the construction of Australia as a terra sine tempore (timeless land) was a precondition for its classification as terra nullius (60). David Martin-Jones applies Gilles Deleuze's concept of the time-image and Homi K. Bhabha's postcolonial analysis of progressive time with national cinema, arguing that "during times of historical transformation, films often appear that experiment formally with narrative time" (1). MartinJones theorises that narratives which disrupt spatio-temporal continuity "deterritorialise" or denaturalise "the performance of national identity" by undermining the linear temporality necessary for historical progression narratives and untethering historical narratives from their 
geographic signifiers (35). Together, Nanni's and Martin-Jones' research indicates how Australian sample filmmakers might challenge the doctrine of terra nullius through nonlinear structuring devices.

Camera Natura, Outback and Beyond and TERROR NULLIUS all use experimental time to challenge colonial representations of the Australian landscape. Robert Rosen describes Camera Natura as a historical "net" woven from many "diachronic and typological" threads (1127). These diachronic threads create a sense of history by discussing the evolution of representational technologies and the Australian landscape's shifting relationship with national identity, but do not demarcate a clear timeline as they jump back and forward between media from the nineteenth century and the 1980s. Gibson further disrupts the chronology of these threads by slipping fluidly between sampled footage, still images, staged performance and original narration. This temporal ambiguity implies that the present is both built from past legacies and is in a perpetual state of becoming, situating the viewer inside an ongoing notion of history in which they are an active agent, rather than passively looking back the past. Camera Natura supports a postcolonial agenda, by drawing attention to the ongoing nature of colonial epistemology and implying the future is open to change. Outback and Beyond also implicates the present in the past through live remix. Each performance, Cooke "raids" his library of 130 archive samples in a new way, producing a dynamic, shifting portrayal of the outback (Cooke 106). Cooke's performative sampling resists static historicisation and embraces Benjamin's fluid, pluralist notion of history as "an image which flashes up at the instant when it can be recognised and is never seen again" (257). Cooke's live, idiosyncratic time-images present history as a labyrinth, emphasizing the many "possible pasts" and choices involved in narrating history (Martin-Jones 28). TERROR NULLIUS, likewise, orders its samples in a non-chronological fashion, bringing archives from different historical contexts into contact. For instance, a clip of an Aboriginal group protesting mining exploration from the docudrama Where Green Ants Dream (1984) is cut with footage of contemporary mining magnate Gina Rineheart, highlighting the ongoing commercial exploitation of indigenous land. In blurring past and present and relocating samples to new settings, Soda_Jerk challenge the notion of archives as snapshots of the past, suggesting they are still deeply implicated in the present. Presenting colonial images through a non-colonial time chronology, Camera Natura, Outback and Beyond and TERROR NULLIUS deterritorialise colonial perceptions of Australian as terra nullius and position the present-day viewer within, not beyond history. 
Postcolonial archival analysis is often as much about what is absent from the archive as what is there. While colonial archives often include images of or documents about indigenous peoples, they rarely contain media by them (Ghaddar 23). Archival records tend to obscure the negative repercussions of colonialism for indigenous people, and when they do, it is often within a "dying race” framework (Ghaddar 24). Tracey Moffatt's 2017 Venice Biennale work, The White Ghosts Sailed In, grapples with the absence of Aboriginal perspectives in Australian archives in a complex, provocative manner. The two-minute film opens with a title card "From an eyewitness account at Sydney Cove Australia 1788", followed by a landscape view of the ocean taken from high on a coastal cliff. The sepia, scratchy footage has the aesthetic of decaying nitrate. In the exhibition description and subsequent interviews, Moffatt claims the footage was shot by Aboriginal filmmakers on " $26^{\text {th }}$ January 1788" (the day the British 'First Fleet' arrived to establish the New South Wales penal colony, also known as Invasion Day) by a "local Aboriginal person" (Brett 113, 140). Moffatt says the footage was shot on nitrate made from "melted-down pig hooves" using a camera left by Joseph Banks and preserved in "a seal-up vault" in a Sydney mission (Brett 113, 140).

Given that histories of photography date the earliest surviving photograph to 1826 and the earliest film footage to 1888 , and the conditions for preserving nitrate film are highly delicate, reviewers have taken Moffatt's claims as "entirely specious" (Searle). The footage likely dates to the early twentieth century or potentially was shot by Moffatt and edited to achieve a nitrate aesthetic. But determining the 'true' provenance of the footage is less significant than understanding the intention behind Moffatt's elaborate narrative. Baron's chapter on "fake" archive films (such as found-footage horror genre, or mockumentaries), explains that fabricating archival provenance "undermin[es]" the archives privileged historical position (50). In providing an implausible provenance, Moffatt reminds viewers to "interrogate why, when and how we lend our belief to archival documents and their claims to historical truth in service of particular narratives" (Baron 77). By "faking it with the truth", Moffatt uses the "hyperreal imaginary" to retrospectively reinstate an "indigenous point of view" into the archive (Biddle and Lea 5; Ginsberg 71). The film's visual glitches further challenge the archive's privileged claim to historical truth. Mid-way through, the empty ocean is interrupted, for a split second, by a shape that looks like a sailing ship but could easily be a damaged spot on the celluloid. For the next sixteen seconds, the footage is completely eroded: cracked nitrate flickers like a rapid time-lapse until the image of the 
empty ocean returns. This temporal gap evokes the censorship and erasure of indigenous perspectives of colonisation in both Australia's archive and contemporary political climate.

Moffatt's complex engagement with archival authenticity and emphasis on reinstating indigenous perspectives in The White Ghosts Sailed In provides a useful lens for understanding how Soda_Jerk create a "rogue historiography" through "speculative fiction" (Soda_Jerk. Qtd Buckmaster). Like Moffatt, many of the historical events or ideologies Soda_Jerk seek to represent do not have direct audiovisual archival representation. Instead, Soda_Jerk recontextualise fictional footage, using clips of Mel Gibson from Mad Max (1979) to comment on Mel Gibson's 2010 abusive behaviour (see Chapter Four) or Puberty Blues (1981) as a stand-in for the 2005 Cronulla riots (see Chapter Five). By using fictional material to form a "revisionist history," TERROR NULLIUS pushes the viewer to question their assumptions of archival authenticity and historical legitimacy (sodajerk.com.au).

Postcolonial theory and its expression in Australian archival sample films is particularly useful for understanding TERROR NULLIUS' historical discourse and its political ramifications. This section has outlined three of Australian postcolonial archival sampling's key projects: interrogating legacies of terra nullius; destabilising Western historical time; and criticising archival absences. Building on the discursive historical logic of postmodernism, postcolonialism deconstructs and denaturalises colonial logics and how they have, and continue to impact policy and cultural identity. By analysing Australian culture in postcolonial terms TERROR NULLIUS, like Camera Natura, Outback and Beyond and The White Ghosts Sailed In, encourage audiences to critique their own historical understanding of Australian colonisation, the terra nullius mythology and its role in ongoing Aboriginal land alienation and the politics of reconciliation and reparation.

This chapter has outlined three major trends in historical discourse and analysed their expression in archival sampling. Demonstrating a modernist approach to sampling, Shub's films and theory assume an authentic relationship between non-fiction newsreels and history and produce ideological, persuasive historical narratives. Godard's Histoire(s) du Cinéma illustrates a postmodern historicity, blurring distinctions between fictional and nonfictional source material, adopting a nonlinear, subjective constellation framework and engaging with themes of violence and trauma. Films by Gibson, Cooke and Moffatt demonstrate a postcolonial historical approach to archive sampling, repurposing the Australian audiovisual archives to challenge Australian's colonial mythologies around land, time and historical evidence. TERROR NULLIUS aligns with and diverges from these three historical discourses in different ways. Soda_Jerk share Shub's ambition for politicised history and adopt some of 
her archival manipulation techniques. They also align with Godard's view that fictional cinema can communicate history and his constellation style of filmmaking. Building on Gibson, Cooke and Moffatt, TERROR NULLIUS uses postcolonial historical frameworks to contribute to Australian political discourses that challenge the terra nullius mythology and ongoing colonial oppression. More broadly, this chapter demonstrates sample filmmaking's strong connection to history and its ability to produce various historical discourses. The films discussed in this chapter all engage with the politics of identity and explicit politics by presenting histories that affirm or challenge dominant political and cultural mythologies. Archival sample films have the ability to "reconfigure the past" in ways that call critical attention to the politics of the present (Soda_Jerk qtd. in Maunder). 


\section{CHAPTER THREE \\ “NOT SHOT BUT BUILT"7: TERROR NULLIUS' SUBVERSIVE EDITING}

Sample filmmakers are, first and foremost, editors. Using the tools of copy/cut/paste, they select, trim and order raw ingredients into a new creation (Navas 15; Russo and Coppa 2.3; Manovich 135). The previous chapters unpack how a sample's form, content and origin influences its meaning; this chapter explores how filmmakers accentuate or subvert that meaning through editing. Most popular press on TERROR NULLIUS focuses on the tone and meanings of its scenes but gloss over the details of how such scenes are actually constructed. To understand how TERROR NULLIUS produces political meaning, it is necessary to unpack Soda_Jerk's complex editing style. This chapter examines three editing strategies dialectical montage, uncanny continuity and collage composition - and explains how TERROR NULLIUS combines them to encourage critical spectatorship and subversive political consciousness.

While the existing literature on sample filmmaking analyses editing (Wees; Leyda), it tends to focus on montage alone and is not sufficient for describing Soda_Jerk's sophisticated hybridisation of montage, continuity and collage. As montage is the structural foundation of most sample filmmaking, including TERROR NULLIUS, it is important to outline its central theories, historical uses and function in TERROR NULLIUS, before expanding on the other two forms of editing. Citing Soviet film theorists, particularly Eisenstein, this chapter explains how dialectic montage creates cinematic meaning through the intellectual and emotional repercussions of contrasting shots rather than continuous spatiotemporal action (Eisenstein 46). Soviet and Third Cinema films, such as October (1927) and The Hour of the Furnaces (La Hora des los Hornos, 1968), illustrate how dialectical montage encourages a critical consciousness and revolutionary sentiment associated with leftist politics. While Soda_Jerk are influenced by montage theory, they also employ continuity editing techniques to transition smoothly between samples and fabricate interactions amongst characters from different sources. Analysing Surrealist films, such as An Andalusian Dog (Un Chien Andalou, 1929) and Meshes of the Afternoon (1943), in conjunction with theories of the "uncanny" (Freud; Mori; Jay) clarifies how Soda_Jerk employ continuity editing in a disconcerting fashion to unsettle the viewer's assumptions of reality. Soda_Jerk's sophisticated use of digital compositing to collage samples within a single frame sets TERROR NULLIUS' editing apart from most prior sample films. Lev Manovich and Robert Burgoyne's analysis of

\footnotetext{
${ }^{7}$ (Pudovkin xiv)
} 
compositing and art literature on static collage suggests how TERROR NULLIUS' collage compositions create Benjaminian historical constellations (Steinberg 92) and draw Brechtian attention to their own construction (Stam, Reflexivity 6). In discussing the history, characteristics and impacts of dialectical montage, uncanny continuity and collage compositing, and demonstrating how Soda_Jerk combine them in a novel manner, this chapter provides insight into the subversive politics of TERROR NULLIUS' form. Moreover, this chapter pushes sample filmmaking scholarship to look beyond montage and consider how sample films engage multiple editing traditions simultaneously.

\section{DIALECTICAL MONTAGE}

Montage editing, the "secret weapon" of sample filmmaking according to David Cox, originated in the Soviet Union in the early twentieth century (Cox). Film production was severely limited in the Soviet Union between 1917 and 1922 due to ongoing civil war blockades causing a shortage in raw film stock (Mast and Kawin 198). Unable to produce new footage, filmmakers began experimenting with pre-existing clips. Without the ability to control production elements such as cinematography, lighting and acting, Soviet filmmakers focused their creative energy on the one process they could: editing. An experiment conducted by Lev Kuleshov and his students at the Moscow film school found that placing discrete clips of two material objects in combination caused viewers to interpret logical, conceptual connections between them (Leyda, Kino 165). In the most renowned montage of the experiment, a close up of a man with a neutral expression combined with a shot of a bowl of soup was interpreted as hunger; however, if the soup shot was exchanged for a shot of a coffin, the man was understood to be expressing sorrow. The "Kuleshov effect," or "editors' effect" as feminist scholar Karen Pearlman reframes it, forms the basis of montage logic and is a prominent technique in sample filmmaking. ${ }^{8}$ Soda_Jerk employ the editor's effect to connect unrelated samples throughout TERROR NULLIUS and in many moments, replicate the eyeline match montage of the Kuleshov experiment. In Act Two, Soda_Jerk cut between a close-up shot of Sonny (from Skippy the Kangaroo) looking inquisitive, to an image of the Aboriginal flag emblazoned with "White Australia has Black History", back to an extreme

\footnotetext{
${ }^{8}$ In her film After the Facts, a poetic analysis of Esfir Shub, Karen Pearlman highlights the sexism behind the term "Kuleshov effect", arguing that "editor's effect" would be a more accurate term. Pearlman emphasises that many early Soviet editors were women and asks "why would you name something lots of women and editors were doing after one man who observed them doing it?" Women's early role in montage editing furthers claims made in Chapter One that women have utilised sampling to create films in an industry where gender discrimination is often a barrier to live production (Dall'Asta and Chiarini).
} 
close up of Sonny looking alarmed, therby manipulating the original Skippy the Kangaroo scene into a commentary on the erasure and recognition of colonial violence. Used in this way, the editor's effect allows Soda_Jerk to subvert samples into a détournement (Debord). Sample filmmakers continue the early Soviet ethos that film is a medium "not shot but built," using montage editing to produce meaning (Pudovkin xiv).

Eisenstein, the most influential montage practitioner and theorist, articulated montage as a filmic manifestation of dialectics (Aumont, Montage vi). Dialectics is a theory of rational logic developed by German philosopher G. W. F. Hegel that regards conflict between two concepts as productive, rather than problematic. Hegel describes the dialectic process having three states: the "moment of understanding," or the thesis, when a concept is stably defined, "negative rational," or antithesis, which contradicts and destabilises the thesis, and the "positive rational" when the thesis and antithesis synthesise to form a new concept (79). The synthesis is not so much a compromise as a new idea that comes from putting two oppositional positions to debate. An infinite process, the synthesis then becomes the new thesis, against which another antithesis arises. Marx applied this dialectic theory to class struggle, arguing "critical and revolutionary" progress (synthesis) could be achieved through "inevitable" proletariat (antithesis) revolution against the bourgeoise (thesis) (15).

Eisenstein's theory of dialectic montage is grounded in this Hegelian-Marxist view of conflict as positively productive $(46,81)$. By placing antithetical shots next to one another, montage filmmakers encourage the audience to synthesise new critical concepts.

Soda_Jerk employ Eisenstein's theories of montage to generate an "emotional dynamization" associated with a revolutionary sensibility (Eisenstein 57). Eisenstein theorised five categories of conflict-based dialectical montage; metric, rhythmic, tonal, overtonal and intellectual. The first four categories operate on a sensory, emotional level, creating conflict by pairing shots with different lighting, depths, angles, framing, length, mood, camera movement and direction and speed of action (Eisenstein 39, 54, 72-81). When soundfilm technology was developed in the late 1920s, Eisenstein argued that the dialectical effect created through visual clash could also be achieved with asynchronous sound (258). Sensory conflict is a strong feature of Eisenstein's films, particularly in moments of extreme violence. A riot scene in October cuts rapidly between a canon and horse and carriage being gunned down. The shallow depth of field, right-facing angles and dark colouring of the canon footage contrast with the deep framing, leftward motion and pale horse in the corresponding shots, evoking chaos and agitation. TERROR NULLIUS, likewise, is rich with sensory clash.

Sequences are fast-paced and packed with an excess of characters and noise: in the girl-gang 
attack on Max Rockatansky, Soda_Jerk make 70 cuts within 120 seconds, chopping between dynamic shots of women brandishing weapons to close-ups of the car's destruction, paired with a layered soundscape of screaming and crashing. Instead of portraying a scene from a single, static viewpoint, sensory montage uses a "collision of independent shots" to stimulate "a whole new system" of perception that provokes the viewer to see the world in dynamic ways (Eisenstein 49, 53).

TERROR NULLIUS also utilises Eisenstein's fifth category of montage, intellectual conflict, to political effect. Intellectual montage cuts between footage with antithetical connotations to push the viewer to independently deduce a logical synthesis (Eisenstein 62). Eisenstein cites a scene from October, in which images of deities from various religions are cut together, as an example: the thesis of the monotheistic Christian God, challenged by the antithesis of other religions' gods, pushes the viewer to rationalise a Marxian scepticism of religion (62). Chapter Five provides an in-depth break down of how Soda_Jerk bring texts with different conceptual associations, including John Howard's 2001 election campaign speech, Mad Max 2 and news footage from the Cronulla riots, together to produce a political commentary on white Australia's xenophobia. To make sense of TERROR NULLIUS, Soda_Jerk expect the viewer to recognise conceptual discord between a thesis and antithesissuch as the Mad Max 2 villain, Lord Humungus speaking in ex-Prime Minister John Howard's voice - and rationalise the connection between them. Eisenstein believed intellectual montage was a more powerful way of imparting political messages than directly stating them. According to Brecht's theory of verfremdungseffekt (distancing effect), art which prevents audiences from fully immersing in its diegesis fosters ongoing critical consciousness (Stam, Reflexivity 212-213; Begin 1120). By establishing the first two steps of the dialectic process (the thesis and antithesis) and leaving it up to the audience to interpret the synthesis, montage films like TERROR NULLIUS enable the audiences to "help themselves" to, rather than be spoon-fed political ideology (Eisenstein 84).

Third Cinema filmmakers further emphasise dialectical montage as a strategy of subversive, anti-establishment politics (Alea; Solanas and Getino 69; Armes 89). Third Cinema was a radical film movement, largely based in Latin American in the 1960s and 1970s, that challenged American media imperialism (Armes). Like their contemporary North American avant-garde found-footage filmmakers, Third Cinema filmmakers used montage techniques to respond to post-war media proliferation and U.S. cultural imperialism, but with an attitude of revolutionary activism rather than postmodern ambivalence. In their influential Third Cinema manifesto, Fernando Solanas and Octavio Getino advocate for a "militant 
cinema" that destroys "the imaginary bourgeoise universe" of Hollywood cinema (76, 68 ). Echoing Eisenstein's belief that film should "grip, not amuse" (84), Third Cinema filmmaker Thomas Alea accused Hollywood of producing "complacent, tranquil, empty, worn out, and inert" audiences. Following a Brechtian logic, Third Cinema filmmakers deliberately defied the rules of immersive continuity editing to promote critical consciousness. Film perception research supports this notion that "discontinuity" editing makes viewers "highly aware [that] the film that is being viewed [is] a technolog[ically] mediated and constructed object" (Swenberg and Erikson 223; Berliner and Cohen). For Solanas, Getino and Alea, dialectical montage editing, as opposed to classical continuity, was a direct way to challenge Hollywood hegemony and encourage critical media consumption.

Third cinema film The Hour of the Furnaces demonstrates how cutting between footage associated with different genres, as TERROR NULLIUS does frequently, produces multiple layers of dialectical montage. Solanas and Getino's The Hour of the Furnaces is an epic 4-hour long dialectical montage criticism of Argentinian neo-colonialism. Early in the film, a sequence cuts between footage of paintings and sketches of Imperial British merchants with clips of upper-class Argentinians playing golf. The frontal, static footage of the artworks generates a museum-like, atemporal, objective viewing experience. Meanwhile, the golfing shots evoke a feeling of guerrilla surveillance; the telephoto lens, handheld tracking and leaves encroaching into the foreground of the first shot indicate the camera is hidden and embodied, illustrating Third Cinema manifesto refrain, "the camera [is] our rifle" (72). At the level of subject matter, the montage cut inspires comparison between the nineteenth-century British empire and the contemporary Argentinian elite, implying the contemporary capitalist regime is simply a continuation of colonial exploitation and inequity. The montage cut also draws attention to the footages' contrasting genres and the interpretive modes associated with them. The thesis of archival, iconic representation cuts against the antithesis of live, indexical surveillance: history, distance, entrenched mythology cuts against the "recognisable... accountable," assailable human body (Stam, Two Avant-Gardes 274). Through this conflict emerges a politically charged synthesis: representation and reality are closely intertwined, and just as art has been used to prop up elite power, guerrilla art, like The Hour of the Furnaces, can also undermine it. TERROR NULLIUS likewise creates multilayered intellectual conflict by montaging material with different subject matter and genre. The aforementioned Sonny/Aboriginal flag montage juxtaposes both the subject matter of each clip - a young white boy and an anti-colonial flag - and their associated genres/forms a 1960s children's television show and a political protest artwork. In creating a dialectical 
montage from multiple forms of media, TERROR NULLIUS, like The Hour of the Furnaces, draw critical attention to forms of mediation and their associated politics.

Soda_Jerk openly draw on Eisenstein's theories and techniques of dialectical montage. In SinCity, a 2006 publication to accompany an exhibition by Sydney art collective d/Lux/MediaArts, Soda_Jerk's Dan Angeloro defines remix culture in terms of its roots and different branches. The first section of Angeloro's article foregrounds the importance of Eisenstein:

Eisenstein once said, "art begins the moment the creaking of a boot on the soundtrack occurs against a different visual shot and thus gives rise to corresponding associations." Hollywood would have replied that the sound of a boot should be paired with an image of a boot, at which point online remix culture would have interrupted "stuff that, let's sample the 'boot sound' from the Hollywood flick and reuse it in as many twisted ways as we can.” Perhaps this was not exactly what the Russians had in mind when they insisted on the independence of montage pieces, but it just might turn out to be something even more promising. (20)

Angeloro not only positions Eisenstein as the forefather of remix filmmaking but frames remix practice as the result of dialectic process. Here, Russian montage's belief in asynchronisation is the thesis, Hollywood's use of naturalistic synchronisation is the antithesis, and remix culture's 'poly-synchronisation' of Hollywood footage is the synthesis. Dialectical sensory and intellectual montage (subject and form) are dominant organising principles of TERROR NULLIUS and key to its consciousness-raising, activist intentions. Like Eisenstein, Soda_Jerk decouple images from their audio and deconstruct unified sequences. However, Angeloro's statement also implies remix as a 'run-away' use of montage that does not quite fit within Eisenstein's original definitions.

\section{UNCANNY CONTINUITY}

While TERROR NULLIUS is inspired by dialectical montage principles, in many ways its editing strives for continuity. Unlike The Hour of the Furnaces and many of the 1960s avantgarde found-footage films that montage footage without creating spatio-temporal consistency, Soda_Jerk use aspects of continuity editing to bring disparate clips into a shared diegesis. TERROR NULLIUS employs classical continuity editing techniques such as establishing shots, eyeline matches, cutting on action and diegetically motivated sound to create a "continuous sensation of time and space," transforming samples with different settings into a "spatial whole" (Berliner and Cohen 45, 49). The two-minute hitchhiking 
sequence in Act One demonstrates such continuity techniques. The sequence begins with an establishing tracking shot from The Adventures of Priscilla, Queen of the Desert that provides a wide view of the desert landscape from the back of a fast-moving vehicle. The establishing shot cuts to a mid-shot from Road Games inside a truck cab with the driver Quid looking in the rear-view mirror, fabricating an eyeline match between the two films. After a shot-reverse-shot conversation between Quid and Frita from the original Road Games, Quid gets out of the truck and looks off-screen using binoculars. The sequence cuts to a wide-shot of a van crash from "Opalville" (an episode of Wolf Creek), with a binocular shapped mask added to the edges of the frame to emphasise the eyeline match (fig. 6). The P.O.V. shot cuts back to Quid with the binoculars; in the back of the frame, Frita begins to run into the empty desert. Cutting to Frita's P.O.V., a downward tracking shot skims over desert earth until suddenly, impossibly, it comes to a coastal cliff. Though the scene migrates from the outback to coast in seconds, there is no clear time-jump or break in narrative flow. In a match-onaction, the P.O.V. cuts to a birds-eye-view of Frita teetering at the edge of the cliff, then to an extreme wide shot of Frita as a tiny figure atop a giant ocean bluff. The sound of waves crashing, seagulls screeching and the opening notes of "The Heart Asks Pleasure First" from The Piano (1993) begin to play. The extreme long shot of the bluff functions as the establishing shot for the following beach-based sequence. With the music acting as a bridge, the bluff shot cuts to shots of Ada playing her piano on the sand and a new sequence begins. Throughout the hitchhiking sequence, Soda_Jerk sample four films/television shows and transition geographic settings without breaking continuity. In fact, the only time TERROR NULLIUS has a clean break between scenes, with no continuity transitions between settings, is at the start of each of the three acts. Soda_Jerk skillfully fabricate a false sense of narrative cohesion by utilising classical Hollywood editing techniques to blend samples and guide the viewer through a continuous diegesis. 


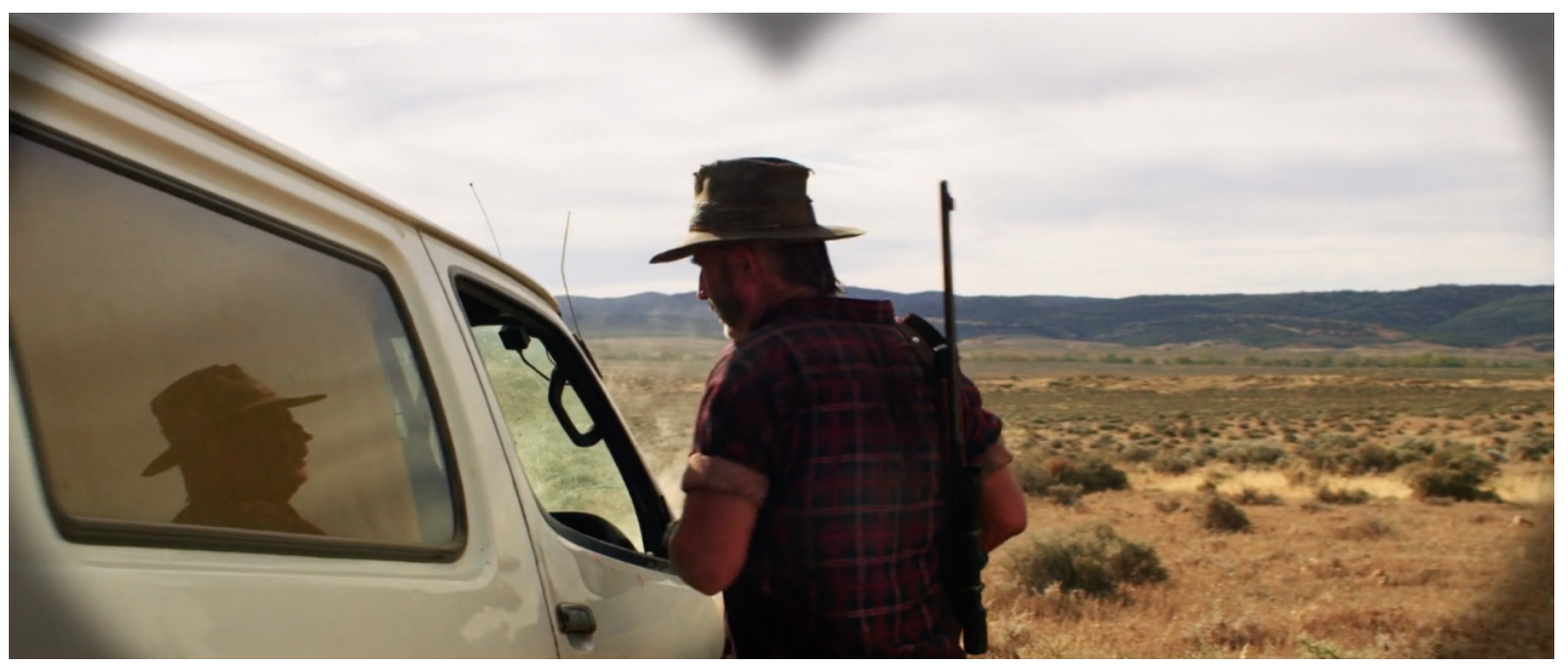

Fig. 6 A binocular mask emphasises the eyeline match between clips from Road Games and “Opalville”, TERROR NULLIUS, Soda_Jerk, 2018.

However, by nature of sampling from so many stylistically and narratively disconnected sources, TERROR NULLIUS never achieves the "unobtrusive... seamless" effects associated with total classical continuity (Bordwell et al. 23) - nor does it aspire to. TERROR NULLIUS' success lies Soda_Jerk's ability to balance a fine line between the consistent spatio-temporal diegesis and cause-and-effect motivation of continuity editing, and the conflict, fragmentation and distancing effect of dialectical montage. Drawing on both editing traditions, TERROR NULLIUS' achieves an uncanny continuity. Sigmund Freud's psychoanalytic theory of the uncanny has been influential in film studies, applied across scholarship on horror, world cinema, animation and postcolonial cinema, among others (Gunning; Ginsberg; Hubner; Tinwell; Kavka; Rudd; Avery; Masschelein). The uncanny is a discomfort or disturbance caused by "something repressed which recurs" (Freud 241, emphasis in original). Roboticist Masahiro Mori's theory of the "uncanny valley" argues that people have an "affinity" for both strangeness or sameness, but objects or representations of near likeness (such as humanoid robots) produce an unpleasant "eerie sensation" (3). Tom Gunning claims early cinema initially had an uncanny effect, reviving familiar images in unexpected ways, but the effect gradually reduced as filmic representations became normalised ('Re-Newing' 47). Due to its similarity with real-life vision (Berliner and Cohen 44), and mainstream dominance (Keil and Whissel 2), continuity editing's spatio-temporal logics have also become normalised. Following Mori's thesis, montage editing that presents perspectives so overtly unfamiliar to normal vision (jumping through time and space) does not disconcert viewers, but films which slightly breach continuity (through techniques like 
jump-cuts, mismatched action cuts and lighting inconsistency) provoke uncanny unease. The slight logical dissonances in TERROR NULLIUS' visual or narrative flow, such as Frita running from dessert to coast in seconds or the change in image quality from 1981 footage (Road Games) to 2016 footage (Wolf Creek) produce "feelings of uncertainty" and a "critical disturbance of what is proper" associated with the uncanny (Royle 1). The uncanny aspects of TERROR NULLIUS' editing are exacerbated by the uncanniness of sampling itself, which revives familiar characters and texts in unfamiliar ways. Linking back to the notions of archival trauma discussed near the end of the previous chapter, TERROR NULLIUS can be conceived as a "return of . . repressed" characters and tropes from the pop culture of Australia's past (Freud 154). By applying classical continuity techniques to samples, Soda_Jerk produce an uncanny continuity and demonstrate that sample film editing is not limited to montage.

Blending montage and continuity techniques to evoke an unsettling, uncanny sensibility is particularly apparent in Surrealist cinema. Surrealist filmmakers like Luis Buñuel were inspired by the revolutionary zeal of Soviet montage techniques, but where Soviet filmmakers were focused on promoting a specific Marxist viewpoint, Surrealism was more concerned with the subconscious and undermining traditional bourgeois realism (Buñuel 88). Commentators have often articulated Surrealism works as uncanny; reviving subconscious repressions and eliciting feelings of unease or scepticism toward reality (Jay 20; Foster, Compulsive Beauty; Saler 186). Renowned as one of the pioneering works of Surrealist cinema (Edwards 59), Buñuel's An Andalusian Dog (1929) has many uncanny moments of partial continuity. A shot of a man falling inside his urban apartment ends with a shot of him landing in a rural meadow; the match-on-action maintains continuous motion but disrupts spatial continuity. Similarly, in Maya Deren's famous Surrealist film, Meshes of the Afternoon (1943), a series of profile shots of feet walking are cut so that each new step lands in a new terrain (sand, dirt, grass, pavement, carpet), maintaining seamless motion continuity, through a dialectical montage of settings. These slight dissonances in An Andalusian Dog's and Meshes of the Afternoon's continuities destabilise their representations of reality. Though not always necessarily leftist in its politics, Surrealism's political project was to unhinge set notions of reality and make room for new ways of thinking (Edwards 19; Flitterman-Lewis 141). Likewise, Soda_Jerk believe that "counter-mythologies" which challenge the representational status quo have "tactical power" for provoking cultural and political change (qtd. in Sharp and Juers). Uncanny continuity employs aspects of continuity editing to establish the illusion of realism, then disrupts that realism in absurd, illogical and unsettling 
ways to challenge the status of the image, destabilise signification and break down the distinction between imagination and reality. TERROR NULLIUS' uncanny continuity makes it simultaneously immersive and unsettling; the viewer is both engaged in the narrative flow of the film and is continually reminded of its artificial, constructed nature. The hitchhiking scenes asks the viewer to be absorbed inside the drama of Quid seeing the killer and Frita running away and remain outside the text, reflecting on the trope of the outback as a site of gothic horror. Like Surrealist cinema, TERROR NULLIUS' uncanny representations push the viewer to see the world in new ways.

\section{COLLAGE COMPOSITING}

TERROR NULLIUS' editing stands out from most prior sample films because, in addition to cutting samples adjacent to one another using dialectical montage or uncanny continuity, Soda_Jerk also cut and paste elements of samples into a single frame. Using digital compositing technology, Soda_Jerk isolate a character, remove the background image, layer that character onto another sample then use feathering, rescaling and level adjustments to blend the layers together. Compositing editors who work with raw footage, often shot on green-screens, tend to use software to automatically isolate subjects and track their movements across the frame. However, Soda_Jerk have found the "software just isn't up to" isolating characters from files that are already compressed and rendered so they manually edit frame-by-frame (McCarthy). This process is labour intensive; a couple of seconds of footage can take a week to create (Bull-Clark; McCarthy). Soda_Jerk are not the only sample artists who use compositing (Craig Baldwin, People Like Us and Bryan Boyde are examples of others that do) but the intensity of TERROR NULLIUS' compositing, in regard to its length, layers and near-invisibility, make Soda_Jerk leaders in remix compositing. Combining theories of digital compositing by Lev Manovich and Robert Burgoyne with visual collage theory clarifies how TERROR NULLIUS uses compositing to create meaning in a manner unique from the strategies of montage or continuity editing.

TERROR NULLIUS represents new developments in the long history of film compositing. In contradiction to Jay Leyda's 1964 assertion that "you cannot rearrange the elements within a piece of newsreel," filmmakers have always striven to push beyond the boundaries of pro-filmic reality and composite multiple images within a frame (22). Manovich's influential 2001 book on "new media" provides a detailed chronology of film compositing technologies (145-155). Life of an American Fireman's superimposed dream sequence shows that from as early as 1903, editors were cutting, pasting and layering nitrate 
film frames on top of one another to express a surreal vision (Manovich, New Media 148; North 41). The invention of rear projection in the 1930s enabled filmmakers to project prerecorded footage onto the background of live-action, thereby creating composite images on set (Manovich, New Media 147). These types of manual composition were used by both mainstream Hollywood and avant-grade filmmakers. Rear projection driving shots and splitscreen phone conversations were absorbed into the Hollywood narrative continuity system (Rogers 73-76). Meanwhile, Surrealist film used superimposition to disrupt laws of physical reality. In Germaine Dulac's The Seashell and the Clergyman (La Coquille et le Clergyman, 1928), live flames burst impossibly into life on a stone floor. Though film compositing has always been possible, physically manipulating each frame by hand was highly labour intensive, so was used sparingly as a novelty rather than a stock technique. When electronic video technology emerged in the 1970s, keying enabled editors to automatically replace block colours with other footage. Blue/Green screen became, and remains, a central part of mainstream action, sci-fi and fantasy filmmaking (Gupta and Samantaray 178). Video and electronic mixing offered other compositing techniques like cross dissolves and layering as demonstrated in Histoire(s) du Cinéma (Manovich, New Media 151). In the 1980s special effects editors at studios like Lucasfilm developed digital bit masking and alpha channel technologies that allowed them to alter the transparency of frames and layer them into composite images with precision (Alvy Smith 8; Turnock 128). Over the last three decades, digital compositing tools have become increasingly sophisticated and a core part of mainstream cinema production. Affordable, user-friendly software like Adobe Photoshop and After Effects have made digital compositing increasingly accessible to avant-garde, amateur and low-budget filmmakers (Tofts and McCrea 1). Essays by Lev Manovich, Steven Shaviro, Bruce Isaacs and Steen Christiansen in a recent 2016 book on post-cinema highlight the prevalence of digital compositing, and how it has impacted the nature of cinema. "Freed from the burden of an indexical mapping" of the world, film has now achieved "plasticity that was previously only possible in painting or animation" (Isaacs 468; Manovich, Post Cinema 27). TERROR NULLIUS is a testament to this plasticity, producing tableaux that defy historical reality and fictional canon.

In Manovich's view, digital compositing has come to replace montage with an entirely new cinematic logic (New Media 143). By blending different sources into "a single gestalt," compositing erases rather than foregrounds boundaries and overwrites dialectical distinctions between antithesis and thesis $(144,155)$. Compositing further problematises cinema's claim to indexical authenticity; where montage enabled the filmmaker to construct 
fake temporality, compositing allows them to simulate spatial relations (Manovich New Media 154; Burgoyne 220). Robert Burgoyne expresses concern over the use of digital compositing in archival sampling, showing that compositing archival footage can "rewrite" history in a way montage or continuity editing cannot and that such historical revisions can have political consequences (229). Forrest Gump (1994) composits Tom Hanks into archival footage of the Alabama University integration in 1963 and manipulates footage to show him shaking hands with J.F.K. and Ricard Nixon in a way that celebrates nationalism and "ameliorates" the history of racism (229). Burgoyne notes that this conservative historical revisionism made Forrest Gump a "rallying cry" for conservative political campaigns in the mid-1990s (231). For film critic David Cox, compositing had a confusing, conflating effect on TERROR NULLIUS' historical commentary. In Cox's view, the film's non-composited montage cuts allow the archival media to retain the status of evidence, but the composited shots create "digital puppets cut loose from the strings of time." Cox's argument that a sequence of composited images has a different relationship to history than a sequence of montage cuts is valuable but underdeveloped. In compositing samples, Soda_Jerk's intention is not to tell an "as it really was" history (as Benjamin puts it, 257) but to liberate characters from the limits of their source material to create a "revisionist history" and propose a "counter-mythology" for the future (qtd. in Sharp and Juears). Moreover, the assumption that compositing erases samples' histories does not take into account the way TERROR NULLIUS' compositing is foregrounded rather than undetectable. Instead of compositing having the opposite effect of montage, Soda_Jerk use both to draw attention to TERROR NULLIUS' construction.

While the majority of cinematic compositing aspires to naturalistic realism in which edits are invisible, TERROR NULLIUS foregrounds the boundaries between samples and encourages dialectical comparison. Soda_Jerk are highly skilled at digital compositing - all TERROR NULLIUS' layers are meticulously cut out, re-sized and their lighting and colour adjusted - but the samples' incongruous subject matter always reveals the artifice. A composite shot in Act Two (used as the promotional screencap) features a woman in the foreground and a biker gang behind her (fig. 7). The formal elements of the two samples are seamlessly integrated. The lighting in both shots is bright sunlight and comes from the top left corner. There is no noticeable difference between saturation and contrast levels. As a gust of wind blows through the woman's hair, the flags in the background flutter simultaneously. However, even viewers who do not recognise the populist politician, Pauline Hanson or the scene from Mad Max 2 (1981) notice the mismatch between the middle-aged woman in 
modern office dress and the leather-clad biker-punks. This in-frame uncanny continuity reveals the scene's fabrication and directs the viewers' attention to the conceptual connection between the two samples. TERROR NULLIUS composits footage from different diegesis and historical contexts, not to blend them into one but to draw attention to shared tropes and political links.

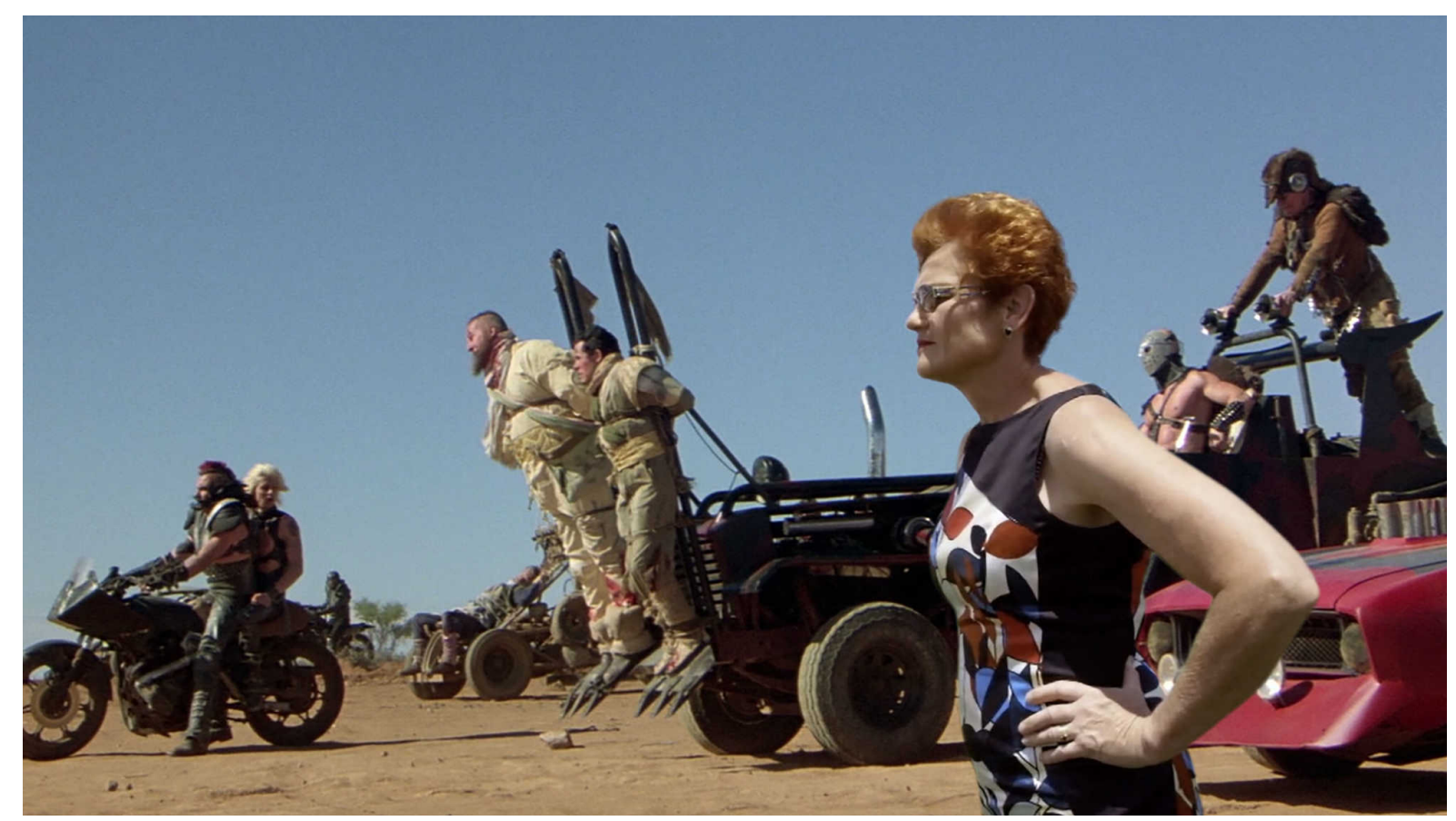

Fig. 7: Pauline Hanson is composited onto a scene from Mad Max 2, from TERROR NULLIUS, Soda_Jerk, 2018.

Reviewers often describe TERROR NULLIUS as a collage but do not expand on what that means (T. Wong; McCarthy; Cox; Juers; Di Rosso; Bull-Clark; Cox; Harris; MacInnes). Collage is a static visual arts term and is not clearly defined within film studies. William Wees uses collage to describe a particular subset of montage sample films that "actively promote... analytical and critical attitudes[s]" toward media culture (47). Alternatively, Charles Warner, in his analysis of Histoire(s) du Cinéma, describes montage as the filmic equivalent of static collage (5) as does Yuval Etgar in The Ends of Collage (4). There are valid conceptual connections between montage and collage. Eisenstein himself advocated for montage to be perceived as a "superimposition of layered shots" projected on top of one another rather than a linear line of adjacent frames (49). However, where montage only achieves a collage-like effect over time, composited frames are collages in their own right. 
Applying analysis of Cubist and Surrealist static collage to cinematic compositing further elucidates how TERROR NULLIUS' editing creates meaning. Collage techniques originated with Synthetic Cubism in the first decade of the twentieth century (Greenberg 80). Pablo Picasso's and George Braque's papiers collés combined paper and newspaper clippings with paint, defying the "illusionism of traditional realism" and creating an "interplay between artistic expression and the experience of the everyday world" (Ulmer 84; Wolfram17). Like film, collage upset the distinction between reality and representation. In the 1920s and 1930s, Surrealist/Dada artists, Hannah Hoch and Max Ernst in particular, pushed collage to new extremes. Where Synthetic Cubism was more focused on appropriating raw materials, Surrealist and Dada collages turned their attention to representation (Adamowicz 87). In Ernst's collage-book made from nineteenth-century illustrations, The Hundred Headless Woman (La Femme 100 Têtes 1929), drawings of classical nude women haunt woodcut scenes of daily nineteenth-century life. Hoch's photomontages collage photographic images into hybrid bodies; Flight (Flucht 1931) features a man's face on a dove's body and a face that is half chimp, half woman. By applying the “alienating" effect of collage to representations of the human body, Ernst and Hoch's works call into question viewer's assumptions about their bodily boundaries. Responding to a collection of Surrealist collage manifestos, Ali Smith explains collage in terms of edges: “edges," Smith writes, "are very much about identity...the brink...between one thing and another" (233). Collage draws the viewer's attention to edges, where identities are forced into “dialogue" (233). Using Smith's description, we can define a collage approach to compositing as one that stylistically emphasises the boundaries between layers, inspiring a Brechtian awareness of construction and destabilising human boundaries and spatio-temporal certainty.

Collage compositions which emphasise edges, whether through visible boundaries (as in Historie(s) du Cinema) or inconsistencies in subject matter (as in TERROR NULLIUS) foreground dialectical relationships between layers within the frame. The aesthetic contrast between Pauline Hanson and the gang of violent, oppressive post-apocalyptic bad guys raises the question of why they are on the same side in the narrative conflict: what thematic, conceptual or political threads bind them together? Unlike a film that has cohesive digital compositing, noticing TERROR NULLIUS' edges and layers is an important, pleasurable part of the viewing experience. By foregrounding its multi-layered compositing, TERROR NULLIUS avoids overwriting and obscuring history in the manner of Forrest Gump and operates more like Obsessive Becoming (1995), Burgoyne's example of historically 
constructive archival compositing (231). Obsessive Becoming (1995) uses digital composition to create a "productive" memory-like temporality that presents close, embodied links with the past (231). By emphasising edges, TERROR NULLIUS focuses on connections and continuities across history, challenging perceptions of historical progress and distance and emphasises the importance of the past to the present. Compositing archival samples into a collage counters principles of historical "unity, linearity and closure" and presents history as active dialogues between different identities from different times and contexts. Rather than conflating history (as Cox suggests in his review) or claiming to represent an empirical “eternal image" of history, TERROR NULLIUS" collage compositing creates Benjaminian historical constellations that offer a "unique experience with the past" (264).

TERROR NULLIUS' highly sophisticated editing combines dialectical montage, uncanny continuity and collage compositing. Eisenstein's principles of clash and consciousness-raising are at the heart of Soda_Jerk's filmmaking. Many shot combinations throughout the film create a conflict in subject matter or genre, pushing audiences to synthesise meaning using dialectical logic. In addition to montage, TERROR NULLIUS also relies heavily on continuity editing techniques to link samples into coherent sequences. As TERROR NULLIUS' samples are visually and thematically distinct, this continuity always has slight discrepancies, generating a sense of uncanniness that keeps the audience on edge. Edges, where two samples meet in a dialectical dialogue, are an essential part of TERROR NULLIUS' compositing style. Just as the differences between samples make TERROR NULLIUS' continuity editing uncanny, inconsistencies in subject matter between its composited layers create collages that foreground their own construction. In combination, Soda_Jerk's use of dialectical montage, uncanny continuity and collage compositing add to TERROR NULLIUS' subversive politics by fostering a critical spectatorship and encouraging viewers to consider the past and present as a realm of uncertain possibility. The following two chapters expand on how this subversive editing informs TERROR NULLIUS' politics of identity and explicit politics; Chapter Four shows how TERROR NULLIUS' editing strategies bring disconnected characters together in a show of political solidarity; Chapter Five's close reading of TERROR NULLIUS' refugee storyline demonstrates how Soda_Jerk's editing draws critical historical connections. Furthermore, in considering TERROR NULLIUS through the lens of three distinct traditions or techniques - montage, continuity and compositing - this chapter has demonstrated the value in pushing analysis of sample filmmaking editing beyond montage alone. 


\section{CHAPTER FOUR \\ CYBORG CINEMA: A HARAWAYAN READING OF TERROR NULLIUS}

Thus far, this thesis has contextualised TERROR NULLIUS within the history of sample filmmaking - its various aesthetic forms, historical discourses and editing strategies. The previous three chapters emphasise TERROR NULLIUS as, in many respects, a continuation of techniques and political sensibilities associated with sample filmmaking. They also show how TERROR NULLIUS' manipulation of problematic texts, blending of fictional and non-fiction samples, constellation approach to history and hybrid editing techniques produce a subversive political sensibility that challenges dominant frameworks of representation and fosters critical consciousness. This chapter expands on these ideas, arguing that TERROR NULLIUS' promotes particular political values and forms of collective action relevant to contemporary identity politics. This chapter thus demonstrates TERROR NULLIUS' unique use of pre-existing techniques to emphasise Soda_Jerk's original contribution to sample filmmaking.

Haraway’s influential cyberfeminist essay, “A Cyborg Manifesto: Science, Technology and Socialist-Feminism in the Late Twentieth Century" (1984) is a useful text for interpreting TERROR NULLIUS” identity politics. Like TERROR NULLIUS, “A Cyborg Manifesto" is also a political revenge fantasy, or, in Haraway's words, an "ironic political myth faithful to feminism, socialism and materialism" (5). TERROR NULLIUS demonstrates three key principles of Haraway's cyborg theory; this theory in turn clarifies TERROR NULLIUS' philosophy of identity politics. Firstly, cyborg theory proposes deviant appropriation of technology as a solution to cultural problems associated with advanced capitalism. In contrast to some ecofeminist stances, Haraway argues that feminism should embrace the rogue possibilities of technology rather than fear and reject it (10). TERROR NULLIUS has an analogous approach to media, in that it repurposes problematic media in subversive ways, rather than rejecting it entirely. Secondly, Haraway promotes political connection according to shared affinity for a cause rather than a common essential, biological or cultural characteristic (16). Similarly, Soda_Jerk's sampling unites a diverse range of characters to model an intersectional politics that prioritises solidarity and 'accompliceship' among marginalised groups. Thirdly, "A Cyborg Manifesto" presents irony and multiplicity as radical oppositions to Western positivist and dualistic logic (5). Embodying cyborg epistemology, TERROR NULLIUS creates ironic tensions that discourage a single or closed reading and pose multiplicity and fluidity as legitimate ways of understanding history, 
politics and identity. In reading "A Cyborg Manifesto" in concert with TERROR NULLIUS, this chapter demonstrates the continuing relevance of Haraway's theory and clarifies TERROR NULLIUS' progressive, intersectional and conceptually radical identity politics.

Zoë Sofoulis describes "A Cyborg Manifesto" as a "seismic" text that "shifted the terrain of debate about culture and identity" (281). While Sofoulis' claim is somewhat hyperbolic, Haraway's theory has influenced a range of disciplines, including film and media studies, disability studies, cyberfeminism and queer theory (Kroker 5; Plant 59; Reeve 91; Bryson 283; Hayles 84; Halberstam and Livingston 2). Haraway's cross-disciplinary success is partly due to the flexibility of her cyborg theory. Sheryl N. Hamilton outlines three ways scholars employ Haraway's cyborg: as a metaphor for a radical epistemological framework; to describe literal embodied social relations between human and machine; or to analyse popculture representation of technology (111-115). Film studies has largely favoured the latter, using Haraway to analyse primarily science-fiction narratives (Hamilton 109, 113). Thus multiple engagements with "A Cyborg Manifesto" appear in Sherryl Vint's and Sean Redmond's edited collections on sci-fi cinema and cultural theory, and "A Cyborg Manifesto" is also cited frequently in analyses of sci-fi films like Blade Runner (1982), Avatar (2009) and Ex-Machina (2014) (Smelik; Brown; Fernandez; Pearson; Jones). However, I argue that Haraway's rich conceptual framework has relevance to film studies far beyond the thematic or narrative analysis of literal robotic or cybernetic characters. " $\mathrm{A}$ Cyborg Manifesto"'s epistemological arguments (that plurality and partiality are radical alternatives to the binary, totalising logics that ground Western imperialism) are useful for analysing subversive narratives of all kinds and for interrogating film at a formal level. Hamilton argues that cyborg theory is most insightful when its metaphoric, literal and representational frameworks are combined (110). I propose that Hamilton's three-fold approach can be achieved in a film studies context by linking: an abstract cyborg reading of a film's formal strategies (metaphoric analysis); a study of the technology involved in the film's production (literal analysis); and a discussion of how the film's narrative engages with themes of identity, cybernetics and the future (representational analysis). This chapter uses TERROR NULLIUS to test this multi-faceted cyborg analysis.

Cyberfeminist theory is an important influence on Soda_Jerk's practice. Soda_Jerk do not explicitly describe TERROR NULLIUS as a cyberfeminist text, but their other works, past and upcoming, are inspired by cyberfeminist theory. Soda_Jerk's 2014 video work Undaddy Mainframe combines footage from 1990s computer manuals with an automated reading of VNS Matrix's “A Cyberfeminist Manifesto for the $21^{\text {st }}$ Century." VNS Matrix was an 
Australian feminist art collective operating in the early 1990s, whose mission was to "hijack the toys from techno-cowboys and remap cyberculture with a feminist bent" (vnsmatrix.net). Partially inspired by Haraway, the collective launched their own manifesto and plastered it on a giant billboard and posters around Sydney. Soda_Jerk cite this underground punk, queer resistance scene in 1990s Sydney as one of their inciting creative influence (Capaldi; BullClark; J. Scott). Undaddy Mainframe pays homage to VNS Matrix, thereby aligning Soda_Jerk's sampling practice with the collective's cyberfeminist reclamation of digital culture. ${ }^{9}$ Soda_Jerk's current work-in-progress, Hello Dankness, also applies cyberfeminist ideas to current concerns around internet freedom, surveillance and abuse (Maunder). ${ }^{10}$ Soda_Jerk's recurring engagement with cyberfeminist theory and practice underscores the value of reading TERROR NULLIUS through a Harawayan lens.

\section{OVERCOMING PROBLEMATIC ORIGINS}

As Chapter One and Two show, the original context of the sample is a major component of how sample films create meaning. Origins are also crucial to Haraway's politics. "Cyborgs," Haraway writes, "are the illegitimate offspring of militarism and patriarchal capitalism, not to mention state socialism" (9). Since the 1940s, cybernetic theorists like Norbert Weiner have struggled with the tension between machine technology's potential to aid, liberate and connect people, and the realities of military-industrial research funding driving it towards violence, exploitation and surveillance (Hayles 86). Developments in electronic and digital technologies have in part been motivated by WWII, the cold war arms race and advanced global capitalism (Haraway 9). It is understandable, therefore, that radical ecofeminists, such as Susan Griffin, Audre Lorde and Adrienne Rich, have been broadly critical of modern technologies as tools of oppression and advocate a return to the organic (53). Lorde encapsulates this view in her often-cited adage "the master's tools will never dismantle the master's house" (also the title of an essay Lorde published the same year as "A Cyborg Manifesto"). In contrast, Haraway argues that rejecting problematic technologies prevents the discovery of "emerging pleasures" and ways to "chang[e] the rules of the game" (51). Cyborgs have the potential to be "exceedingly unfaithful to their [oppressive] origins" and find political agency in "seizing the tools to mark the world that marked them as other" $(10$,

\footnotetext{
${ }^{9}$ Undaddy Mainframe was Soda_Jerk's contribution to the Forever Now project (2015). Based on Carl Sagan's 1997 Voyager Golden Record, Forever Now brings together Australian audio and video projects that "speak from this current historical moment" (Northover; Frost; soda_jerk.com.au).

${ }^{10}$ Hello Dankness is scheduled to premiere at the Adelaide Film Festival in October 2020.
} 
55). "A Cyborg Manifesto" also criticises Western ideologies that construct women and indigenous people in terms of "original innocence", ruined by "the fall" into literacy (55-57). By reinforcing dualisms of nature and culture, woman and man, civilised and uncivilised, such ideologies relegate technology to the realm of white men and discourage 'others' from exploring its possibilities. Haraway celebrates Cherrie Moraga's story of Malinche, the 'mother' of the Mestizos (people of mixed European and indigenous American descent), who "mastered. . . both conquerers languages," creating a "spliced chimaera of English and Spanish" as a tool of survival. Malinche exemplifies the cyborg ethos of repurposing problematic tools, technology and forms of communication to activist ends.

Soda_Jerk's sampling reflects “A Cyborg Manifesto"”s ethos of drawing on all possible resources, including those previously used in counter-productive ways. Like cybernetic technology, cinema's capacity for progressive change is sometimes by the hegemonic tendencies of mass-media systems. Mainstream cinema is, first and foremost, a commercial entertainment industry designed to make products for profit (A. Scott 5; Miller et al. 5). Resultingly, these products tend to perpetuate rather than confront dominant cultural ideologies, often at the expense of truth or justice (C. Wilson et. Al 78; Benshoff et al. 11). Within the context of national cinema, films aiming for wide domestic appeal are likely to reinforce dominant mythologies about a nation's "goals, heritage and history" (Hjort and Mackenzie 4). For instance, film scholars have criticised a number of mainstream Australian films for representing problematic mythologies: Crocodile Dundee (1986) as sexist, racist and transphobic (Lucas 142; Buckmaster); A Man from Snowy River (1982) as promoting a patriarchal hierarchy and a conservative, heteronormative form of masculinity that ignores indigenous claims to land (Lucus 141-142; Golding 120; White 141); and Mad Max 2 (1981) as Islamaphobic, anti-queer and xenophobic (Winn 4; P. Williams 309; Lewis 23). Soda_Jerk embrace, rather than reject, such films, but find ways to rework them to produce progressive politics. Like Haraway, they extract "pleasures" from offensive or problematic films, "changing the rules of the game" without changing the players (51). Soda_Jerk are also careful not to wholly damn cinema in a manner that recalls Haraway's argument against characterising European literacy as "the fall" of women and indigenous people. Citing films like Lucky Miles and Wake in Fright, Soda_Jerk interpret Australian cinema as a powerful tool for "muckraking national mythologies" and consider themselves working alongside, rather than against, many of the texts they sample (Bull-Clark). TERROR NULLIUS demonstrates a cyborg approach to film production, achieving its progressive politics through 
appropriating and transforming oppressive representations and collaborating with texts which already share its politics.

TERROR NULLIUS' feminist, postcolonial media subversions exemplify a Harawayan, transformative approach to problematic origins. As explained in Chapter One, TERROR NULLIUS frequently appropriates mainstream cultural media to produce alternative messages, an effect known as détournement (Debord). Instead of creating original material, moments of détournement (like cyborgs) create political impact by being "unfaithful to their origins" (Haraway 10). Chapter Two outlines how postcolonial archive sampling draws attention to myths and erasures in archival texts. Following in this vein, TERROR NULLIUS samples a number of mainstream Australian texts that feature problematic representations of gender and race, including Crocodile Dundee, A Man from Snowy River and Mad Max 2, and subverts their original meanings. For example, the Crocodile Dundee clip Soda_Jerk sample in Act Two showcases hero Mick Dundee's dismissive view of women: “you wouldn't last five minutes out here, this is man's country," Mick says to Sue. Soda_Jerk emphasise Mick's misogyny by editing the scene so that it appears as if he is flicking through a Penthouse pornography magazine. Soda_Jerk then subvert Crocodile Dundee's original narrative by manipulating footage to depict Sue shooting Mick and a crocodile finishing him off. The sequence then uses dialectical editing to challenge Crocodile Dundee's perpetuation of indigenous absence and the myth of the outback as terra nullius. Soda_Jerk play Sue's line of dialogue, "despite the rugged beauty of this land, there's a sort of strange emptiness about it, the feeling of being so alone," over a clip of Aboriginal characters jumping out of the longgrass from the film Spear (2015), thereby contradicting Sue's claim of emptiness (fig. 8 and 9). Soda_Jerk's intervention here is not subtle; that is, viewers do not need to be familiar with Crocodile Dundee or Spear to notice the antithetical combination of indigenous erasure and presence, then infer (or to use dialectical language; synthesise) the scene's postcolonial criticism. Soda_Jerk untether representations of women and animals from their original films and undermine dominant colonial mythologies in the same manner in which Harawayan theory liberates technology from its imperialist sources. 

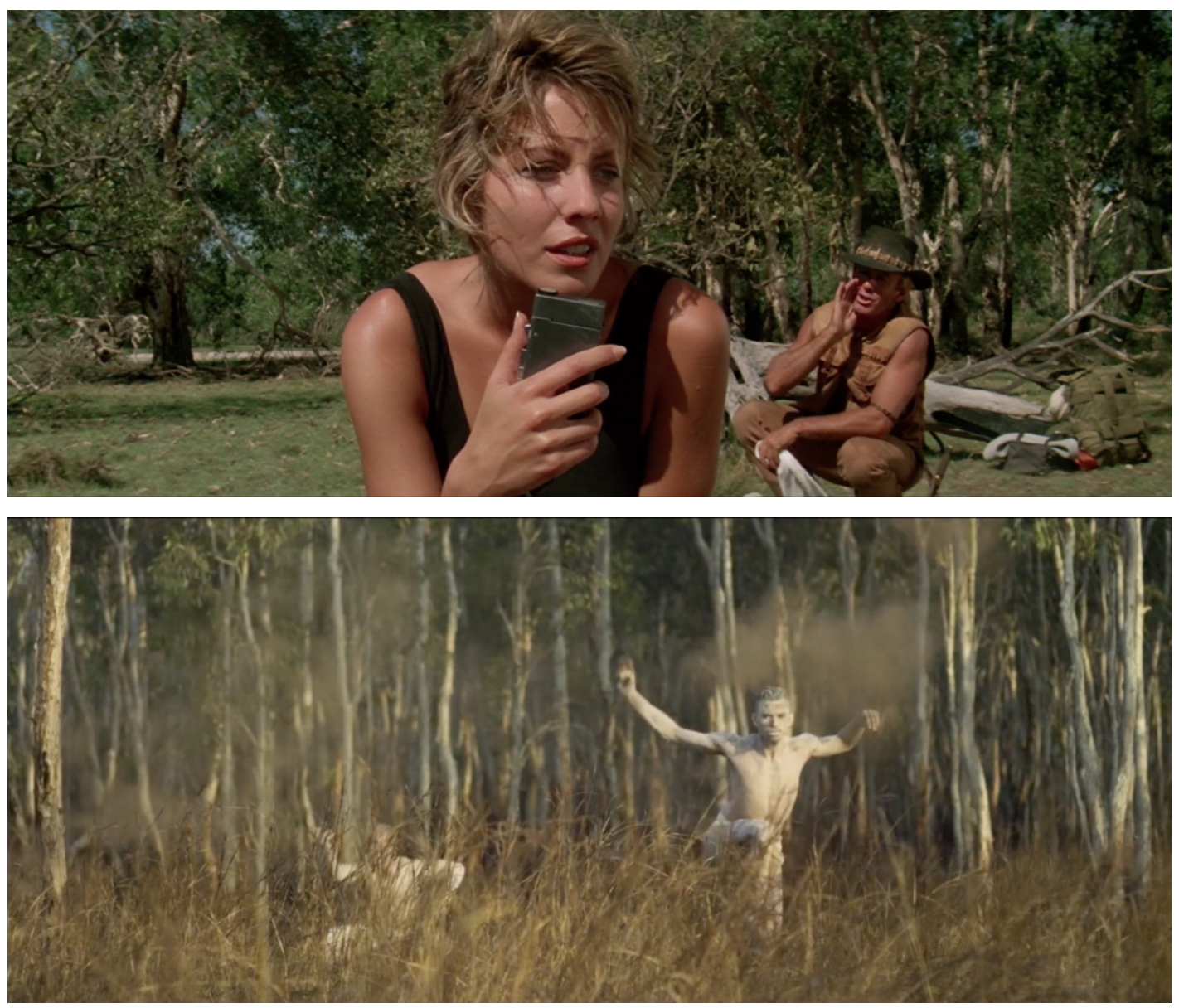

Fig. 8 and fig. 9: A dialectical combination of footage from Crocodile Dundee and Spear, from TERROR NULLIUS, Soda_Jerk, 2018.

In addition to rectifying problematic representations, TERROR NULLIUS also creates détournements by interrupting the commercial frameworks of mainstream cinema. Debord and Wolman frame détournement in anti-capitalist terms, describing it as the dissolution of property and a "powerful cultural weapon in the service of a real class struggle." TERROR NULLIUS exemplifies this anti-capitalist function of détournement. As discussed in Chapter One, Soda_Jerk do not licence or seek copyright holders' permission to use the media they sample. TERROR NULLIUS is intentionally designed to test fair use laws (Sharp and Juers), proposing that the mainstream media which shape people's cultural understandings can be reused to 'talk back' and thereby contribute to cultural debates. TERROR NULLIUS has been widely received as an anti-capitalist commentary; a fact best demonstrated by Glasglow Short Film Festival awarding it their 'Favourite Critique of Capitalism' prize. Given that only one sequence in TERROR NULLIUS explicitly addresses capitalism (mining magnate Gina Rineheart's eerie monologue about "those who are jealous of those with more money"), this award speaks to the powerful anti-capitalist implications of sampling. Repurposing material 
in ways that undermine the systems they were designed to support creates a détournement that resonates with the rebellious, "unfaithful" aspects of cyborg theory (10). Haraway's autonomous cyborg is a "blasphemous" evolution of the Western logics involved in its initial development, including the capitalist principle that a creator owns and controls their creations (1). By treating privately owned commodities as common, free resources through sampling, TERROR NULLIUS models a cyborg style detournement of commercial cinema

When read through a cyborg lens, TERROR NULLIUS models a restorative approach to problematic media that social movements might productively emulate in their navigation of the politics of identity. In recent years, commentators have noted a trend of social media activists responding to offensive behaviour or media content by calling for others (peers, fans, consumers, producers) to shame and boycott the offending person or text (Kosnik; Ross; Romano; Luu; Friedersdorf). "Cancel culture," as it is commonly referred to, has seen minorities identities without conventional institutional power significantly challenge the cultural capital of those who promote racist, sexist or queerphobic ideologies (Kosnik 206). However, critics from within progressive social justice movements have questioned cancel culture's efficacy. Abigail De Kosnik suggests that leftist cancelling techniques have been co-opted by the alt-right to dismiss genuine criticism and spur populism (214). Meanwhile, in a New York Times opinion piece, Black feminist scholar Loretta Ross argues that cancel culture's focus on "expunge[ing] anyone with whom they do not perfectly agree" creates "toxic" in-fighting, detracts attention from the root causes of injustice, and replicates systems of "punishment and exile" rather than modelling a radical "restorative justice." The debate around cancel culture links to current discussions within the humanities and in wider culture about how (or whether) to respond to, display and teach historical artefacts or texts that have (debatably) offensive social politics. There is, for example, debate about whether film studies departments should continue to teach the explicitly racist The Birth of a Nation (1915): some argue the film is of major technical significance and that it is it better to use it to demonstrate how films can perpetuate harmful ideology than censor it; others counter that the film's harmful ideologies have had enough screen time and there are other, understudied films that can be used to teach similar techniques without asking students to watch three hours of racist material (McEwan 98; Italie). Central to both the debate about cancel culture's efficacy and the discussion of offensive historical material's usefulness are questions about censorship and redeemability. How can progressive identity politics movements respond to problematic behaviour or media in productive ways which acknowledge but do not promote offensive messages? I argue that TERROR NULLIUS' cyborg-esque détournements of problematic 
media models one productive method. In overtly reversing the message of problematic media such as Crocodile Dundee, Soda_Jerk indicate the offensive aspects of the original film and call attention to its influence on cultural history without reiterating its offensive message. By using a film to criticise itself and contribute to a new film with progressive messages, TERROR NULLIUS symbolically models the kind of "restorative justice" Ross advocates. Instead of 'cancelling' offensive films, Soda_Jerk repurpose or, in cyborg terms, "regenerat[e]" them (Haraway 67), giving films the opportunity to transcend their problematic origins after they undergo significant, self-critical transformations engineered by Soda_Jerk. In the context of contemporary debates related to identity politics, TERROR NULLIUS advocates a form of identity politics that prioritises accountability over censorship and offers redemption to those with problematic pasts on the condition of their radical transformation.

\section{AFFINITIES AND ACCOMPLICESHIP}

In disregarding "original innocence" as a requirement for political collaboration, "A Cyborg Manifesto" promotes a politics based on affinity rather than essentialism (58). Haraway reiterates criticisms by women of colour of second-wave radical feminism's totalising approach to ‘women's experiences' (18-25). In Haraway's view, any attempt to find an allencompassing definition of women's experience is futile and ends up reproducing the totalising, imperialist logics that underpin patriarchal Western humanism $(16,19)$. Queer and postcolonial scholars have similarly criticised essentialist politics for normalising privileged forms of an identity and thereby erasing others (Spivak 184; Butler 10; Stone 85). "A Cyborg Manifesto" argues that solidarity between groups fighting against related forces of oppression is necessary, but advocates for connection based on "conscious coalition" rather than "natural identification" (18). For Haraway, cyborgs, with their non-organic, hybrid bodies and problematic origins, signify community "not by blood but by choice" (16). Borrowing the biochemistry term for the strong bond between antibody and antigen, Haraway describes this kind of cyborg connection as affinity. Haraway gives the example of her local anti-nuclear group as a cyborg organisation that unites people from across the social and political spectrum to pursue a common goal (15). Cyborg politics regards affinity as the most effective, inclusive model for political action.

Nearly four decades after "A Cyborg Manifesto" appeared in print, progressive social justice movements are still striving and struggling for affinity. Intersectionality, a term coined by critical race scholar Kimberlé Crenshaw in 1991, has inspired and provides a base for 
criticism across social movements (Carroll 600; Bulbeck 497; Keskinen 157; Brettsneider 7). Furthermore, "white feminism" has come under fire in the last few years for its neoliberal, neocolonial attitudes that are complicit in the oppression of women of colour, queer people, working-class people and the environment (Griffin 557). One way contemporary social movements practice affinity instead of essentialism is through allyship. Allies are people who support a cause without claiming a shared identity, often because they themselves belong to the oppressor identity (Bridges and Mather 156). Whether or not allyship is a genuine political commitment or performative lipservice is a major question in the affinity politics of contemporary social justice (Hadley 85; C Rose-Redwood and R Rose-Redwood 650).

Soda_Jerk are invested in building affinities but are also wary of commodified allyship. When asked how they approach intersectional issues in interviews with Tess Maunder and Leo Goldsmith, Soda_Jerk cite Indigenous Action Media (I.A.M)'s 2014 "provocation" text, “Accomplices not Allies: Abolishing the Ally Industrial Complex, An Indigenous Perspective." I.A.M. criticise the "ally industrial complex" - characterised by a saviour attitude, public relations-motivated activism, and a lack of ongoing commitment to and relationships with the community they are purportedly allies of - as the "dead-end of decolonisation" $(1,7)$. Sceptical of allyship, I.A.M. instead advocates for accompliceship, a more radical form of affinity in which people who are part of the majority/oppressive culture "strategise with, not for" marginalised peoples and find "creative ways to weaponise their privilege" (5-6). Dian Squire adapts I.A.M.'s framework to a queer context, criticising the box-ticking, self-absolving expectations of some forms of allyship and advocating, in its place, an accompliceship that is on-going, historically conscious and action-focused (186-8). For Soda_Jerk, making TERROR NULLIUS through an accomplice framework involved "open, informal and rhizomic" consultations with the minority/political communities represented in the films, without expecting "some kind of stamp of approval" in which individuals are taken as authoritative voices of a whole demographic (Sharp and Jeurs). Soda _Jerk express a commitment to their cause[s], "putting [their] own asses on the line" (Goldsmith) by being explicit in their political messages and piracy and "staying with the trouble" when their funding body withdrew its support (Capaldi). Here, Soda_Jerk echo the title of Haraway's most recent book, Staying with the Trouble: Making Kin in the Chthuluecene, which, like "A Cyborg Manifesto," encourages readers to recognise one's non-innocence in cultural problems and commit to revolutionary counter practices and epistemologies. Like Haraway's cyborg, Soda_Jerk approach identity politics as a process of recognition, accompliceship and productive change, rather than one of absolvation. 
TERROR NULLIUS promotes accomplice activism based on affinity rather than essentialism in multiple ways. Set "in a world in which minorities and animals conspire, and not-so-nice white guys finish last," TERROR NULLIUS' narrative emphasises vigilante collaboration. Act One climaxes with a sequence of women characters taking vengeance on a man (1978 Mad Max's Max Rockatansky, played by Mel Gibson). The sequence begins with a post-apocalyptic looking gang of women (Furiosa and her companion from Mad Max: Fury Road, 2015) listening to an audio recording of a man aggressively berating his partner; "if you get raped it'll be your fault"' (Mel Gibson's phone call to Oksana Grigorieva, 2010). Another woman (Peggy from Peterson, 1974), looking out of place midst Furiosa's gang with her 1970s style hair-cut and big wire-frame glasses, speaks up in the language of secondwave feminism: "this is a particularly glaring example of the kind of double standard women are subjected to, and I think we should mount some kind of protest against it immediately" (fig. 10). Soda_Jerk cut and composit clips from thirty films and television shows to portray a swarm of women and girls attacking Max/Mel and destroying his car. Though only on screen for seconds each, their costumes and appearances indicate differences in historical period, age, ethnicity and class. A woman wearing avant-garde style hunting attire shoots Max with a crossbow (Jennifer from Turkey Shoot, 1982), and a pre-teen girl in fluoro lands a bike jump on top of him (Judy from BMX Bandits, 1983). Two Aboriginal women, one wearing a 1960's headband, fiercely stare Max down (Gail and Julie from The Sapphires, a 2012 film set in 1968), while a young white woman in a sari dances with glee at his demise (Ruth from Holy Smoke!, 1999). The scene shows a diverse community of women working as accomplices, punishing misogyny without reinforcing any homogenous group identity.

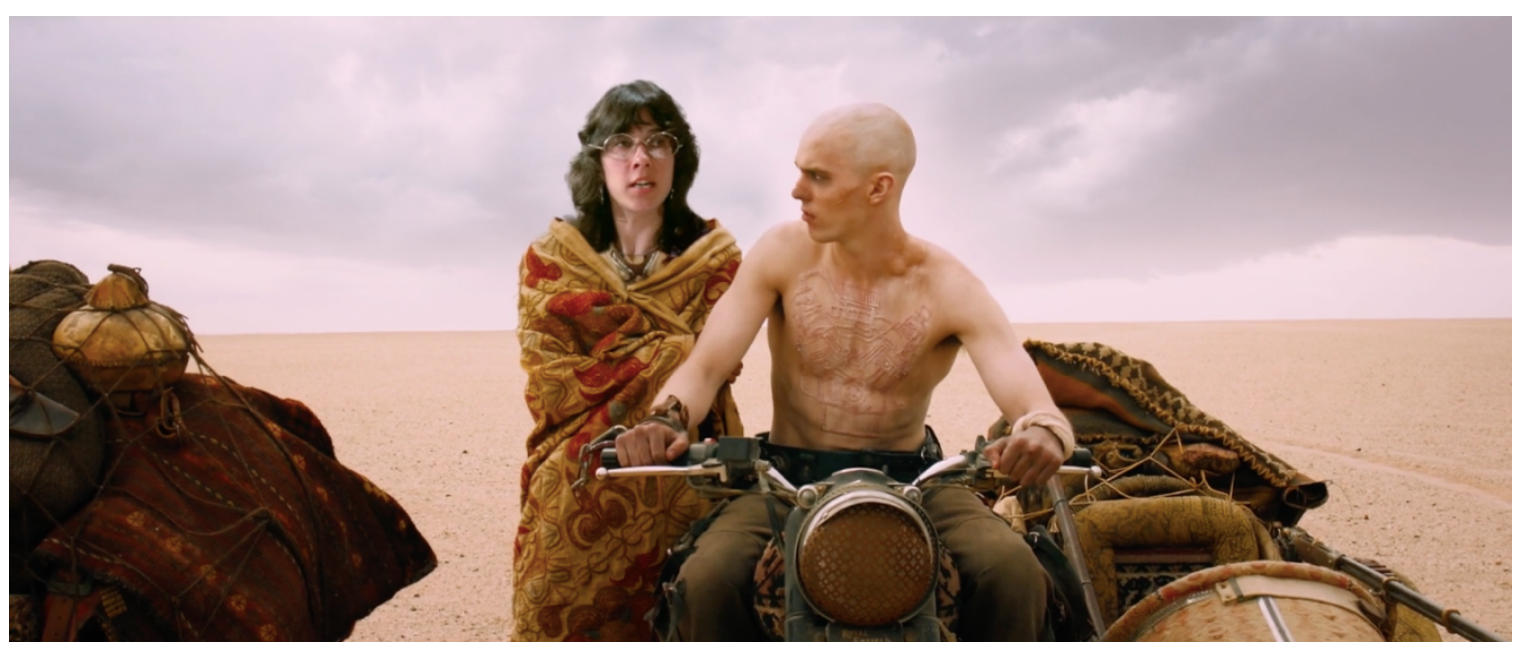

Fig 10. Peterson's Peggy is composited onto a scene from Mad Max: Fury Road, from TERROR NULLIUS, Soda_Jerk, 2018. 
In portraying solidarity between characters from films from different historical periods, TERROR NULLIUS models intergenerational political affinity that embodies a cyborg ethos. The vigilante girl gang scene features films from the 1970s-2010s. Some are period films set even earlier or speculative fictions set in the future, adding even more historical complexity to the compilation. Virginia Wolfe from the 1930s (The Hours, 2002), Peggy from the 1970s, Ruth from the 1990s and Furiosa from an imagined dystopic future conspire for the same cause. TERROR NULLIUS unifies their historically specific feminisms, suggesting ways that people within intergenerational social movements might work productively as accomplices without sacrificing their specific identities and intra-movement differences. Remixing characters from different time period together does not have an ahistorical effect - historical difference is visually coded in the characters' costumes and the quality of the footage - but it does defy typical historical linearity. Returning to ideas discussed in Chapter Two, TERROR NULLIUS' trans-historical sampling produces a Benjaminian constellation: a non-linear construction of history that links past, present and future in a fleeting moment, not to produce a chronology but a historically informed "insight" and "call to...action" (Sahraoui and Sauter xiv; Benjamin 257). In reviewer Chris Dobson's words, "time and place blur as one film feeds into another, creating fascinating new connections in the process." Considered in the context of intergeneration conflict within feminism, the girl-gang scene's trans-historical constellation suggests the possibility of solidarity and action without erasing important identity differences.

Alongside feminist affinity, TERROR NULLIUS also upholds "A Cyborg Manifesto"”s non-humanist, ecological stance and endorses cross-species accompliceship. "A Cyborg Manifesto" is most known for its argument about the blurred boundaries between human and machine but Haraway also includes animals in her cyborg construction of boundaryless relations (10). Undoing the Western dualism of nature and culture, cyborg politics involves affinities and accompliceship between people, animals and machines (10). TERROR NULLIUS is largely inspired by the eco-horror genre, in which wildlife avenges ecological destruction by attacking human perpetrators (Gregersdotter et al. 9; Milatovic 77). Soda_Jerk extend the traditional scope of eco-horror, "applying animal revenge to a much broader spectrum of sociopolitical concerns" (qtd. Goldsmith). Cutting between Romper Stomper (1992), Healing (2015) and Lucky Miles (2007), Soda_Jerk depict an eagle defending asylum seekers by fatally piercing a neo-Nazi in the neck. At other points, a crocodile helps Sue punish Mick Dundee's misogyny, a herd of man-eating-sheep destroy an imperialist celebration, and Skippy the kangaroo educates a young white boy on colonial 
violence. TERROR NULLIUS' portrayal of animals actively participating in its political fights aligns with Haraway's cyborg activism, which is based on collaboration between humans and animals to undermine Western humanism and its binary logic.

In addition to these representations of accompliceship between characters, TERROR NULLIUS' eclectic sampling symbolically models affinity activism by uniting disconnected sources made by different filmmakers and associated with a variety of genres. TERROR NULLIUS is a hybrid entity that combines Soda_Jerk's creative work with hundreds of others'. Not only do Soda_Jerk consider themselves "collaborators" with the filmmakers they sample from (qtd. in Capaldi), TERROR NULLIUS stages unauthorised and unorthodox collaborations between other filmmakers that transcend the usual boundaries of low and high culture: the works of YouTube vlogger Ivan Lentell, Hollywood blockbuster director Steven Spielberg, crass comedy filmmaker Paul Fenech and Palme d'Or winner Jane Campion become unlikely companions in TERROR NULLIUS. Moreover, this rejection of high brow/low brow categorisation and embrace across genres (in contrast to the exclusive sampling of film like Histoire(s) du Cinèma) reflects a sense of affinity and collaboration across different subcultures. The vigilante girl gang scene, for example, combines an action blockbuster (Mad Max), sci-fi horror (Turkeyshoot), a musical (Grease), period drama (The Hours), sitcom (Kath and Kim), art film (Sweetie), comedy-drama (Muriel's Wedding) and a family movie (BMX Bandit). As with the aforementioned point about Soda_Jerk portraying intergenerational solidarity through textual diversity, TERROR NULLIUS' genre compilation does not try to conflate genres and erase their differences but model ways in which difference can be grounds for collaboration.

To recapitulate, TERROR NULLIUS advocates cyborg political formations based on partial connection and shared aims rather than essential similarity through representational and formal means. Throughout the film's narratives, diverse characters and animals form unexpected allegiances to fight back against oppressive forces. At a formal level, Soda_Jerk's sampling brings different filmmakers, genres, nations, and time periods together, fostering textual affinities without erasing difference. Like the culturally diverse anti-nuclear group Haraway describes, Soda_Jerk's cyborg sampling “build[s] a political form that actually manages to hold together" in spite, or rather, because of internal differences (16). TERROR NULLIUS' embodiment of cyborg affinity and accompliceship is a reminder to contemporary identity politics movements that intergenerational and intercultural differences can be sources of productive collaboration rather than division. 


\section{UNRESOLVED IRONIES}

Iconic plurality is at the heart of Haraway's cyborg construction and key to its political philosophy. "A Cyborg Manifesto" opens with a description of irony:

Irony is about contradictions that do not resolve into larger wholes, even dialectically, about the tension of holding incompatible things together because both or all are necessary and true. Irony is about humour and serious play. It is also a rhetorical strategy and political method. (5)

According to Haraway's definition, irony offers an alternative to politics based on innocence and essential identification, which rely on concepts of purity, wholeness and autonomous selfhood (32). These values and their dualistic opposites (corruption, partiality and the Other) are foundations of Western logic and have been used to justify processes of imperialism and oppression (59). The cyborg defies the dualism of Western humanism; a hybrid body of "taboo fusions" and "permeable" boundaries; an ironic combination of parts that is synergistic but never complete $(55,45)$. Cyborg irony is also humorous and irreverent. Cyborg texts find pleasure in the play of bringing incompatible ideas into conversation, without the intention of producing a final, singular reading (58). In the context of identity politics, Haraway's ironic cyborg represents an ethos that is comfortable with multiple perspectives and does not force contradictory viewpoints to resolve for the sake of homogeneity.

TERROR NULLIUS' narrative structure illustrates this Harawayan ironic plurality. While classical narrative films achieve a coherent, closed story by focusing on the psychological motivations and aims of a select few characters and providing a "complete conclusion" of those aims by the film's end (Speidel 84-85), TERROR NULLIUS generates ambiguity by partially engaging with many stories and denying narrative closure. Act One opens with voice-over narration by David Gulpilil from Ten Canoes (2006): “Once upon a time, in a land far away-“ Gulpilil breaks into a laugh, "ha! not like that, I'm only joking, but I am going to tell you a story, not like my story, but a good story all the same.” This opening reference three possible stories, foregrounding the many narratives in tension throughout TERROR NULLIUS. Each of TERROR NULLIUS' three acts contains multiple vignettes, connected by smaller sequences. Across these vignettes, only a few of the film's hundreds of characters appear multiple times - Arun and Youssif from Lucky Miles, the kids from Walkabout and Skippy and Sonny from Skippy the Bush Kangaroo - and they function more as symbols or drivers of action than protagonists with psychological narrative arcs. Each 
vignette provides a window into a scene from a new narrative, creating a collage of stories that do not resolve into a neat whole. For reviewer Adrienne Reese, this is what makes TERROR NULLIUS so captivating: "you can't look away because it is not, on the whole, a coherent movie; there's no one plot-line or set of characters to follow." TERROR NULLIUS' final shots do not resolve its ironic tensions. As mentioned in Chapter Two, the closing scene of the film features Lantana's Detective Zat sobbing in his car to a tape recording of narration about Australian's violent colonisation from A Secret Country. The shot then cuts outside to police officers slowing searching the bush, their objective unknown to the viewer. The sound of insects clicking and chirping is increasingly amplified. The camera slowly descends into the shadowy depths of a lantana thicket, producing a foreboding sense of dread as it fades to black. The static-like cacophony of insects crescendoes, unnervingly. This ending sequence expresses recognition and remorse in relation to TERROR NULLIUS' key themes around colonialism but no sense of closure- there are still stories and trauma to uncover. Suddenly, the black ending screen is interrupted by a mid-shot of a man with a mullet and a toothy grin looking directly into the camera (Dale from The Castle 1997). "I'm Dale Kerrigan, and that was my story” he beams as a cheesy ballad ('We've Only Just Begun' by The Carpenters) kicks in and the credits begin to roll. The lightness of this final image and song clashes with the intensity of the previous scene, creating an uneasy, confusing comic relief. Dale's reference to storytelling works as a bookend, linking back to Gulpilil's opening dialogue. However, the inconsistencies between the opening narrators and the many fragments of stories that have come in-between make Dale's claim to a single story ironic rather than conclusive. The dramatic change in tone and false claim to narrative closure TERROR NULLIUS' ending achieves, demonstrates a cyborg approach to narrative and politics that is ironic, multiple and unresolved. TERROR NULLIUS subverts classical narrative conventions of a consistent protagonist, a single coherent plot and a closed ending in favour of ambiguous storytelling that reflects cyborg preferences for irony and irresolution.

Cyborg irony is a useful framework for understanding the effect of sample films that draw on a diverse range of source. Soda_Jerk share Haraway's irreverent attitude that "no objects, space or bodies are sacred in themselves; any component can be interfaced with any other" (32). TERROR NULLIUS flagrant combinations of fiction, non-fiction, high and low brow media do not combine into a neat whole and instead produce ongoing tensions and excesses of meaning. Compositing Skippy, icon of a quaint, parochial 1960s kids show, into a 2014 vlog of youth raving at a "bush doof" engenders a sense of transgression, humour and ambiguity. As discussed in Chapter One, this ironic aspect of Soda_Jerk's sampling style is 
closely tied to 1960s and 1970s avant-garde found-footage filmmaking. Found-footage artist Chick Strand echoes “A Cyborg Manifesto"'s irreverence in her description of sampling: "nothing is sacred. You just rip it out of one context . . . and mix the whole thing up with something else entirely" (qtd. in Wees 92). Haraway's notion that "any component can be interfaced with any other" (32) also resonates with aspects of Eisenstein's theory of dialectical montage, as discussed in Chapter Three. Eisenstein, like Strand, Soda_Jerk and Haraway takes pleasure in provocative combinations, believing that "sap, vitality, and dynamism arise from the irregularity" of shots (47). Cyborg theory is evidently relevant not only to TERROR NULLIUS, but other sample films and forms of subversive filmmaking.

However, TERROR NULLIUS achieves a cyborg irony in ways many prior sample films do not by complicating its dialectical montage editing with uncanny continuity and collage compositing. Haraway's emphasis that cyborg ironies do not resolve "even dialectically" indicates that dialectical montage cannot alone produce cyborg politics (5). To return to ideas discussed in Chapter Three, dialectic filmmaking provides a thesis and antithesis, leading the viewer to rationalise a specific synthesis. However, Soda_Jerk's Dan Angeloro describes remix sampling as a rogue form of dialectics that inspires excessive meanings and multiple synthesises ('Thoughtware' 20). Many of TERROR NULLIUS' edits bring together more than two samples or references and suggest an array of readings, some partial or nonsensical, rather than a clear, single conclusion. Where dialectic montage needs to maintain a distinction between two clips to emphasises their conflicting differences, continuity editing and collage compositing destabilise the boundaries between one text and another, encouraging the viewer to take pleasure in the irreverent fusions. The Skippy-doof collage is a strong example of how Soda_Jerk use compositing to revel in a Harawayian "tension of holding incompatible things together," rather than produce a particular didactic critique (5). While some moments in TERROR NULLIUS do direct the viewer to a specific reading, the majority of Soda_Jerk's editing is ambiguous, playful and ironic. For Haraway, irony is an antidote to the totalising logic of Western imperialism that some forms of identity politics have problematically adopted (52). Read accordingly, TERROR NULLIUS' ironic editing promotes a political ethos that appreciates that not all conflicts must be resolved into a singular consensus and knows how to sit with - even find joy in - internal tensions.

Several fruitful conclusions arise from this chapter's analysis of TERROR NULLIUS embodiment of three key aspects of Haraway's political manifesto - accepting problematic origins, encouraging collaboration while recognising difference and embracing irony and multiplicity. Firstly, this cyborg reading shows that TERROR NULLIUS' subversive formal 
techniques and unconventional narrative collectively form a political perspective based on values of redemption, affinity, and plurality. In other words, features which I describe simply as negations of filmic and cultural status quo in previous chapters, are read collectively in this chapter as expressing a specific, cyborg political ethos that does not align with mainstream political views or even dialectical approach to counter-politics. Considered in relation to contemporary issues in identity politics and social movements, TERROR NULLIUS challenges the premises that underpin cancel culture and essentialism and instead promotes a belief in radical transformation and intersectional accompliceship.

Secondly, this chapter offers a political reading of TERROR NULLIUS that is separate to its engagement with Australian culture and politics. One of the goals of this thesis, as laid out in the introduction chapter, is to understand why TERROR NULLIUS has been interpreted as political by audiences who are not familiar with the Australian texts it samples and the contexts it references. This cyborg reading, which intentionally focuses on TERROR NULLIUS' formal and representational (rather than referential) aspects, indicates that TERROR NULLIUS has multi-faceted politics that stretch beyond its specific Australian themes. TERROR NULLIUS cyborg philosophies - redemptive transformation, collaborative affinity and ironic plurality - conveyed through the film's sampled form and unconventional narrative are relevant to identity politics and social movements across the world. In Soda_Jerk's Dom Angeloro's view, TERROR NULLIUS “resonate[s] overseas because globally there's such a tidal wave of conservatism and such a horror in the political climate globally that I think international audiences can identify with a political revenge fantasy" (qtd. in McCarthy). TERROR NULLIUS radical, irreverent, progressive cyborg attitudes are one form this political revenge fantasy, which, as reviews from outside Australia show, translates across international contexts. Swedish film festival director, Christoffer Olofsson, praises TERROR NULLIUS' sense of hybridity and inconclusive plurality, expressing joy at the way TERROR NULLIUS “slip[s] in and out of cracks between set genres" and "gnaw[s] away at...most other boundaries you can think of." Meanwhile, other international reviewers celebrate TERROR NULLIUS ironic humous and irreverent sampling; Vancouver-based Allan MacInnes acknowledging the film's "playful sense of humour”, Erin Harrington from New Zealand proclaiming it "wickedly funny" and Ben Nicholson from Northern England dubbing the film "an absolute riot." Other quotes spread throughout this chapter are all from non-Australian reviewers, demonstrating the international resonance of TERROR NULLIUS' cyborg qualities. Cyborg analysis draws attention to TERROR NULLIUS' more general, conceptual politics that make it impactful for international audiences. 
Finally, this chapter demonstrates that "A Cyborg Manifesto" is a unique and versatile analytical tool for film studies. Throughout this chapter I have employed Hamilton's three forms of Harawayan cyborg analysis - literal, representational and metaphoric - to TERROR NULLIUS, thereby illustrating the various ways film scholars can utilise cyborg theory (111). Firstly, this chapter shows literal cyborg analysis provides a new way of understanding cinema's technical form and industrial practices, reframing film as a collaboration between human(s) and machine, rather than the brainchild of a solo auteur or the product of commercialised conventions. Considering TERROR NULLIUS as a literal cyborg has enabled me to describe its authorship as a hybridised, "many-headed" collaboration between Soda_Jerk, the filmmakers they sample from, and the digital editing technologies they use (Haraway 15). In addition, literal cyborg analysis provides the language to understand TERROR NULLIUS' détournement and un-licenced sampling as an "exceedingly unfaithful" transformation of commercial cinema (10). Applied to representation, cyborg theory directs attention to a film's portrayal of identity, relationships and power. Evidencing the relevance of Harawayan representational analysis beyond science fiction cinema, this chapter uses cyborg theory to understand the radical implications of TERROR NULLIUS' representation of accompliceship between human and animal characters from media of different genres, locations and time periods. Reading TERROR NULLIUS in concert with "A Cyborg Manifesto" clarifies how the film's representation of minorities bringing down figures of Western patriarchy advocates values of solidarity and intersectionality relevant to real-world identity politics. Finally, cyborg theory in its metaphorical capacity sheds light on a film's underpinning epistemologies. This chapter's Harawayan analysis illuminates how TERROR NULLIUS challenges totalising Western paradigms through its multiple, unresolved narratives, eclectic sampling and ironic, irreverent humour. By reading TERROR NULLIUS literally, representationally and metaphorically as cyborg cinema, this chapter makes a case for film studies to revisit "A Cyborg Manifesto" and consider how it can be applied in diverse ways. 


\section{CHAPTER FIVE \\ AUSTRALIAN INTERVENTIONS: TERROR NULLIUS CRITIQUES XENOPHOBIA}

This chapter delves deep into TERROR NULLIUS' Australian cultural and historical references to address my final research question: what are TERROR NULLIUS' explicit politics and how does express them? The primary objective of this thesis is to understand the multiple senses in which TERROR NULLIUS is political, thereby contributing to scholarship on sample filmmaking's political capacities. Chapters One, Two and Three largely focus on the politics of TERROR NULLIUS form, analysing how it creates a subversive ethos by diverging from dominant conventions of cinema and positivist history. Chapter Four builds on the previous chapters to demonstrate how these subversive formal techniques advocate values of radical transformation, intersectional collaboration and pluralism relevant to progressive identity politics. Meanwhile, this final chapter details TERROR NULLIUS' explicit politics, and how the film engages with the histories and cultural values behind them. In doing so, this chapter works in conjunction with Chapter Four to achieve the secondary aim of this thesis - which is to reveal why the film has resonated with domestic and international audiences and thereby demonstrate sample filmmaking's ability to produce complex and multiple meanings. This chapter's focus on the Australian context employs an alternative research process to produce different (though not necessarily incompatible) conclusions from Chapter Four's cyborg interpretation of TERROR NULLIUS' politics. While the previous chapter used one central conceptual theory to read TERROR NULLIUS' direct content, this one engages with Australian history and national cinema scholarship to analyse TERROR NULLUS from the perspective of a viewer with knowledge of the original meanings, historical contexts and political references of the media Soda_Jerk sample. In doing so, I clarify TERROR NULLIUS' commentary on contemporary Australian politics and present sample filmmaking as a sophisticated tool for historically conscious, culturally engaged explicit political discourse. Moreover, focusing on TERROR NULLIUS' Australian political interventions sheds light on the connection between sample filmmaking and Australian culture, and why sampling is a particularly apt tool for postcolonial cultural critique.

TERROR NULLIUS' explicit political critique is both the driving force of the film and the aspect of TERROR NULLIUS' politics least accessible to viewers without detailed prior knowledge of Australian history and culture. Soda_Jerk attribute TERROR NULLIUS to their "growing urgency to respond to the increasingly sinister turn in Australian politics" and say 
that "fundamentally, the film comes from a place of rage, of being truly pissed off that any kind of social justice is so far removed from the national agenda" (qtd. in Maunder). As foregrounded in Chapter Two, Soda_Jerk use history to contextualise the power imbalances and cultural ideologies that underlie current political issues. Soda_Jerk consider TERROR NULLIUS a "rogue documentary" that reworks media related to "touchstones" in Australian history, such as Gough Whitlam's dismissal from office in 1975 or the Tampa crisis in 2001, to "reconfigure the past and present in potentially more productive ways" (qtd. in Maunder). However, the connection between TERROR NULLIUS' samples and the historical events they reference is rarely straightforward. Like other postmodern and postcolonial sample filmmakers before them, Soda_Jerk appreciate the complex relationship between media and reality: instead of direct representation of the past, Soda_Jerk "think of samples as encrypted historical documents that are imbedded with clues about the histories, personal experiences and politics of where they are and where they have been" (qtd. Sharp and Juers). Soda_Jerk's statement indicates that decoding the rich references that make up TERROR NULLIUS' explicit political critique involves analysing both a source's initial message (how the source text reacts to or is inspired by real-life events and attitudes) and its cultural afterlife (how it was received and remembered). In sum, this chapter examines the content, context and afterlife of samples to reveal the political stakes of TERROR NULLIUS' key scenes.

Taking a holistic approach to political and cultural critique, TERROR NULLIUS addresses a wide range of themes including colonialism and its legacies, sexism, queerphobia and toxic heteronormative masculinity, racism and xenophobia. This chapter focuses on TERROR NULLIUS' anti-xenophobic commentary because it is a particularly strong example of Soda_Jerk's diverse and sophisticated contextual referencing. TERROR NULLIUS' critique of xenophobia is most clearly expressed in two scenes featuring Arun and Youseff, the Cambodian and Iraqi asylum seekers from the film Lucky Miles (2007). Using dozens of samples (from primarily fiction films but also documentaries, television shows and news broadcasts), these two scenes reference an array of historical events that highlight Australia's hostile and hypocritical attitudes and policies towards non-white immigrants. I begin by outlining the background knowledge necessary to understand TERROR NULLIUS' references to Australian immigration politics, including a historical overview of the tension between white nationalism and multiculturalism, and descriptions of the Tampa crisis, Woomera detention centre, the Cronulla riots and anti-migrant rhetoric of politicians such as John Howard and Pauline Hanson. I then closely analyse the two scenes featuring Arun and Yousiff, explaining how samples from Lucky Miles, The Piano, Romper Stomper (1992), 
Mad Max 2 and Down Under (2016) relate to Australia's race relations and immigration history and how Soda_Jerk use them to criticise xenophobia. Analysing these two scenes in their entirety demonstrates how references build and interact throughout the scene in a way that spotlighting a few isolated moments does not. Importantly, one of these scenes is the same scene featured in TERROR NULLIUS Unmixed (the showdown at the Mad Max 2 compound). Analysing the same scene through two different mediums shows the unique values of each and demonstrates how written and videographic forms of research can complement one another. Finally, to emphasise that TERROR NULLIUS' explicit politics are consistent throughout the film, I briefly summarise two additional references to Australian political issues - one to indigenous land rights in the film's opening scene and another to the same-sex marriage postal survey in The Babadook scene. In conclusion, the chapter argues that TERROR NULLIUS' ironic, referential method of political discourse reflects an “antipodean camp" cultural tradition (Perry 95). This reading helps explain why TERROR NULLIUS, despite being described as "un-Australian" by its funders (Heller-Nicholas), is a quintessentially Australian production in both form and content.

\section{HISTORICAL OVERVIEW OF AUSTRALIAN IMMIGRATION}

The tension between white nationalism and multiculturalism is deeply rooted in Australian culture and comes to the fore in immigration discourse (Jupp 6). As a colonial settler state, Australia was founded on notions of racial hierarchy and white superiority (Tavan 137; Jupp 7). Despite geographically belonging to the Asia Pacific region, Australia considered itself as an outpost of Western Europe and, when it became a self-governing Federation in 1901, made concerted efforts to remain culturally distinct from its neighbours (except settlercolonial New Zealand) (Cerwonka 225). Between the first British fleets' arrival in 1788 and 1945, the vast majority of migrants to Australia were Anglo-Celtic (Elder 118). Furthermore, government legislation suppressed any perceived challenges to white hegemony, such as by taxing Chinese sojourner gold miners in the 1850s (Elder 119). Throughout the first half of the twentieth century, Australia maintained a 'white Australia' immigration policy through bipartisan agreement (Jupp 8). As a consequence of British colonialism succeeded by xenophobic immigration policies, Anglo-Celtic migrants and their descendants (hereafter referred to as white Australians) obtained and maintained demographic dominance and political power in Australia. 
White Australians' near-hegemonic demographic dominance began to unravel in the wake of WWII. In desperate need of a labour workforce, Australia reduced prior landing tax restrictions for "white-but-not-white-enough" Southern and Eastern European refugees and migrants (Nicolacopoulus and Vassilacopoulus 45; Poynting and Mason 368). In the 1970s, the remnants of the 'white Australia' policies were formally overhauled by the Whitlam administration (Batrouney 51). Gough Whitlam, regarded by many (including Soda_Jerk) as one of Australia's most progressive Prime-Ministers, redefined Australia as "on the edge of Asia" and advocated for multiculturalism (Hawkins 94; Goldsmith). Whitlam believed Australia had a humanitarian duty to offer refuge to those displaced by the Vietnam War and created an "extensive and well-organised refugee programme" (Elder 124; Jupp 118). As Australian multiculturalism developed over the next few decades, xenophobic backlash also became more prominent (Elder 124). In 1997, Pauline Hanson established One Nation, a populist party with a white nationalist ethos that spread vitriol about an "Asian invasion" (Aslan 26). Opponents of multiculturalism like Hanson characterised non-Anglo cultural expressions as "un-Australian" and frequently use this phrase to promote xenophobic attitudes towards new immigrants (Elder 136). The fact that TERROR NULLIUS funders also criticised it as "un-Australian" is testament to its criticism of white nationalism and advocacy of multiculturalism (Heller-Nicholas).

Detention centres are the physical manifestation of Australia's anti-migrant attitudes. The first detention policies were developed in 1989 in response to the unauthorised arrival of boats carrying several hundred Cambodian asylum seekers. Labour Prime Minister Bob Hawke declared the asylum seekers economic, rather than political refugees, and they were consequently detained (Stratton 630; Mares 68). In the early 1990s, the Paul Keating-led Labour government (1991-996) built several detention centres for "boat people", and the following John Howard-led Liberal government (1996-2007) further "radicalised" detention policy (Stratton 630). Woomera Immigration Reception and Processing Centre, a detention facility with capacity for 2000 detainees, located in the small outback town of Woomera, was "notorious" for its human rights controversies (Millbank; Jupp 194). In the early 2000s, Woomera was frequently in the news regarding hunger strikes, unhealthy conditions and, in August 2001, a mass break-out, and was criticised by the United Nations, Red Cross, the Australian Human Rights Commission and Amnesty International (Mares 35-36). Woomera closed in 2003, but other detention centres remained open, including offshore detention facilities at Manus Island and Nauru. Asylum and detention policy remains a controversial 
political and humanitarian issue in Australia and is a key theme of TERROR NULLIUS' political commentary.

Anti-immigrant rhetoric and policy intensified further in the early 2000s. In August 2001, a federal election year, a boat smuggling 433 refugees (predominantly Shi'a Muslims fleeing Afghanistan and Iraq) sunk on its way from Indonesia to Australia. A passing Norwegian freighter, MV Tampa, rescued the passengers, who requested Australian asylum. A "hysterical" public outcry ensued, one fanned by media and conservative politics (Elder 122). The Howard government tried to refuse the refugees but were unable to under international law; they then detained them offshore at Nauru instead. Less than a month later, 9/11 occurred. Border control anxiety and anti-migrant hysteria, especially against Middle Eastern migrants, became even more pronounced (Schlutz 7). Howard capitalised on this public xenophobia in his federal election campaign, and commentators attribute his win to his hard-line response to immigration (Mares 133; Collins 29; Elder 122; Schlutz 7). The Howard government intensified the strict migration policy, and Howard's "we are not a soft touch" rhetoric remained a part of successive Liberal party leadership's vernacular (Elder 126). Tony Abbott, leader of the Liberal party from 2009 and Prime Minister from 20132015, frequently reiterated Howard's hard-line anti-migrant, pro-detention messages and placed significant pressure on the Labour government to re-open Nauru in 2013 (Kirk; Kenny; Abbott). TERROR NULLIUS references Tampa, the 2001 election, John Howard and Tony Abbott, drawing attention to the relationship between anti-migrant discourse and political power.

TERROR NULLIUS also references the Cronulla race riots - one of the most pronounced outbursts of Australia's "simmering" white nationalism in recent history (McGrath 14). In December 2005, a violent altercation between a small group of Lebanese Australian youths and two white Australian lifeguards took place at a beach in the Sydney suburb of Cronulla. In reaction, young white supremacists organised a riot; 270,000 people received a text calling for "Aussies" to partake in "Leb and wog bashing day" to "claim back" Cronulla beach (Dunn 97). 5000 people attended the riot. Many wore Australian flags or had the southern cross drawn on their arms. Others had racist slogans written across their chests: "We grew here, you flew here", "save "Nulla, fuck Allah", "100\% Aussie Pride" (Noble 167-168; Taylor 122). The rioters flooded the beach and surrounding streets, violently attacking anyone of "Middle Eastern appearance" and injuring at least thirteen people (Poynting 44). The riots were widely reported on, with right-wing media blaming multiculturalism, not racism, as the cause (Poynting 50). Prime Minister Howard denied that 
racism and white nationalism motivated the riots, instead emphasising the impact of the inciting incident with the lifeguard and blaming the Lebanese targets of the riot (Dunn 83; McGrath 17). The Cronulla riots "cut deep into the national psyche;" the positive cultural image of 'the beach' tarred by the evocative scenes of white supremacist violence (Collins 27; Taylor 112). The Cronulla riots' strong imagery and prominent place in national memory make the event a useful reference point for the analysis of Australian xenophobia.

The Islamophobia apparent in the Cronulla riots is a dominant feature of Australian white nationalism. TERROR NULLIUS references specific events and politicians associated with Islamophobia, including the 1970s oil crisis, Tampa and Pauline Hanson. Like the U.S. and other industrialised Western countries, Australia was negatively impacted by Middle Eastern oil embargoes in the 1970s. Middle Eastern leaders were cast in the media as "manipulators" who "threatened [the West] with their vast oil reserves" (Aslan 14). The 1979 Iranian Revolution, in which Islamic leader Ayatolla Khomeini overthrew the U.S. supported Iranian monarchy, reinforced perceptions of Islam as a threat to Western power (Semati 259). The series of U.S. - Middle Eastern wars throughout the 1990s and 2000s (in which Australia supported the U.S.) led to an increase in Iraqi, Iranian, Afghan and Palestinian refugees seeking asylum in Australia, including the majority of those involved in the Tampa affair (Stratton 637; Hage 241). After 9/11, stigma against Muslims intensified, manifesting in immigration discourse that framed undocumented refugees as potential terrorists, who for example let their children become malnourished and sick to manipulate immigration authorities into letting them stay in Australia (Hage 242). By dehumanizing Muslim immigrants, Australia could legitimise their own dehumanizing detainment policies (Hage 242). In addition to justifying xenophobic immigration policies, some politicians also used Islamophobia's popularity to drum up political support. When Hanson rebooted her political career in the 2010s, she shifted focus from her 1990s "Asian invasion" rhetoric to demonising Islam (Maddox 32). In 2015, Hanson's campaign posters promised "no more mosques, sharia law, halal certification, [or] Muslim refugees" (Crosby 121). Hanson has become a figurehead of the white nationalist, populist movement in Australia and a symbol of Islamophobia (Crosby 103). The upcoming textual analysis shows how TERROR NULLIUS condemns Hanson's hate-speech and links it to a history of Islamophobia in Australia by referencing the 1970s oil crisis, Tampa and the Cronulla riots.

Concern about Australia's racist ideologies, discriminatory practices and unjust treatment of refugees was prominent at the time of TERROR NULLIUS' production and reception. In 2018, the year TERROR NULLIUS was released, Hanson's motion to 
acknowledge alleged anti-white discrimination, titled "It's OK to be white" (a long-standing neo-Nazi white supremacy slogan), nearly passed in the senate (Karp, "Ok to be White”; J. Wilson). Nelson et al.'s study on high perceptions of "reverse racism" among white Australians reveal the widespread nature of these populist reactionary attitudes (356). In 2019, when an Australian white supremacist killed 51 Muslims in a mass shooting in Christchurch, New Zealand, Hanson's fellow senator and former One Nation member Fraser Anning claimed the "real cause of bloodshed... is the immigration programme which allowed Muslim fanatics to migrate to New Zealand in the first place" (Newson). While less overtly Isalmophobic than Hanson and Anning, the Liberal party, who have been in power since 2013, have been criticised for their preoccupation with detecting extremism in recent immigrant communities and neglect to act on the rising extremism of far-right white supremacists (Barton; Karp "Labour Pushes"). Refugee detention also remains a prominent political and humanitarian issue. The Liberal Party "will not compromise on strong border protection" and have recently repealed the previous Labour government's detention centre medical care policies (liberal.org.au ). In 2018 numerous rallies throughout the year in Melbourne, Canberra, Sydney, Adelaide and Perth protested the conditions on Manus Island and Nauru and called for an end to offshore detention. Soda_Jerk's representation of asylum seekers, detention centres and white supremacist violence joins this critique of contemporary right-wing immigration policy by framing it as xenophobic, Islamophobic and populist.

\section{TERROR NULLIUS' REFUGEE NARRATIVE}

TERROR NULLIUS' refugee narrative confronts Australian xenophobia, white nationalism, anti-Asian racism and Islamophobia through references to Woomera, Tampa, Cronulla, and right-wing politicians including Howard, Hanson and Abbott. Two of the few characters who reappear at multiple points throughout the film are Arun and Youssif, the protagonists of Lucky Miles. Soda_Jerk sample clips of Arun and Youssif to tell a story of asylum seekers who arrive undocumented on a beach, face neo-Nazi violence, become stranded in the outback, stumble upon a detention centre, declare asylum and are threatened by right-wing politicians. The samples Soda_Jerk use to depict this story carry their own complex connections to the history and politics of Australian xenophobia and immigration policy. Soda_Jerk work “in solidarity" with films like Lucky Miles and Romper Stomper that critique Australian race relations, repurpose films that do not explicitly address xenophobia like Puberty Blues and The Black Balloon, and subverts texts which propagate anti-migrant 
sentiment, like John Howard's 2001 election campaign speech (qtd. Maunder). Researching the original historical context and meaning of each archival sample and examining the editing strategies Soda_Jerk apply to it illuminate TERROR NULLIUS' critique of Australian antimigrant xenophobia.

Arun and Youssif's story begins in Act One, with a scene that samples eight films and television shows: Lucky Miles, The Piano, Romper Stomper, Puberty Blues (film and series) Healing, Down Under and Japanese Story. For clarity's sake, I will introduce these sources before unpacking the scene. Lucky Miles is an Australian off-beat comedy-drama about Cambodian and Iraqi refugees. Though made in 2007, it is set in 1990 and loosely inspired by the 1989 Cambodian refugee fleet. The arthouse period drama The Piano is a 1993 Australian-French-New Zealand co-production about a nineteenth-century Scottish woman arriving in early colonial New Zealand. Romper Stomper is a gritty Australian drama made in 1992 about the rise of a neo-Nazi youth gang who terrorise local Vietnamese-Australians. Puberty Blues, both the 1981 film and 2010s television series remake, are coming-of-age narratives set in the 1970s about white Australian surfer teens. Healing is a 2014 Australian drama about an incarcerated white man who develops a strong bond with a raptor eagle named Yasmin through the prison's animal rehabilitation programme. Down Under (2016) is a satirical black comedy about the Cronulla riots, which features archival news footage of the event. Japanese Story is a 2003 arthouse drama about a romance between a Japanese man and an Australian woman. Soda_Jerk synthesise excerpts from these eclectic films to criticise anti-immigrant racism.

The opening sequence of the scene uses contextual references to highlight the hypocrisy of white Australian's xenophobia toward "boat people". The sequence (which follows on from the hitchhiking sequence I used to describe compositing in Chapter Three) opens with a sample from The Piano. Ada plays her piano on the beach, the film's iconic score, 'The Heart Asks Pleasure First,' fills the soundscape. A close-up of Ada glancing upward cuts to simulate her view of Arun from Lucky Miles stumbling out of the surf onto the beach. The Piano score is sustained as the image cuts to another Lucky Miles shot of a small wooden boat crowded with people who begin to jump off and swim to shore. The next cut reveals Ada glancing down to continuing playing, unperturbed. For those familiar with The Piano, the image of the Lucky Miles characters in their baggy clothes swimming to shore is reminiscent of Ada struggling to wade to shore, her Victorian petticoats weighed down by the violent waves. Cross-cutting between Ada, who represents colonial-era Anglo-Celtic antipodean migration, and Arun, representative of the 1989 Cambodian refugees, produces a 
dialectic comparison implying that all non-indigenous Australian are migrants and that early white migrants arrived in much the same dangerous, haphazard way as contemporary undocumented refugees. This destabilises white Australians' privileged claim to natural belonging and monocultural, Western definition of Australian-ness (Elder 115).

While the Lucky Miles/The Piano comparison points to white Australians' immigrant heritage, later events in the sequence deter/discourage the colour-blind move of conflating all migrant experiences as equal. Elder explains a common problem with the "we are all immigrants" narrative of Australian identity_in addition to undermining Aboriginal people's indigenous status, it "flatten(s) out" the "differences and hierarchies" in political, social, economic and cultural power between Anglo-Celtic, Southern/Eastern European, Asian and Middle-Eastern Australians. After Arun and his companions make it out of the water, the scene cuts to a close up of a lifeguard from Puberty Blues blowing an emergency whistle. The whistle alerts Hando and Davey, neo-Nazis from Romper Stomper, who come running toward the refugees. Next, Soda_Jerk cross-cut between a clip of Hando violently beating someone in the surf with clips of the Lucky Miles characters sprinting up the beach in fear, which indicates that Hando is attacking one of the refugees. The scene immediately evokes the white supremacist mob violence against Lebanese and non-white Australians at Cronulla beach. That reference is then reinforced with archival footage from the riots (sampled from Down Under) featuring a white torso bearing the phrase "we grew here, you flew here," followed by an eyeline match to a close-up shot of Youssif looking afraid. A clip of lifeguards fighting with beachgoers - a comic moment in Puberty Blues - is paired audio of people screaming, to further reference the Cronulla riots. Employing sensory dialectical editing, Soda_Jerk rapidly cut between images full of movement to generate a feeling of chaos. Another cut suggests Youssif's attention back to the surf, where Hando is still beating someone up with vicious rage. A parallel montage then develops between Hando and Yasmin the raptor, who circles high in the sky, then dives. Soda_Jerk composit Yasmin's dive over a shot of Davey stabbing Hando fatally in the neck, so it appears instead that the bird has killed him. Hando staggers backwards, blood spurting from his neck, and collapses into the surf. Two characters from Lucky Miles watch Hando's bloody demise, looking stunned. In the background behind them, ' $100 \%$ Aussie Pride' has been edited into the sand - another instance of Cronulla riots iconography (fig. 11). Shots of Sandy from Japanese Story and the Puberty Blues teens lounging in the sand, watching impassively, are interspersed throughout the scene to imply the passivity of many Australians in the face of white supremacy. In this scene, Soda_Jerk use continuity editing (especially the eye-line match) to combine excerpts 
from the films in a single diegesis, compositing to make the samples explicitly interact and sensory dialectic editing to generate agitation. Soda_Jerk select and edit the samples to evoke the Cronulla riots and criticise Australia's tolerance for white supremacist violence.

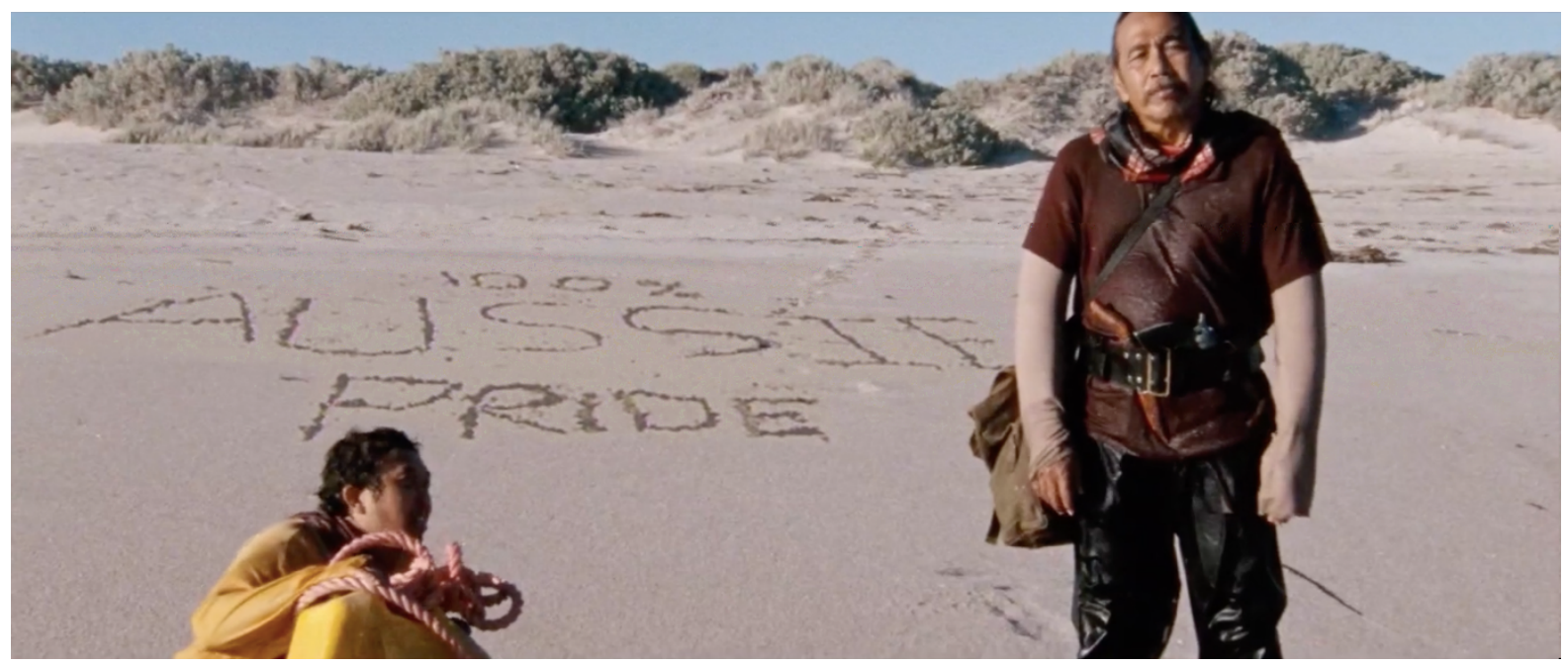

Fig. 11: Lucky Miles characters on a beach with a slogan from the Cronulla riots carved into the sand, from TERROR NULLIUS, Soda_Jerk, 2018.

In addition to re-using existing representations to critique contemporary politics, this scene also demonstrates how sampling can address criticisms of its source texts' politics. The films TERROR NULLIUS samples to address Australian's immigration history have previously been subject to critique regarding their historical legitimacy. Māori and African American scholars have critiqued The Piano for its "colonial gaze" and stereotypical depiction of Māori (Pihama 2; Reid 107). Jon Stratton and Dave Hoskin both read Lucky Miles' historic setting - in the early, more humane era of refugee detention, rather than postTampa when it was filmed - as a nostalgic move that evades the hostility of contemporary hard-line policy and attitudes (Stratton 631; Hoskin, "Going Walkabout" 20). Similarly, Kenta McGrath argues that Down Under's satirical account of the Cronulla riots downplays the racism of the riots and minimises white guilt by portraying the Lebanese gang as equally problematic as the white supremacist one (16). One way to interpret TERROR NULLIUS' sampling of these films is that it upholds the problematic aspects of their histories. However, this interpretation does not take into account the way TERROR NULLIUS' sampling recontextualises and transforms its original sources. TERROR NULLIUS challenges The Piano's debatable lack of engagement with colonial injustice by sampling it alongside scenes that overtly criticise colonial land theft and indigenous cultural erasure. The Lucky Miles 
clips are not confined to their original 1990 setting but are integrated into a broader history of immigration that includes references to events like Tampa and the Cronulla riots, which amplify the white-supremacist violence and racist prejudice Arun and Youssif face. TERROR NULLIUS' use of Down Under's archival footage of the Cronulla riots and emphasise the riots as a product of white supremacy, not multiculturalism. Whether or not Soda_Jerk engaged with critical scholarship on their samples is unclear, but regardless of intentionality, TERROR NULLIUS' progressive politics has the effect of 'updating' samples in ways that respond to critiques of the original films. Reiterating Chapter Four's arguments about the transformative power of sample filmmaking, my interpretation of this sequence shows how TERROR NULLIUS' redresses some of the problematic historical meanings of its samples. In doing so, TERROR NULLIUS models an innovative way of using media to engage with its own criticisms.

TERROR NULLIUS' critique of anti-xenophobia continues in Act Two, as Arun and Youssif's story intersects with ten more sources, which reference the oil crisis, detention centres, Tampa, Howard's election campaign and Hanson's white nationalism. After wandering through the desert, the two refugees stumble across the compound from Mad Max 2. Mad Max 2 (released in the U.S as The Road Warrior) is a 1981 post-apocalyptic action blockbuster set in the Australian outback. The premise is that World War III has caused a mass-shortage in oil, and civil society has devolved into tribal warfare. The protagonist, hardened vigilante Max Rockatansky, is caught in a conflict between the settlers - a community stuck in the desert with a highly valuable gasoline tanker - and the marauders (led by the formidable Lord Humungus), who are trying to steal the tanker. TERROR NULLIUS samples a scene where the settlers warily allow Max inside the compound, which is followed by a standoff with the marauders who are threatening the settlers from outside. Without disrupting the spatial and narrative continuity of the compound standoff, Soda_Jerk cut and composit a diverse range of other samples into the scene. In addition to Lucky Miles and Down Under, they also sample Turkey Shoot (1982, a dystopian horror film), Wentworth (2010s, a prison drama serial), Pauline Hanson: Please Explain (a 2016 documentary), Housos Vs. Authorities (2012, a crass comedy film), Mystery Road (2013, an outback thriller film), My Tehran For Sale (2009, an Iranian-Australian arthouse film), Braveheart (1995, a medieval war blockbuster), Black Balloon (2009, a comedy-drama film) and news footage of Tony Abbott and John Howard. As TERROR NULLIUS Unmixed shows, these samples form a web of cultural and political references that calls attention to how pop culture and politicians propagate xenophobia and to the unethical nature of Australia's refugee detention 
policy.

As the dominant sample of the scene, Mad Max 2's references to the oil crisis and Islamophobic undertones establish the context for the rest of the scene. Mad Max 2 has explicit political connections to late 1970s/early 1980s Western anxieties about the Middle East (Winn). The post-apocalyptic oil scarcity plot reflects the real 1979 oil crisis, and the racial coding of the heroes and villains align with the demonisation of the Middle East (Winn 3). The heroic settlers are all fair-skinned, have clean-shaven uncovered faces, and wear natural, light coloured agrarian clothing such as cream tunics and brown cotton pants (Williams 309). Though played by white actors, Humungus and his marauders are visibly coded as other, with their animal fur, bondage leather, masks and head coverings and punk haircuts (Winn 4). John Stratton likens this civilised/savage binary to the cowboy/Native American tropes of conventional Westerns. Meanwhile, J. Emmet Winn links the marauders with "a negative stereotype of Middle Eastern terrorists and Islamic fundamentalists" (4). In the context of Ayatollah Khomeini's rise to power in Iran, Toadie announcing Humungus as the "the Ayatollah of Rock'n'Rollah!" has clear Islamophobic denotations. Furthermore, the narrative of resource scarcity and invasion by the 'other' reflects a conservative fear of nonwhite immigration (Lewis 24). Max, with his tough, fend-for-himself attitude, reflects a Reaganite hard-line ethos and neoliberal prioritisation of "atomised individuals" over “collective interests" (Mayer and Beattie xii; Winn 7). Mad Max 2's conservative, xenophobic aspects make it fertile ground for Soda_Jerk to subvert into a progressive, proimmigrant commentary.

TERROR NULLIUS subverts Mad Max 2's original meanings, reframing the settlers' compound as a detention centre and the marauders as white nationalists. Soda_Jerk composit a sign onto the establishing shot of the settlers' compound, so the metal door reads "Camp 47/ Reeducation and behaviour modification/ WOOMERA/ your stay here will make you an asset to society." The sign, without the "WOOMERA," is sampled from Turkey Shoot: in that film, Camp 47 is a prison for people who do not conform to the fascist society, and where they are hunted by elites for sport (Shelley 75). Soda_Jerk have replaced the original sign's "WELCOME" with "WOOMERA," thereby likening Australia's migrant detention practices to Turkey Shoot's inhumane fascist regime. This establishing composition shot is followed by crosscuts between Mad Max 2 and Lucky Miles, replacing Max, the icon of conservative tough justice, with Arun and Youssif. The settlers in the compound ready their crossbows defensively as Arun and Youssif approach. Youssif raises his hands in the air: "Under Article One of the United Nations Convention 1951, I seek asylum from the government of 
Australia." The settlers rush out to meet them, but in a defensive rather than welcoming way, brandishing weapons and yelling "put your hands on your head." The scene reconfigures the settlers as detention centre guards, who will not outright harm Arun and Yousiff or turn them away into the desert, but still see them as a threat to be contained. Soda_Jerk's use of fictional sources to address real conflicts is comparable with Godard's mix of narrative cinema and documentary to criticise the inhumanity of Nazi concentration camps, or Arthur Lipsett and Bruce Connor's recasting of scenes of disaster in entertainment films and newsreels alongside WWII footage. All three reflect postmodern ironic and indirect mediations of historical trauma. Instead of directly addressing refugee detention by sampling a news clip or interview, Soda_Jerk edit fictional sources to emphasise the role of popular culture in supporting cultural ideologies. In addition, this moment further demonstrates how Soda_Jerk intensify and update the politics of the original films they sample. In the original Lucky Miles scene, Youssif's plea for asylum is met with a casual "Yeah...okay" from the soldiers who track them down. As Hoskin notes, this "blasé attitude" does not accurately reflect the real authorities" "genuine antipathy" towards undocumented refugees ("Going Walkabout" 20). TERROR NULLIUS' depiction of the settlers treating Arun and Youssif as if they are criminals more accurately reflects refugees' experiences with Australian authorities than Lucky Miles does. By subverting Mad Max 2's xenophobic coding and updating Lucky Miles' representation of immigration authorities, this scene demonstrates that a sample film's politics are brought to the fore when it transforms the original messages of its source material.

As well as replacing Max with Arun and Youssif, the compound scene also subverts the 'other' coding of the villainous marauders by associating them with right-wing politicians and populist white nationalists. Following Arun and Youssif's acceptance into the compound, a composited shot shows Joan Fergusson, the cruel, corrupt prison officer from Wentworth, inside the compound's walls, speaking covertly into a cellphone. "I appreciate your help, as always," she says, her sinister tone amplified by a tense drone sound effect. The camera tracks upward above the compound wall, revealing the mob of marauders approaching. A series of composited shots add extra characters to the mob: two men carrying Australian flags and a blow-up kangaroo (Cronulla riot attendees sampled from Down Under's archival footage); Pauline Hanson (sampled from Pauline Hanson: Please Explain!); and Shazza and the Sunnydale biker gang, stereotypes of white working-class populism from the "inexorably lowbrow, comedically crude" suburban satire, Housos Vs. Authorities (Hoskin, "Look into the Mirror" 26). Later in the scene, we see Ditch, a white supremacist character involved in 
the fictionalised Cronulla riots in Down Under, and a crooked cop wearing a mask from Mystery Road are also part of the gang. These additions subvert Mad Max 2s original politics, aligning the savage, invading, villainous marauders with Islamophobic white nationalists. Casting Hanson and her supporters as a threat is particularly poignant in the context of the Australian government's perception of terrorism as a Muslim migrant issue and negligent approach to home-grown white supremacy (Barton; Karp). TERROR NULLIUS' détournement of Mad Max 2 calls attention to the hypocrisy of xenophobic sentiment, arguing that white nationalists, rather than immigrants, should be scrutinised for their violent hate crimes.

The scene continues to castigate the political right's xenophobia. Soda_Jerk utilise Eisenstein's idea of asynchronous sound, dialectically combining visual footage from Mad Max 2 with famous soundbites by John Howard. TERROR NULLIUS' Toadie announces Humungus as the Ayatollah as per the original Mad Max 2 scene, but when Humungus speaks, his original dialogue is replaced with audio recordings of Howard's response to Tampa in Parliamentary question time on August 27th , 2001. "Whilst this is a humanitarian decent country, we are not a soft touch and we are not a nation whose sovereign rights in relation to who come here will be trampled on," says Humungus in Howard's voice.

Soda_Jerk fabricate continuity, altering the audio to sound as though it is coming through the P.A. system in Humungus' hand and making use of the mask covering Humungus' face to avoid lipsyncing inconsistencies. However, the disconnect between the dystopic villain and Howard's formal political language makes this continuity uncanny. The disconnect produces an intellectual dialectic, which pushes the viewer to synthesise the two concepts and consider Howard's rousing of anti-migrant sentiment for political gain as villainous. Moreover, attributing a conservative politician's voice to a camp, shirtless villain ironically mocks Howard's conservative image.

Humungus continues talking, this time quoting John Howard's federal election campaign speech from October $28^{\text {th }}$, 2001: "We are a generous, open-hearted people, but we will decide who comes to this country and the circumstance in which they come." In addition to referencing the xenophobic response to Tampa and Howard's strategic anti-migrant messaging, Soda_Jerk subtly nod to the Cronulla riots by editing a Southern Cross tattoo onto Humungus's shoulder. In the last two decades, the Southern Cross has become a symbol of "populist sovereignty," which filmmaker Warwick Thornton has compared to the swastika (Johns 352; Buckmaster). Footage of the Cronulla riots shows many white men with the southern cross drawn on their arms or bare torsos. In the wake of the riot, many with white 
nationalist convictions got permanent southern cross tattoos, whilst others who already had the tattoo for more benign reasons opted to get it removed or replaced in fear of being identified as an "Australian redneck" (Evers 192; L. Wong). The Humungus-Howard hybrid is one of the most explicitly political moments in the film, overtly charging conservative politicians' strategic anti-refugee sentiment with fostering white nationalist ideologies and racist violence.

The scene ends with the "revenge" promised by TERROR NULLIUS" tagline. After Humungus-Howard's rant, his gang of marauders jeer. Marzieh (an Iranian woman fleeing persecution in My Tehran for Sale), who is composited onto the settler's barricade, exchanges a worried glance with Arun and Yousif. A moment of solidarity and understanding is shared between the Iranian, Cambodian and Iraqi refugees. As the orchestral score increases in intensity, a settler held hostage by the marauders screams. The settler's original Mad Max 2 dialogue is replaced with the iconic "FREEDOM!" shout from Braveheart, adding yet another anti-imperialist reference. The Feral Kid, from the original Mad Max 2 scene, throws a boomerang, which hits the masked character from Mystery Road fatally in the head. Soda_Jerk cross-cut between a scene of Wez, one of Humungus' marauders, looking down at the body, and a clip from Mystery Road where someone lifts off the man's mask. Soda_Jerk replace the dead man's face with Tony Abbott's, bringing a third conservative politician into their critique. The scene comes to a climax as Wez throws the boomerang, attempting to hit the Feral Kid, but it knocks out Pauline Hanson instead. Ensuring the film's anti-Hanson stance is not lost on anyone, Simon, the dad from The Black Balloon, jumps across the screen with a VB beer in hand, cheering in celebration. The Feral Kid jumps into an underground tunnel and resurfaces in a different setting, which marks the end of the scene. In this finale of the refugee narrative, Soda_Jerk lean into the speculative potential of sample filmmaking, providing a cathartic scene of revenge against the political figures who remain powerful opponents to refugee justice. This radical ending develops the scene from a critique of history and the current status quo, to a call to arms for protest and revolutionary political change.

Significantly, this closing scene has another outsider save Arun and Yousif rather than the settlers, extending Soda_Jerk's critique beyond conservatives to address the left. Though the settlers offer Arun and Youssif protection, it is at the cost of imprisonment in the detention centre. Here, TERROR NULLIUS seems to critique the centrist left who, after all, were the ones to initially implement detention policies in the 1990s (under Hawke and Keating) and fail to fully remove them when they regained power for two terms between 2007 and 2013 (under Kevin Rudd and Julia Gillard). Soda_Jerk have implied dissatisfaction 
with the centrism of the current left political establishment: in an interview with Leo Goldsmith, they describe Whitlam positively as the "most radical left-wing Prime Minister" and criticise his dismissal in 1975 by the monarchy as "as a definitive moment in Australian politics where shit hit the fan and never really stopped raining down." The settlers do not overtly represent Labour politicians in the same way the marauders are literally recast as Hanson, Howard and Abbott, but as the marauders' opponents, the settlers naturally take on the position of the political left. The failure of the settlers to offer freedom, or to even sufficiently defend the refugees from the right, is a subtle but pointed critique of Labour's humanitarian failings. It is also significant that the Feral Kid is the one who defeats Abbott and provokes Wes into attacking Hanson. As Stratton's Mad Max 2 analysis highlights, the Feral Kid is coded as an outsider, affiliated with but not part of the settler community. In having the Feral Kid defend the Asian and Middle Eastern asylum seekers from right-wing politicians, TERROR NULLIUS suggests that the left establishment is ineffective and that radical humanitarian political action comes from accompliceship and solidarity amongst outsiders. This moment resonates with the earlier scene in which the eagle defends the refugees against the white supremacists while the white beach-goers watch impassively. As well as critiquing conservatives, TERROR NULLIUS calls out the apathy of the privileged left and advocates the values of radical affinity and accompliceship discussed in Chapter Four.

This close reading demonstrates how TERROR NULLUS engages in explicit politics, referencing and/or representing real politicians, specific policies and historical events to address current debates. Soda_Jerk employ a combination of sampling strategies to produce this kind of explicit political commentary. Soda_Jerk use media samples directly produced by or associated with politicians and news media, such as Howard's election speech and footage of Hanson from the Pauline Hanson: Please Explain! documentary. Soda_Jerk express their disagreements with Howard and Hanson's political positions by aligning them with fictional villains and representing Hanson and Abbott being struck down. The scene samples archival news footage (Cronulla riot footage), alters fictional samples (changing "WELCOME" to "WOOMERA" on the Turkey Shoot sign), and combine fictional moments to re-enact real events (using the Puberty Blues lifeguard fight with Romper Stomper's Neo-Nazi's to reference the Cronulla riots). In addition to these explicit anti-xenophobia references, the scene's diverse, non-homogenous sampling symbolically advocates the potential of inclusive collaboration amongst diverse communities. In the context of 2018 debates and protest, TERROR NULLIUS shows clear support for abolishing refugee detention and for addressing 
the rise in white nationalist extremism. Significantly, TERROR NULLIUS uses fictional characters to represent collective identities, rather than individuals, to comment on structural dynamics and social imbalances. In contrast to Lucky Miles, where Arun and Youssif have personalities and unique character arcs, in TERROR NULLIUS they are generalised stand-ins for the real Asian and Middle-Eastern migrants affected by political discrimination. Similarly, characters like Romper Stomper's Hando and Housos Vs Authorities Shazza are used to typify white nationalists, without delving into their individual motivations as in the original films. Instead of explaining racism through individual psychology, TERROR NULLIUS provides a systematic analysis that highlights how popular media, historical events and political discourse have shaped cultural attitudes. This systematic focus enables TERROR NULLIUS to highlight the larger causes of xenophobia and direct critique at institutional political forces - politicians and media - rather than isolated individuals. By subverting existing political media, representing specific political events and movements, and focusing on systems rather than characters, TERROR NULLIUS demonstrates how sampling filmmaking techniques can generate explicit political critique.

\section{ANTIPODEAN CAMP IN POSTCOLONIAL POLITICS}

TERROR NULLIUS' engagement with contemporary debates around refugee detention and xenophobia is by no means the film's only political contribution. Without repeating the indepth scene breakdown demonstrated above, I will outline two more key political references to solidify my claims about TERROR NULLIUS' strategies of political engagement. TERROR NULLIUS opening scene is another strong example of referential critique, addressing the struggle for decolonisation and indigenous land rights by sampling audio from the Governor General's controversial dismissal of Whitlam from office in 1975, footage from the 1971 film Walkabout, and the artwork, Aboriginal Anarchy (2012), by Kamilaroi artist Archie Moore. In the scene, the family from Walkabout sit in their Morris Minor car listening to Whitlam's dismissal on their transistor radio. The young boy then spray paints the car door with Moore's work; the anarchist symbol (an 'A' in a circle) in yellow on top of a red and black background, visually mirroring the Aboriginal flag (fig. 12). As mentioned above, Soda_Jerk consider Whitlam's dismissal as a major negative turning point in Australian politics, including "put[ing] an end to the restitution of indigenous land rights that had gained momentum under his leadership" (qtd. in Goldsmith). By beginning the film with this audio sample, Soda_Jerk contextualise their critique in relation to the post-Whitlam era and suggest that contemporary political discourse should not forget the moment the British monarchy 
forcibly removed a progressive leader from office. Combining this audio with Walkabout strengthens the reference to the 1970s progressive, anti-colonial moment in Australian culture. Walkabout was one of the first films to depict a nuanced Aboriginal protagonist and emphasise a first people's perspective on land and colonisation - a political move in the context of the 1970s land rights movement (Barber 2). The Aboriginal Anarchy work connects the dismissal and Walkabout's 1970s context to the present, calling attention to the lack of significant progress on indigenous rights and redress. Comparable to Soda_Jerk's use of sampling to update Lucky Miles' politics, the graffiti version of Moore's artwork updates some of Walkabout's problematic aspects, such as its atavistic representation of Indigeneity (Collins and Davis 143), emphasising Aboriginal agency in an urban/modern context. By opening the film with these references, Soda_Jerk centre anti-colonial sentiment and the struggle for indigenous land rights at the heart of TERROR NULLIUS' political commentary.

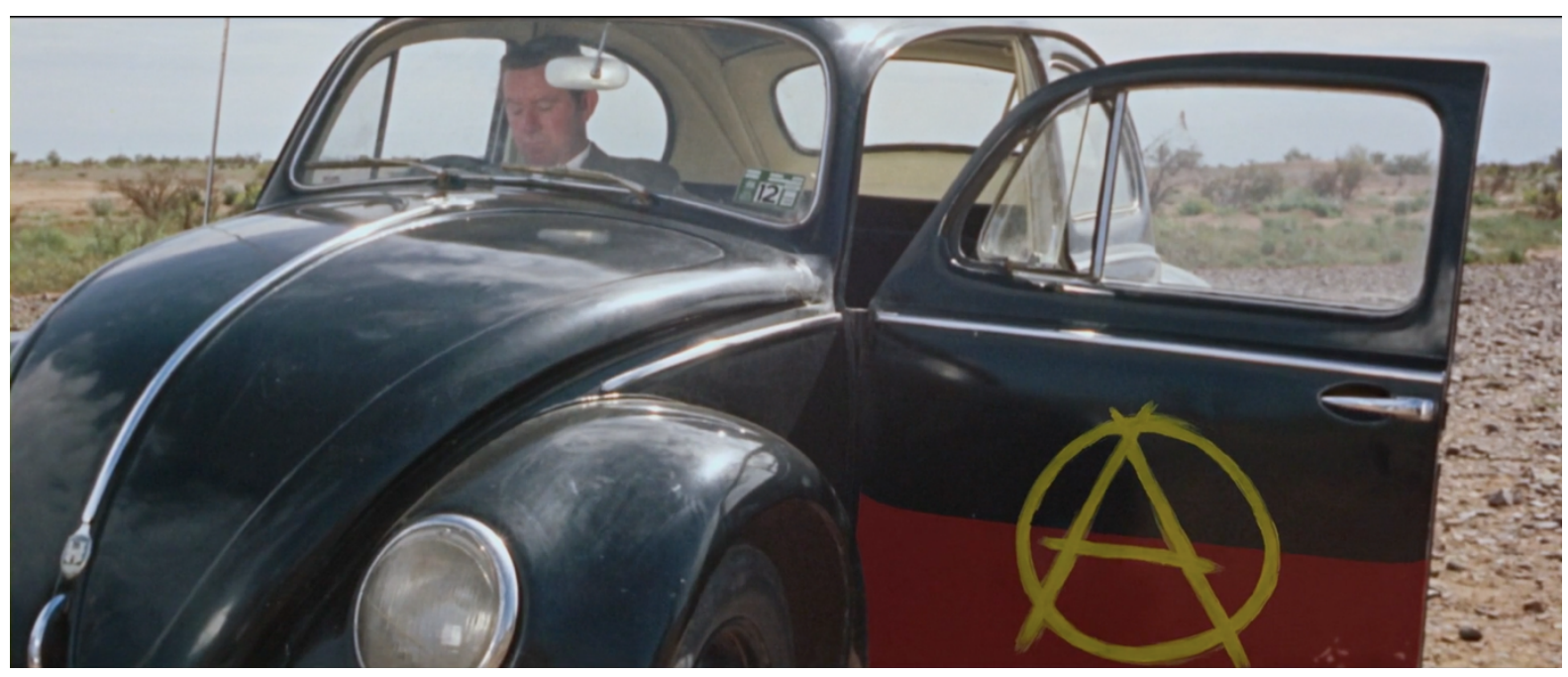

Fig. 12: Archie Moore's Aboriginal Anarchy art is composited onto a scene from Walkabout, from TERROR NULLIUS, Soda_Jerk, 2018.

The Babadook scene - in which Soda_Jerk utilise a queer pride in-joke to parody homophobia- is another important example of referential political critique that demonstrates TERROR NULLIUS' attention to the cultural afterlife of its sample sources. Directly following the Mad Max 2 vignette is a scene that uses the 2014 Australian psychological monster horror The Babadook as its foundation sample. The original film is about a terrifying shadowy form, the Babadook, who haunts Amelia, a suburban widowed mother suffering traumatic grief, and does not have any obvious queer characters or themes. However, when a tumblr post jokingly suggesting the Babadook monster represents suburban queer repression 
became a viral internet meme, the Babadook was transformed into a gay icon (PheasantKelly 82; Hunt; Abad-Santos). Riffing on this queer internet in-joke, Soda_Jerk replace the Babadook with Australian gay icons. As Amelia flips through the Babadook picture book, images of the monster are replaced with a bare-chested photo of camp performer Peter Allen and a drawing of the Babadook wearing pink flamingo glasses, an iconic accessory of drag person Dame Edna Everage. Queer figures haunt Amelia'a house; Carol (Cate Blanchette from 2015 lesbian romance, Carol) is composited onto the couch next to Amelia's son Sam; in the basement, Amelia's late husband's personal belongings are replaced with gay teen musician, Troye Sivan's record, Ian Thorpe's camp Sports Illustrated photoshoot and framed photos of Benjamin Law, a gay writer, and Kylie Kwong, a gay celebrity chef. The gay dance club superimposed onto Amelia's living room, complete with Kylie Minogue pop song, "Can't Get You Out of My Head," pushes Amelia's homophobia to breaking point: "this is my house!" she screams hysterically. This ridiculous queer parody of The Babadook speaks directly to those already familiar with the meme, i.e. those engaged with online queer communities.

Moreover, this queering of The Babadook critiques the same-sex marriage debate occurring in Australian politics at the time of TERROR NULLIUS' production. In 2017, the Liberal government held a nationwide postal survey to determine popular opinion on legalising same-sex marriage. Pro-marriage demonstrations utilised the Babadook imagery, with signs reading "the Babadook would vote yes" and Babadook costumes adorned with Dame Edna's iconic pink flamingo sunglasses (Connellan). Though the outcome of the survey was in favour of marriage equality and it was soon legalised, the queer community criticised survey for treating an equal rights issue as a matter of public opinion and subjecting the queer community to the 'No' Campaign's scrutiny and discrimination (Ecker et al 293). By substituting Amelia's fear of the Babadook with a fear of queer characters, Soda_Jerk reference a queer Australian in-joke and mock the conservative opposition towards the samesex marriage legislation. This scene provides a strong example of how TERROR NULLIUS utilises the reception context or cultural afterlife of media texts to comment on specific Australian political contexts.

These examples of TERROR NULLIUS using sampling to reference historical events and contemporary debates in Australian politics tell us that national cinema is deeply intertwined with national culture, but that these connections are complex and nonhomogeneous. TERROR NULLIUS relies on fictions to engage with reality: while Soda_Jerk sample some direct political media (John Howard's election speech audio, Cronulla riots 
news footage, Whitlam's dismissal audio) they always contextualise that media through fictional film and television shows. These fictional texts provide contextual meaning by representing past events (Down Under's retelling of the Cronulla riots) or reflecting discourse of the time they were made (Walkabout's anti-colonial ideology). TERROR NULLIUS shows that a film also accrues meaning after its release, using The Babadook as a reference to its queer cultural afterlife. The way TERROR NULLIUS subverts Mad Max 2's original conservative codings and updates Lucky Miles and Walkabout to align with contemporary progressive representation politics testifies to national cinema's internal diversity and changing cultural understandings. The type of politics TERROR NULLIUS surfaces - ultimately questions about identity, rights, belonging and historic injustice suggest that national cinema is particularly attuned to social and legal politics. TERROR NULLIUS affirms Mette Hjort and Scott Mackenzies's claim that national cinema is a "loci of debates about a nation's governing principles, goals, heritage and history" rather than a single, static representation of culture (4), by using Australian films to reference past political debates and reshaping them to engage in contemporary ones.

Furthermore, TERROR NULLIUS' sample form, ironic humous and indirect references seem to reflect a particularly Australian approach to culture which aligns with Nick Perry's theory of “Antipodean camp”. In Dominion of Signs, Perry observes a brand of postcolonial, postmodern nationalism apparent in both New Zealand and Australian popular culture $(6,95)$. Borrowing Susan Sontag's theory of camp as a "sensibility...that is alive to a double sense" of meaning and takes pleasure in "pure artifice" (281), Perry describes this nationalism as "antipodean camp", distinguished by "sardonic distancing and stylised subversion" and "a receptivity to the exposure of . . . culture as artifice" (95). This theory engages with the notion that Australia and New Zealand, as postcolonial settler nations, lack a unique sense of identity because so much of their cultural material and practices are imported from Britain and (post-WWII) the United States. Perry does not deny this narrative of cultural import but argues that Antipodean creators read and reproduce these cultural products, "play[ing] the gap between cosmopolitan and local" (120). This pastiche-based "nationalism of sorts", is seemingly "agnostic" or "ambivalent" rather than patriotic, yet "tends to be in collusion with the pattern of local readings" thus affirms a unique national culture $(6,12)$. As a form of cultural production that reads and recodes imported material to highlight artifice, remix sampling can be understood as a quintessentially antipodean practice. The scenes described above show how Soda_Jerk replicate this camp process of appropriation and adaptation, forging their own unique style and political meaning from the 
combination of pre-existing source material. Antipodean camp theory explains why Soda_Jerk style of sample filmmaking is particularly suited to Australia cultural critique, and why TERROR NULLIUS has resonated with Australian audiences.

Viewing TERROR NULLIUS through the framework of antipodean camp clarifies the ironic tension between Soda_Jerk's critique and celebration of Australia. In the previous chapter, I discuss irony as a form of cyborg plurality, arguing that TERROR NULLIUS' unexpected sample combinations make viewers alert to multiple possible interpretations, even if they do not have the background knowledge to access all those interpretations. By foregrounding this ironic plurality, TERROR NULLIUS challenges the expectations for narrative coherence and more broadly, undermines Western totalising logics that rely on a conclusive, all-encompassing reading. However, for viewers who do have the Australian cultural background to interpret TERROR NULLIUS' referential meanings, irony takes on an additional function as an in-joke that privileges an Australian audience. As demonstrated in the analysis above, each scene contains layers of historical, political and pop culture references, and much of the humour comes from recognising the irony of those references. Employing "local readings, inflections, and uses of derivative cultural material" associated with antipodean camp (Perry 95), TERROR NULLIUS provides a critique of Australia that only those with Australian cultural knowledge can access. Significantly, TERROR NULLIUS' commentary on explicit political issues speaks directly to Australians, who, unlike international audiences, actually have the civic power to make political change around refugee detention, indigenous land reparations and LGBTQ rights. In light of Chapter Four's discussion on how TERROR NULLIUS discourages cancel culture in favour of practical transformation, I interpret TERROR NULLIUS' political in-jokes as a form of 'calling-in' those with the capacity to change, rather than 'calling out' and shaming Australia on an international stage. After all, despite their critique of Australian culture and politics, Soda_Jerk describe TERROR NULLIUS as a "love letter to Australian cinema" and, by extension, the cultures that create it (qtd. in Newall). Unlike the avant-garde found-footage filmmakers who subverted clips with a cynical ambivalence and more like the fans whose comedic remixes are imbued with admiration, Soda_Jerk's subversion of Australian media comes from a place of camp nationalism. 


\section{CONCLUSION: BETWEEN POLITICAL AMBITIONS AND ACTIVIST PRAXIS}

This thesis shows that TERROR NULLIUS is a sophisticated political text that expresses subversive and progressive messages through its form, representations and references. Analysing TERROR NULLIUS in relation to early twentieth-century compilations, post-war avant-garde found-footage films and internet remix videos films highlights the subversive nature of its sampled form. Sampling interrupts media hegemony by challenging copyright and enabling consumers with minimal resources to become creators. Many sample films also unsettle representation norms by blurring the boundaries between high and low cultural media and fiction and non-fiction texts. Soda_Jerk actively emphasise these anticorporate, anti-hegemonic features of sampling, brazenly flexing their rights to fair use and creating humourous yet critical détournements of mainstream media. Comparing TERROR NULLIUS with other historiographic sample films - The Fall of the Romanov Dynasty, Histoire(s) du Cinema, Camera Natura, Outback and Beyond, and The White Ghosts Sailed In - illuminates its postmodern and postcolonial approach to media archives and history. TERROR NULLIUS shapes fiction and nonfiction sources from various time periods into historical constellations that upset the linear, positivist historical discourse that underpins the Australian colonial mythology of terra nullius. Subversive editing strategies are integral to TERROR NULLIUS' media détournements and critique of colonial history. TERROR NULLIUS combines Soviet and Third Cinema dialectical montage techniques, the uncanny continuity editing seen in Surrealism films, and a collage approach to digital compositing to craft individual samples into sequences that defy conventional representation and foster critical consciousness. Reading TERROR NULLIUS in concert with "A Cyborg Manifesto" shows how TERROR NULLIUS' form and representations come together to express transformative, intersectional, pluralist values relevant to contemporary international identity politics. Meanwhile, unpacking TERROR NULLIUS' samples' cultural and historical references reveals its critique of explicit issues in Australian politics, including white nationalism, refugee detention, indigenous land rights and LQBTQ discrimination. With regard to sample filmmaking as a form, TERROR NULLIUS advances strategies of past sample filmmakers and models how future sample filmmakers might use them to political effect.

I have proven that TERROR NULLIUS promotes various radical political messages whether those messages translate into activist praxis or social change is another question. As Anthony Killick notes in his introduction to The Routledge Companion to Cinema and 
Politics's section on cinema, activism and opposition, "activism" is defined by its ends; if it does not produce tangible real-world change, it is an "empty signifier" (77). Killick warns that the "contemporary landscape of video activism is formed by the shifting relation between cultural production and domestic as well as geo-politics, with video activists carving their way through in as best a way they can according to their relative prohibitions" (77). TERROR NULLIUS's exhibition reflects some of these prohibitions. I opened this thesis with a quote from a review by Ben Juers: "simply watching and supporting [TERROR NULLIUS] feels vaguely like activism." Juers goes on to argue, however, the fallacy of this reaction: while it depicts them, TERROR NULLIUS has not actually "spark[ed] any riots" or produced quantifiable social change. Juers links this to the limitations of TERROR NULLIUS' exhibition, noting that the art gallery "atmosphere is unlikely to be conducive" to the "incendiary" attitudes TERROR NULLIUS appears to agitate. The limits of the art gallery environment also apply to festivals, which offer "the possibility of social unruliness and limited rebellion but always within the constraints set by some larger authority that permits it to take place" (Zielinski; also see Tascón 42). Thus far, TERROR NULLIUS' exhibition has been largely limited to art galleries and film festivals (although there are some exceptions, notably it recently streamed online for free as part of a covid-19 lockdown programme, run by Soda_Jerk's local micro-cinema). Resultingly, its audience has been restricted to those with the inclination, access, time and (in the case of festivals) money to attend art cinema screenings, i.e. a predominantly urban, middle-class, liberal cultural elite (Tascón 212), to whom TERROR NULLIUS' progressive messages have perhaps, (as Tara Heffernan notes) a placating effect rather than a challenging or agitative one. In this light, TERROR NULLIUS might simply represent what Arnold Gehlen calls the "institutionalization of the revolution" within the art world, in which rebellious themes are aestheticised and depoliticised (Magerski 82).

The discrepancy between political and activist cinema reflects a wider tension within the festival/gallery distribution model of political art cinema. When asked whether they plan to put TERROR NULLIUS “online for free" like some of their past works, Soda_Jerk replied that they were "committed to touring this work IRL [in real life]" to foster "rowdy," communal forms of spectatorship (qtd. in Goldsmith). However, the prestigious art galleries and film festivals TERROR NULLIUS has exhibited at hardly classify as "rowdy," suggesting Soda_Jerk may have other motivations for not providing open access to TERROR NULLIUS, such as funding. Sampling enables Soda_Jerk to bypass costs of filming original footage but planning, sourcing footage and editing a 54-minute sample film is still a mammoth task, 
amounting to months and months of full-time labour for two people. TERROR NULLIUS was made possible by the Ian Potter Foundation's \$100,000 Moving Image Commission grant. Grants from such philanthropic institutions often come with the expectation of exhibiting in art institutions; the Moving Image Commission brief explicitly requests a "gallery-based outcome." Meanwhile, festival and galleries often require that films not be available online, as people are less likely to go out of their way to attend (and pay for) a screening if they can watch it for free at home. Moreover, to acquire further grants and maintain careers as experimental filmmakers, artists like Soda_Jerk need to prove their success according to metrics recognised by art institutions: being exhibited in prestigious galleries and festivals.

TERROR NULLIUS', sampled nature heightens the problematic tension of not distributing it online for free. As artists who rely on footage being available to download and rework, Soda_Jerk's decision not to provide open access to TERROR NULLIUS undermines their radical advocacy of fair use and free culture. However, aside from the funding impracticalities, simply uploading TERROR NULLIUS online immediately would not necessarily improve its accessibility issues. Steven Presence notes that "with so much content competing for attention. . . on video sharing sites it is difficult both for video-activists to distinguish themselves and for audiences to locate their work" (104). TERROR NULLIUS, like most low-budget art cinema, relies on festival and galleries for publicity and circulation. Without the programming and surrounding reviews and interviews of the art cinema institution, TERROR NULLIUS would risk getting lost in the internet void. Indeed, it is unlikely I would have found the film and had the impetus to study it without seeing it and meeting Soda_Jerk at the New Zealand International Film Festival. While the internet has opened up new potential for exhibiting political sample films, how to fund and promote them is still a problematic issue (Killick 77).

A second factor that limits TERROR NULLIUS' activist potential is the complexity of its politics. Generally speaking, films that mobilise people and effect real widespread change, have transparent, didactic political messages (Torchin 124). The fact that this entire thesis is dedicated to unpacking TERROR NULLIUS' politics is testament to its complexity and openended-ness. This is not to say TERROR NULLIUS would be more political if its messages were obvious and simple. As I discuss recurringly throughout this thesis, citing Brecht, Eisenstein, Buñuel, Debord, and Solanas and Getino: films that challenge familiar forms of media communication and do not deliver easy answers necessitate active spectatorship and foster critical consciousness. Many of TERROR NULLIUS' messages are necessarily complex and would be less engaging if delivered didactically. Moreover, as I discuss in 
chapters Two and Four, a key part of TERROR NULLIUS' postmodern historical discourse and ironic cyborg politics is encouraging viewers to be alive to the fact that each sequence contains multiple valid interpretations, even if the viewer cannot understand them all. Complexity, in itself, does not prohibit TERROR NULLIUS from being an activist film. However, for audiences who are only able to view the multi-layered, fast-paced film once in a live theatre, its complex messages are difficult to fully comprehend. I was provoked to write this thesis after watching TERROR NULLIUS at the NZIFF and being moved yet bewildered by its politics. Without Soda_Jerk granting me private access to a digital copy, enabling me to play sequences over and over, pause frames to detect composited layers, and use the credits to identify samples, this research would have been impossible. While some aspects of TERROR NULLIUS politics certainly translate to first-time viewers, its full potential is hampered by the inability to rewatch it online.

One way Soda_Jerk could address TERROR NULLIUS' accessibility problem without hindering their festival distribution is releasing it online now that it has largely outdated the new release festival circuit. Although, the chance of viewers actively seeking out an experimental film two years after originally seeing it is unlikely. Plus, delayed exhibition means the film's specific references to the 2018 political climate would lose their contemporary relevance. Another potential solution could be giving festival viewers a private link to re-watch the film again online, thereby providing them with the ability to come back to particular moments and unpack them as I have. Perhaps assuming distribution is the artists' responsibility is limiting; instead, viewers could take a more active role sharing TERROR NULLIUS within their communities. While Soda_Jerk are resistant to uploading TERROR NULLIUS online, they are eager to show TERROR NULLIUS in "micro-cinemas, academic conferences, community centres, queer spaces [and] town halls" (qtd. in Goldsmith) and seem receptive to requests to screen the film freely in a live community-oriented setting. Many of TERROR NULLIUS' messages will remain politically relevant in the coming decade and, through broader distribution, it still has the potential to function as an activist film.

One final reflection: TERROR NULLIUS models anti-establishment strategies that can be employed by future political sample filmmakers, but anti-establishment does not necessarily equate to socially progressive. This thesis has focused on sample films with left, progressive politics: from Esfir Shub's Marxist representation of the Russian revolution, to Histoire(s) du Cinéma's horror at the holocaust, to Victor De Meer's light mockery of the current Australian Prime Minister in his Scott Morrison/Hot Chocolate speech remix. Historically, sample filmmaking has been dominated by left politics, reflecting the broader 
liberal tendencies of the modern art world (Magerski 84). However, reworking mainstream media to mock the political opposition and create radical messages is not the exclusive prerogative of the political left. The last few years have seen a rise in an alt-right internet culture that uses many of the same subversive remix strategies as TERROR NULLIUS to propagate discriminatory politics, misinformation and hate speech (Sobande 156). While an alt-right sample film is unlikely to circulate in art festivals, memes and remix videos can spread virulently online and as, as recent U.K. and U.S. elections indicate, perhaps have a more significant real-world impact than art cinema(Sobande 157). Soda_Jerk are alert to this issue:

as the current US presidential situation has made crushingly obvious, mainstream image culture is a principal substrate of contemporary politics. Being able to translate, transform and circulate images has never been more politically important than it is at this moment (qtd. in Capaldi).

Hello Dankness, Soda_Jerk's upcoming film, scheduled to be released at the Adelaide film festival in October 2020, "engages with the profound impact the internet has had on the constellation of collectivity, political extremism, the news media, and the nation state" (qtd. in Maunder). As the alt-right continues to increasingly utilise sampling logics, Soda_Jerk, and other leftist sample filmmakers' work will become ever more valuable. TERROR NULLIUS shows us that sample films are capable of expressing complex progressive ideas, both through content and form. In a world where remix culture is being weaponised by the alt-right, ensuring that TERROR NULLIUS and other politically progressive sample films can fulfil their activist potential has high stakes. 


\section{WORKS CITED}

Abad-Santos, Alex. "How the Babadook Became the LGBTQ Icon We Didn't Know we Needed.” Vox, 2017, www.vox.com/explainers/2017/6/9/15757964/gay-babadooklgbtq. Accessed 1 Mar. 2020.

Abbott, Tony. "Protecting Our Borders." Lowry Institute, Distinguished Speaker Series, 2011.

Adamowicz, Elza. "Toward a Definition of Surrealist Collage." 1998. The Ends of Collage, edited by Yuval Etgar, Luxembourg and Dayan, 2017, pp. 88-95.

The Adventures of Priscilla, Queen of the Desert. Directed by Stephan Elliot. Polygram Filmed Entertainment, 1994.

After the Facts. Directed by Karen Pearlman. [in]Transition: Journal of Videographic Film \& Moving Image Studies, vol. 6, no. 4, 2019.

Alea, Tomás Gutiérrez. “The Viewer's Dialectic.” Translated by Julia Lesage, Jump Cut: A Review of Contemporary Media, vol 29, 1984, pp. 12-21.

An Andalusian Dog. Directed by Luis Buñuel. 1929.

Andersson, Jonas. "For the Good of the Net: The Pirate Bay as a Strategic Sovereign." Culture Machine, vol. 10, 2009.

Angeloro, Dan. “Thoughtware: Contemporary Online Remix Culture.” SynCity: Remixing Three Generations of Sample Culture, edited by Mark Titmarsh, d/Lux/MediaArts, 2006, pp. 19-25.

Angels of Sin. Directed by Robert Bresson. Synops, 1943.

Appiah, Kwame Anthony. "Is the Post- in Postmodernism the Post- in Postcolonial?" Critical Inquiry, vol. 17, no. 2, 1991, pp. 336-357.

Armes, Roy. Third World Film Making and the West. University of California Press, 1987. Ashcroft, Bill et al. Post-Colonial Studies Reader. Routledge, 1994.

Aslan, Alice. Islamaphobia In Australia. Agora Press, 2009.

Aumont, Jacques. Montage Eisenstein. 1979. Translation by Lee Hildreth et al., Indiana University Press, 1989.

---. "Mortal Beauty." The Cinema Alone: Essays on the Work of Jean-Luc Godard, 19852000, edited by Michael Temple and James S. Williams, Amsterdam University Press, 2000, pp. 97-112.

Avatar. Directed by James Cameron. 20 $0^{\text {th }}$ Century Fox, 2009.

The Babadook. Directed by Jennifer Kent. Causeway Films, 2014. 
The Ball. Directed by Wilhelm Thiele. Les Films Marcel Vandal et Charles Delac, 1931.

The Back of Beyond. Directed by John Heyer. Shell Film Unit, 1954.

Barber, Susan. "Walkabout: A Timeless Cross-Cultural Journey.” Quarterly Review of Film and Video, 2020, pp. 1-15, DOI: 10.1080/10509208.2020.1731275.

Barnett, Chelsea. “TERROR NULLIUS.” History Australian, vol. 17, no. 1, 2018, pp. 190191.

Baron, Jaimie. The Archive Effect: Found Footage and Audiovisual Experience of History. Routledge, 2013.

Barton, Greg. “Australia Isn't Taking the National Security Threat From Far-right Extremism Seriously Enough.” The Conversation, 2019, theconversation.com/australia-isnt-taking-the-national-security-threat-from-far-rightextremism-seriously-enough-122717. Accessed 1. Mar. 2020.

Barthes, Roland. "Historical Discourse." 1967. Introduction to Structuralism, edited by Michale Lane and translated by Peter Wexler, Basic Books, 1970, pp. 145-155.

Batrouney, Trevor. "From 'White Australia' to Multiculturalism: Citizenship and Identity." Arab-Australians Today: Citizenship and Belonging, edited by Ghassan Hage, Melbourne University Press, 2002, pp. 37-63.

Battleship Potemkin. Directed by Sergei Eisenstein. Mosfilm, 1927.

Begin, Paul. "Buñuel, Eisenstein, and the 'Montage of Attractions': An Approach to Film in Theory and Practice” Bulletin of Spanish Studies, vol. 83, no. 8, 2006, pp. 11131132.

Benjamin, Walter. Illuminations. 1955. Edited by Hannah Arendt and translated by Harry Zohn, Jonathan Cape, 1970.

---. The Origins of German Tragic Drama. 1928. Translated by John Osborne, London NLB, 1977.

Benshoff, Harry and Sean Griffin. America on Film: Representing Race, Class, Gender, and Sexuality at the Movies. John Wiley \& Sons, 2011.

Bergland, Renée. The National Uncanny: Indian Ghosts and American Subjects. University Press of New England, 2000.

Berliner, Todd and Cohen, Dale J. "The Illusion of Continuity: Active Perception and the Classical Editing System.” Journal of Film and Video, vol. 63, no. 1, 2011, pp. 4463.

Bhabha, Homi K. The Location of Culture. 1994. Routledge, 2012.

Biddle, Jennifer L. and Tess Lea. "Hyperrealism and Other Indigenous Forms of 'Faking It 
with the Truth."' Visual Anthropology Review, vol. 43, no. 1, 2018, pp. 5-14.

The Birth of a Nation. Directed by D. W. Griffith. David W. Griffith Corp., 1915.

The Black Balloon. Directed by Elissa Down. Icon Entertainment Interntional, 2009.

Blade Runner. Directed by Ridley Scott. Shaw Brother Studios, 1982.

Blainey, Geoffrey. "Drawing Up a Balance Sheet of Our History.” Quadrant, vol. 37, no. 78, 1993, pp. 10-15.

BMX Bandits. Directed by Brian Trenchard-Smith. Nilsen Premiere, 1983.

Boon, Marcus. In Praise of Copying. Harvard University Press, 2010.

Borschke, Margie. "Rethinking the rhetoric of remix." Media International Australia Incorporating Culture and Policy, no. 141, 2011, pp. 17-25.

Braveheart. Directed by Mel Gibson. Icon Productions, 1995.

Brett, Simone interview with Tracey Moffatt. Tracey Moffatt: My Horizon, edited by

Nathalie King, Thames and Hudson, 2017, pp. 113 and 140-141.

Brettschneider, Marla. "Queer Intersectionalities in Politics.” Oxford Research

Encyclopedias, 2019, doi: 10.1093/acrefore/9780190228637.013.1266.

Bridges, Christopher and Peter Mather. "Joining the Struggle: White Men as Social Justice

Allies.” Journal of College and Character, vol. 16, no. 3, 2015, pp. 155-168.

Brøvig-Hanssen, Ragnhild and Aram Sinnreich. "Do You Wanna Build a Wall?

Remix Tactics in the Age of Trump." Popular Music and Society, 2019, DOI:

10.1080/03007766.2019.1650990.

Brown, Katherine Emery. "The Cyborg in Pieces: Gender Identity in Her and Ex Machina." The Journal: MALS At Dartmouth, Fall 2015, pp. 27-38.

Bryson, Valerie. Feminist Political Theory. Palgrave Macmillan, 2016.

Buckmaster, Luke. "Crocodile Dundee was sexist, racist and homophobic. Let's not bring that back." The Guardian, 2018. www.theguardian.com/film/2018/jan/23/crocodiledundee-was-sexist-racist-and-homophobic-lets-not-bring-that-back. Accessed 1. Mar. 2020.

---“Teenage Kicks Review - A Compelling New Voice in Queer Australian Cinema.” The Guardian, 2016, www.theguardian.com/film/2016/jun/11/teenage-kicks-review-acompelling-new-voice-in-queer-australian-cinema. Accessed 1. Mar. 2020.

---. "Terror Nullius review - dazzling, kinetic, mishmashed beast of an Australian film." The Guardian, 2018, www.theguardian.com/film/2018/mar/20/terror-nullius-reviewdazzling-kinetic-mishmashed-beast-of-an-australian-film. Accessed 1. Mar. 2020.

---. "Warwick Thornton: Racists have ruined the Southern Cross for everyone." The 
Guardian, 2017, www.theguardian.com/film/2017/jun/07/warwick-thornton-racistshave-ruined-the-southern-cross-for-everyone. Accessed 1. Mar. 2020.

Buffy vs Edward: Twilight Remixed. Directed by Jonathan McIntosh, 2009.

Bulbeck, Chilla. “(White) Feminism and Foreigners: My Quest for Connection-Musings Spurred by the Festschrift in my Honour.” Australian Feminist Studies, vol. 25, iss. 66, 2010, pp. 493-503.

Bull-Clark, Frazer. “TERROR NULLIUS - An Interview with Soda_Jerk.” Four Three Film, 2018, fourthreefilm.com/2018/08/terror-nullius-an-interview-with-soda_jerk/. Accessed 1 Mar. 2020.

Buñuel, Luis. My Last Sigh. Knopf, 1983.

Burgess, Jean. “'All Your Chocolate Rain Are Belong to Us'? Viral Video, YouTube and the Dynamics of Participatory Culture." The Video Vortex Reader: Responses to YouTube, edited by Geert Lovink and Sabien Nierderer, Institute of Network Cultures, 2008, pp. 101-109.

Butler, Judith. Gender Trouble: Feminism and the Subversion of Identity. 1990. Routledge, 2011.

Camera Natura. Directed by Ross Gibson. 1985.

Capaldi, Eleanor. "Soda_Jerk on TERROR NULLIUS.” The Skinny, 2019, www.theskinny.co.uk/film/interviews/soda_jerk-on-terror-nullius. Accessed 1 Mar. 2020.

Carol. Directed by Todd Haynes. Studio Canal, 2015.

Carr, David. Time, Narrative and History. Indiana University Press, 1991.

Carroll, Tamar W. "Intersectionality and Identity Politics: Cross-Identity Coalitions for Progressive Social Change.” Signs: Journal of Women in Culture and Society, vol. 42, no. 3 2017, pp. 600-607.

Cerwonka, Allaine. Native to the Nation: Disciplining Landscapes and Bodies in Australia. University of Minnesota Press, 2004.

Christiansen, Steen. "Metamorphosis and Modulation: Darren Aronosfky's Black Swan." Post-Cinema: Theorizing 21 st-Cenutry Film, edited by Shane Denson and Julia Leyda, REFRAME Books, 2016, pp. 514-537.

Chung, Sheng and Michael Kirby. "Media Literacy Art Education: Logos, Culture, Jamming, and Activism." Art Education, vol. 62, no. 1, 2009, pp. 34-39.

Collins, Felicity and Therese Davis. Australian cinema after Mabo. Cambridge University 
Press, 2004.

Collins, Jock. "Sydney’s Cronulla Riots: the Context and Implications." Lines In The Sand: The Cronulla Riots, Multiculturalism and National Belonging, edited by Greg Noble, Institute of Criminology Press, 2006, pp. 27-44.

Connellan, Shannon. "These are the best signs from Australia's pro-marriage equality rallies." Mashable, 2017. www. mashable.com/2017/09/10/australia-marriageequality-rally-signs/. Accessed 1 Mar. 2020.

Conor, Liz and Jane Lydon. "Double Take: Reappraising the Colonial Archive." Journal of Australian Studies, vol. 35, no. 2, 2011, pp. 137-143.

Constable, Catherine. "Postmodernism and Film." The Cambridge Companion to Postmodernism, edited by Steven Connor, Cambridge University Press, 2004, pp. $43-$ 61.

Cooke, Grayson. "Performing archival remix in Outback and Beyond." International Journal of Performance Arts and Digital Media, vol. 11, no. 1, 2015, pp.100-115.

Coppa, Francesca. “An Editing Room of One's Own: Vidding as Women's Work.” Camera Obscura: Feminism, Culture, and Media Studies, vol.. 26, no. 2, 2011, pp. 123-130.

Cox, David. “Skippy and the Kuleshov Effect: Soda Jerk's Terror Nullius.” Pure Shit Australian Cinema, 2018, www.pureshitauscinema.com/critiques/terror_nullius.html. Accessed 1. Mar. 2020.

Crittenden, Roger. Film and Video Editing. Routledge, 1996.

Crosby, Raphaella Kathryn. (2019) "Pauline Hanson, Personality, and Electoral Fortunes." The Rise of Right-Populism, edited by Bligh Grant, Tod Moore and Tony Lynch, Springer, 2019, pp. 103-142.

Crossley, Michele L. "Narrative Psychology, Trauma and the Study of Self/Identity." Theory \& Psychology, vol. 10, no. 4, 2000, pp. 527-546.

Dall'Asta, Monica and Alessandra Chiarini. "Found Footage: Women Without a Movie Camera."Feminist Media Histories, vol. 2, no. 3, 2016, pp. 110, DOI: $10.1525 / \mathrm{fmh} .2016 .2 .3 .1$.

Debord, Guy. "Definitions.” Internationale Situationniste, no. 1, 1958. Translated Ken Knabb, Situationist International Online, www.cddc.vt.edu/sionline///si/is1.html. Accessed 1 Mar. 2020.

---. The Society of the Spectacle. 1967. Translated by Kenn Knabb. Bureau of Public Secrets, 2014.

Derrida, Jacques, translated by Eric Prenowitz. "Archive Fever: A Freudian Impression.” 
Diacritics, vol. 25, no. 2, 1995, pp. 9-63.

Di Rosso, Jason. “TERROR NULLIUS Review: Controversial Australian Film Offers a Radical Critique of the Nation." ABC News, 2018, www.abc.net.au/news/2018-03-

23/terror-nullius-review-jason-di-rosso/9576730. Accessed 1 Mar. 2020.

Do You Want to Build A Wall? Donald Trump (Frozen Parody). Derrick Watts and The Sunday Blues, 2016. www.youtube.com/watch?v=GVN17U3Vg34. Accessed 1 Mar. 2020.

Dobson, Chris. "GDFF: TERROR NULLIUS.” Take One, 2019, takeonecinema.net/2019/gsff-terror-nullius/. Accessed 1 Mar. 2020.

Down Under. Directed by Abe Forsythe. Emu Creek Pictures, 2016.

Downes, Briony. “Ian Potter Cultural Trust withdraws promotional support for Soda_Jerk's TERROR NULLIUS.” Art Guide Australia, 2018, artguide.com.au/ian-potter-culturaltrust-withdraws-promotional-support-for-soda_jerks-terror-nullius. Accessed 1 Mar. 2020.

The Dreyfus Affair. Directed by Francis Doublier, Lumière, 1898.

Dunn, Kevin M. "Performing Australian Nationalisms at Cronulla." Lines In The Sand: The Cronulla Riots, Multiculturalism and National Belonging, edited by Greg Noble, Institute of Criminology Press, 2006, pp. 76-95.

Dyshlyuk, Liubov and Anastasia Kostina. "Esfir Shub: Selected Writings." Feminist Media Histories, vol. 3, no. 2, 2016, pp. 11-28.

Ecker, Saan, Ellen Riggle, Sharon Rostosky and Joanne Byrnes et al. "Impact of the Australian marriage equality postal survey and debate on psychological distress among lesbian, gay, bisexual, transgender, intersex and queer/questioning people and allies." Australian Journal of Psychology, vol. 71, no. 3, 2019, pp. 285-295.

Edwards, Gwynne. The Discreet Art of Luis Buñuel: A Reading of His Films. Boyars, 1982. Eisenstein, Sergei. Film Form: Essays in Film Theory. Edited and translated by Jay Leyda, Harcourt Brace and World, 1941.

Elder, Catriona. Being Australian: Narratives of National Identity. Allen and Unwin, 2007. Elsaesser, Thomas. "Subject Positions, Speaking Positions: From Holocaust, Our Hitler, and Heimat to Shoah and Schindler's List." The Persistence of History, edited by in Vivian Sobchack, Routledge, 1996, p. 145-183.

Etgar, Yuval, editor. The Ends of Collage. Luxembourg and Dayan, 2017.

Evers, Clifton. “'The Local Boys': Violence, Care, Masculinity and the Riots.” Lines In The Sand: The Cronulla Riots, Multiculturalism and National Belonging, edited by Greg 
Noble, Institute of Criminology Press, 2006, pp. 185-200.

Ex-Machina. Directed by Alex Garland. Film4, 2014.

The Fall of the Romanov Dynasty. Directed by Esfir Shub. Goskino, 1927.

Fletcher, Alex. "Late Style and Contrapuntal Histories: The Violence of Representation in Jean-Luc Godard's Le Livre d'image.” Radical Philosophy vol. 2, no. 4, 2019, pp. 5972.

Flitterman-Lewis, Sandy. "Surrealist Cinema: Politics, History, and the Language of Dreams.” American Imago, vol. 50, no. 4, 1993, pp. 441-456.

Follows, Stephen and Alexis Kreager. Cut Out of the Picture: A Study of Gender Inequality Amongst Film Directors in the U.K. Film Industry. Directors U.K., 2016.

Forrest Gump. Directed by Robert Zemeckis. Wendy Finerman Productions, 1994.

Foster, Hal. Compulsive Beauty. The MIT Press, 1993.

--. Postmodern Culture. Pluto Press, 1985.

---. "Survey." Pop, edited by Mark Francis and Hal Foster, Phaidon Press, 2005, pp. $16-41$.

Foucault, Michel. The Archaeology of Knowledge and The Discourse on Language. 1969. Translated by A. M. Sheridan Smith, Pantheon Books, 1972.

Freud, Sigmund. The Standard Collection of the Complete Psychological Works of Sigmund Freud. Edited and translated by James Strachey Macmillan, 1964.

Friedersdorf, Conor. "The Destructiveness of Call-Out Culture on Campus." The Atlantic, 2017, www.theatlantic.com/politics/archive/2017/05/call-out-culture-is-stressing-outcollege-students/524679/. Accessed 1 Mar. 2020.

Frost, Andrew. "Forever Now: What sound or video would you send into space?" The Guardian, 2013, www.theguardian.com/culture/australia-cultureblog/2013/jul/12/golden-record-voyager-forever-now. Accessed 1 Mar. 2020.

Ghaddar, J.J. "The Spectre in the Archive: Truth, Reconciliation, and Indigenous Archival Memory." Archivaria, vol. 82, 2016, pp. 3-26.

Gibson, Ross. 'Camera Natura: Landscape In Australia Feature Films.' Framework: The Journal of Cinema and Media, vol. 22/23, 1983, --. 47-51.

Ginsberg, Faye. “The Indigenous Uncanny: Accounting For Ghosts in Recent Indigenous Australian Experimental Media.” Visual Anthropology Review, vol. 34, no. 1, 2018, pp. 67-76.

Godard, Jean-Luc and Youssef Igashpour. Cinema: The Archeology of Film and the 
Memory of a Century. 2000. Translated by John Howe, Berg, 2005.

Golding, Dan. “The Man From Snowy River.” Metro Magazine: Media \& Education Magazine, no. 194, 2017, pp. 114-123.

Goldsmith, Leo interview with Soda_Jerk. "Revenge Remix.” Art Forum, 2018. www.artforum.com/film/soda-jerk-tk-77952. Accessed 1. Mar. 2020.

Good Copy, Bad Copy. Directed by Andreas Johnsen, Ralf Christensen and Henrik Moltke, 2007.

Graf, Alexander and Dietrich Scheunemann, editors. Avant-Garde Film. Brill Rodopi, 2007.

Grant, Catherine. "The Shudder of a Cinephiliac Idea? Videographic Film Studies Practice as Material Thinking." Aniki: Portuguese Journal of the Moving Image, vol. 1, no. 1, 2014, pp. 49-62.

Grease. Directed by Randal Kleiser. Paramount Pictures, 1978.

The Great Dictator. Directed by Charlie Chaplin. Charles Chaplin Film Corporation, 1940.

The Great Road. Directed by Esfir Shub. 1927.

Greenberg, Clement. “Collage.” 1959. The Ends of Collage, edited by Yuval Etgar, Luxembourg and Dayan, 2017, pp. 73-86.

Gregersdotter, Katarina, Johan Höglund and Nicklas Hållén. Animal Horror Cinema: Genre, History and Criticism. Palgrave, 2015.

Griffin, Penny. "\#MeToo, White Feminism and Taking Everyday Politics Seriously in the Global Political Economy." Australian Journal of Political Science, vol. 54, no. 4, 2019, pp. 556-572.

Guldemond, Jaap. "Introduction.” Found Footage: Cinema Exposed, edited by Jaap Guldemond et al., Amsterdam University Press, 2012, pp. 10-16.

Gunning, Tom. "The Cinema of Attractions: Early Film, its Spectator and the AvantGarde.” 1986. Early Cinema: Space, Frame, Narrative, edited by Thomas Elsaesser, BFI Publishing, 1990, pp. 56-62.

---. "Finding the Way: Films Found on a Scrap Heap." Found Footage: Cinema Exposed, edited by Jaap Guldemond et al., Amsterdam University Press, 2012, pp. 49-5.

Gupta, Shipra and Swati Samantaray. "Tracing the Evolution of Infromation and Communication Technologies in the Cinema." Smart Intelligent Computing and Applications, edited by Suresh Chandra Stapathy, Vikrant Bhateja, J. R. Mohanty and Siba K. Udgata, Springer, 2020, pp. 175-183.

Habermas, Jürgen. “Modernity: An Incomplete Project.” Postmodern Culture, edited by Hal 
Foster, Pluto Press, 1985, pp. 3-15.

Hadley, Bree. “Advocacy, Allies, and 'Allies of Convenience' in Performance and

Performative Protest." The Routledge Companion to Theatre and Politics, edited by

Peter Eckersall and Helena Grehan, Routledge, 2019, pp. 85-88.

Hage, Ghassan. Arab-Australians Today: Citizenship and Belonging. Melbourne University Press, 2002.

Halberstam, Judith and Ira Livingston. Posthuman Bodies. Indiana University Press, 1995.

Halliwell, Martin. American Culture in the 1950s. Edinburgh University Press, 2007.

Hamilton, Sheryl N. "The Cyborg, 11 Years Later: The Not-So-Surprising Half-Life of the Cyborg Manifesto.” Convergence: The International Journal of Research into New Media Technologies, vol. 3, no. 2, June 1997, pp. 104-120.

Haraway, Donna. “A Cyborg Manifesto: Science, Technology and Socialist-Feminism in the Twentieth Century." 1984. Manifestly Haraway, edited by Cary Wolfe, 2016, pp. 5-90.

---. Staying With the Trouble: Making Kin in the Chthuluecene. Duke University Press, 2016.

Harkins-Cross, Rebecca. "No Country." The Lifted Brow, 2018, www.theliftedbrow.com/lift ed brow/2018/11/23/no-country-by-rebecca-harkins-cross. Accessed 1 Mar. 2020.

Harrington, Erin. "Whakanuia: 14 Films Worth Celebrating at the 2018 New Zealand

International Film Festival.” Pantograph Punch, 2018, www.pantographpunch.com/posts/whakanuia-NZIFF-2018. Accessed 1 Mar. 2020.

Harris, Lauren. “TERROR NULLIUS: Soda_Jerk.” Running Dog, 2018, rundog.art/terrornullius-soda_jerk/. Accessed 1 Mar. 2020.

Hawkins, Freda. Critical Years in Immigration: Canada and Australia Compared. McGill Queen's Press, 1991.

Hayles, Katherine. How We Became Posthuman: Virtual Bodies in Cybernetics, Literature and Informatics. University of Chicago Press, 1999.

Healing. Directed by Craig Monahan. Pointblank Pictures, 2014.

Hegel, G.W.F. Encyclopaedia of Philosophical Sciences. 1817. Translated by T.F. Geraets et al., Hackett, 1991.

Heffernan, Tara. “TERROR NULIUS by Soda_Jerk." Third Text: Critical Perspectives on Contemporary Art and Culture, 2019, www.thirdtext.org/heffernan-terrornullius. Accessed 1 Mar. 2020.

Heller-Nicholas, Alexandra. "Soda_Jerk: TERROR NULLIUS.” Artlink, vol. 38, no. 2, 2018, 
pp.88-93.

Hill, Erin. Never Done: A History of Women's Work In Media Production. Rutgers

University Press, 2016.

Hill, Jonathan and Thomas Wilson. "Identity Politics and the Politics of Identities." Global

Studies in Culture and Power, vol. 10, no. 1, 2003, pp. 1-8.

Histoire(s) du Cinéma. Directed by Jean-Luc Godard. Gaumont, 1998.

Hjort, Mette and Scott Mackenzie. Cinema and Nation. Psychology Press, 2000.

Hoberman J. Bridge of Light: Yiddish Film Between Two Worlds. The Museum of Modern Art, 1991.

Höch, Hannah. “On Collage.” 1971. The Ends of Collage, edited by Yuval Etgar,

Luxembourg and Dayan, 2017, p. 143.

Hoffman, Robert L. More than a Trial: The Struggle Over Captain Dreyfus. The Free Press, 1980.

Holberg, Amelia S. "Betty Boop: Yiddish Film Star." American Jewish History, vol. 87, no.

4, 1999, pp. 291-312.

HOLLYWOOD BURN. Directed bySoda_Jerk. 2006.

Holy Smoke!. Directed by Jane Campion. Jan Chapman Films, 1999.

Horwatt, Elijah. The Work of Art in the Age of [Ctrl]-c: Digital Remixing and

Contemporary Found Footage Practice on the Internet. York University, MA thesis, 2009. ProQuest, search.proquest.com/docview/305044445?accountid=14782.

Hoskin, Dave. “Going Walkabout: Lucky Miles.” Metro Magazine: Media and Education, no. 153,2007 , pp. $28-20$.

---. "Look into the mirror, Australia: Housos vs Authority." Metro Magazine:

Media and Education, no. 177, 2013, pp. 26-29.

Howard, John. "The Liberal Tradition: The Beliefs and Values Which Guide the Federal Government." Sir Robert Menzies Lecture, 1996, pmtranscripts.pmc.gov.au/release/ transcript-10171. Accessed 1 Mar. 2020.

The Hour of the Furnaces. Directed by Octavio Getino and Fernando Solanas. Solanas Productions, 1968.

The Hours. Directed by Stephen Daldry. Scott Rudin Productions, 2002.

Housos Vs Authorities. Directed by Paul Fenech. Transmission Films, 2012.

How Much is That Geisha in the Window. Directed by Lierdumoa. 2008.

Hubner, Laura. Fairytale and Gothic Horror: Uncanny Transformations in Film. Palgrave 
Macmillan, 2018.

Hunt, Darnell and Ana-Christiana Ramón. Hollywood Diversity Report 2019: Old Story,

New Beginning. UCLA College of Social Sciences, 2019.

Hunt, Elle. "The Babadook: how the horror movie monster became a gay icon." The

Guardian, 2017. www.theguardian.com/film/2017/jun/11/the-babadook-how-horrormovie-monster-became-a-gay-icon. Accessed 1 Mar. 2020.

Hutchinson, Linda. "Circling the Downspout of Empire." Post-Colonial Studies Reader, edited by Bill Ashcroft et al. Routledge, 1994, pp. 130-135.

Huyssen, Andreas. "High/Low in an Expanded Field." Modernism/Modernity, vol 9, no. 3, 2002, pp. 363-374.

Indigenous Action Media. "Accomplices not Allies: Abolishing the Ally Industrial

Complex, An Indigenous Perspective.” 2014, www.indigenousaction.org/ accomplices-not-allies-abolishing-the-ally-industrial-complex/. Accessed 1 Mar. 2020.

Isaacs, Bruce. "Reality Effects: The Ideology of the Long Take in the Cinema of Alfonso

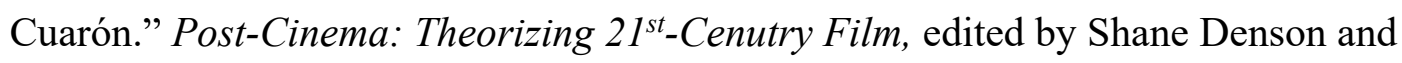
Julia Leyda, REFRAME Books, 2016, pp. 474-513.

Italie, Hillel. "100 Years on, Debate on Birth of a Nation Endures." The Oakland Press, 2015, www.theoaklandpress.com/entertainment/movies-years-on-debate-on-birth-ofa-nation-endures/article_e174bd6b-90c5-5960-b5b0-05e6c2965f21.html. Accessed 1 Mar. 2020.

Iskandar, Adel and Hakem Rustom. Edward Said: A Legacy of Emancipation and Representation. University of California Press, 2010.

Jameson, Fredric. "Postmodernism and Consumer Society." Postmodern Culture, edited by Hal Foster, Pluto Press, 1985, pp.111-125

---. Postmodernism, or, The Cultural Logic of Late Capitalism. Duke University Press, 1991. Japanese Story. Directed by Sue Brooks. Samuel Goldwyn Films, 2003.

Jay, Martin. Cultural Semantics: Keyword of our Time. University of Massachusetts Press, 1998.

Jenkins, Henry et al. Spreadable Media: Creating Value and Meaning in a Networked Culture. New York University Press, 2013.

Jenkins, Keith. The Postmodern History Reader. Psychology Press, 1997.

Johns, Amelia. "Flagging White Nationalism 'After Cronulla': From the Beach to the Net." Journal of Intercultural Studies, vol. 38, no. 3, 2017, pp. 349-364. 
Johnson, Miranda. Australia's First “First People.” Oxford University Press, 2016.

Johnston, Claire. "Women's Cinema as Counter-Cinema." 1973. Film Manifestos and Global Cinema, edited by Scott McKenzie University of California Press, 2014.

Jones, Gwyneth. “Alien Constructions: Science Fiction and Feminist Thought.” Science Fiction Film and Television, vol. 1, no. 2, 2008, pp. 327-331.

Juers, Ben. "Some Big Fatalism: A Review of TERROR NULLIUS." The Lifted Brow, 2018, www.theliftedbrow.com/liftedbrow/2018/4/4/terror-nullius-a-review-by-ben-juers. Accessed 1 Mar. 2020.

Jupp, James. From White Australia to Woomera: The Story of Australian Immigration. Cambridge University Press, 2002.

Karp, Paul. "Labor Pushes For Greater Response to Extreme Rightwing Terrorism Threat." The Guardian, 2019, www.theguardian.com/australia-news/2019/oct/18/labor-pushesfor-greater. Accessed 1. Mar. 2020.

---. “'OK to be white': Australian government senators condemn 'anti-white racism."” The Guardian, 2018, www.theguardian.com/australia-news/2018/oct/15/ok-to-be-whiteaustralian-government-senators-condemn-anti-white-racism. Accessed 1. Mar. 2020.

Kath and Kim. Created by Gina Riley and Jane Turner. ABC TV, 2002-2005.

Kavka, Misha. "The Gothic on Screen." The Cambridge Companion to Gothic Fiction, edited by Jerrold Hogle, Cambridge University Press, 2002, pp. 209-228.

Keathley, Christian. "La Caméra-Stylo: Notes of Video Criticism and Cinephilia." The Language and Style of Film Criticism, edited by Andrew Klevan and Alex Clayton, Routledge, 2011, pp. 176-191.

Keil, Charlie and Kristen Whissel, editors. Editing and Special/Visual Effects. Rutgers University Press, 2016.

Kenny, Mark. "'Caught red-handed': How Tony Abbott's national security push is being used for political gain.” The Sydney Morning Herald, 2015. www.smh.com.au/ politics/ federal/caught-redhanded-how-tony-abbotts-national-security-push-is-beingused-for-political-gain-20150625-ghx6gm.html. Accessed 1 Mar. 2020.

Keskinen, Suvi P. "The 'Crisis' of White Hegemony, Neonationalist Femininities and Antiracist Feminism.” Women's Studies International Forum, vol. 68, 2018, pp. 157163.

Killick, Anthony. "Cinema, Activism and Opposition." The Routledge Companion to Cinema and Politics, edited by Yannis Tzioumakis and Claire Molloy, Routledge, 2016, pp. 77-78. 
King, Natalie, editor. Tracey Moffatt: My Horizon. Thames and Hudson, 2017.

Kirk, Alexandra. “Abbott Calls For Tough Stance on Border Protection.” ABC News, 2010. www.abc.net.au/am/content/2010/s2799547.htm. Accessed 1 Mar. 2020.

Kosnik, Abigail de. “\#CancelColbert:: Popular Outrage, Divo Citizenship, and Digital Political Performativity." Hashtagging Race, Gender, Sexuality, and Nation, edited by Abigail de Kosnik and Keith Feldman, University of Michigan Press, 2019, pp. 203-217.

Krauss, Andrea. “Constellations: A Brief Introduction.” MLN, vol. 126, no. 3, 2011, pp. 439-445.

Kreisinger, Elisa. "Queer Video Remix and LGBTQ Online Communities." Transformative Works and Cultures, no. 9. 2012. doi.org/10.3983/twc.2012.0395.

Kroker, Arthur. Body Drift: Butler, Hayles, Haraway. University of Minnesota Press, 2012. Laderman, David and Laurel Westrup. Sampling Media. Oxford University Press, 2014.

Lantana. Directed by Ray Lawrence. Jan Chapman Films, 2001.

Lasn, Kalle. Culture Jam: The Uncooling of America. Eagle Brook, 1999.

Lauzen, Martha M. The Celluloid Ceiling: Behind-the-scenes Employment of Women on the Top 100, 250, and 500 Films of 2019. Center for the Study of Women in Television and Film, 2019.

Leimbacher, Irena and Chick Strand. "An Introduction to the films of Chick Strand." Discourse, vol. 20, no. 1/2, 1998, pp. 127-152.

Lessig, Lawrence. Remix: Making Art and Commerce Thrive in the Hybrid Economy. Penguin Press, 2008.

Lev Tolstoy and the Russia of Nicholas II. Directed by Esfir Shub. 1928.

Lewis, Glen. Australian Movies and the American Dream. Praeger, 1987.

Lewis, Justin. “The Piratical Ethos in Streams of Language.” Popular Communication: The International Journal of Media and Culture, vol. 13, no.1, 45-61.

Leyda, Jay. Films Beget Films: Compilation Films from Propaganda to Drama. George Allen and Unwin, 1964.

---. Kino: A History of the Russian and Soviet Film. George Allen and Unwin, 1960.

liberal.org.au. "Securing Australia's Borders." The Australian Liberal Party, 2020 www.liberal.org.au/our-plan/border-security. Accessed 1 Mar. 2020.

Life of an American Fireman. Directed by Edwin S. Poter. 1903.

Loose Ends. Directed by Chick Strand, 1979.

Lorde, Audre. “The Master's Tools Will Never Dismantle the Master's House.” 1984. Sister 
Outsider: Essays and Speeches. Crossing Press, 2007, pp. 110- 114.

Lovink, Geert. "The Art of Watching Databases: Introduction to the Video Vortex Reader."

The Video Vortex Reader: Responses to YouTube, edited by Geert Lovink and Sabien Nierderer, Institute of Network Cultures, 2008, pp. 9-12.

Lucas, Rose. "Dragging it Out: Tales of Masculinity in Australian Cinema, From Crocodile Dundee to Priscilla, Queen of the Desert." Journal of Australian Studies, vol. 22, no. 56, 1998, pp. 138-146.

Lucky Miles. Directed by Michael James Rowland. Film Finance Corporation Australia, 2007.

Luu, Chi. "Lingua Obscura: Cancel Culture Is Chaotic Good.” JSTOR Daily, 2020, daily.jstor.org/cancel-culture-is-chaotic-good/. Accessed 1 Mar. 2020.

Lyotard, Jean-François. The Postmodern Condition: A Report on Knowledge. 1979. Translated by Geoff Bennington and Brian Massumi, University of Minnesota Press, 1984.

MacInnes, Allan. "Rupture 2019 Review: TERROR NULLIUS.” The Georgia Straight, 2019, www.straight.com/movies/1250196/rupture-2019-review-terror-nullius. Accessed 1 Mar. 2020.

Macintyre, Stuart. "The History Wars.” The Sydney Papers, vol. 15, no. 3-4 2003, pp. 76-83. Mad Max. Directed by George Miller. Kennedy Miller Productions, 1979.

Mad Max 2 / The Road Warrior. Directed by George Miller. Kennedy Miller Entertainment, 1981.

Mad Max: Fury Road. Directed by George Miller. Kennedy Miller Mitchell, 2015.

Maddox, Graham. "One Nation and Militant Democracy.” The Rise of Right-Populism, edited by Bligh Grant, Tod Moore and Tony Lynch, Springer, 2019, pp. 29-41.

Maffettone, Sebastiano. "How to Avoid the Liaison Dangereuse between Post-Colonialism and Postmodernism." Philosophy \& Social Criticism, vol. 37, no. 4, 2011, pp. 493504.

Magerski, Christine. "Arnold Gehlen. Modern Art as Symbol of Modern Society." Thesis Eleven, no. 8, 2012, pp. 81-96.

Mahar, Karen Ward. Women Filmmakers in Early Hollywood: Studies in Industry and Society. John Hopkins University Press, 2008.

Man with a Movie Camera. Directed by Dziga Vertov. VUFKU, 1929.

Manoff, Marlene. "Theories of the Archive from Across the Disciplines." Libraries and the Academy, vol. 4, no. 1, 2004, pp. 9-25. 
Manovich, Lev. The Language of New Media. MIT Press, 2001.

---. "The Practice of Everyday (Media) Life." The Video Vortex Reader: Responses to

YouTube, edited by Geert Lovink and Sabien Nierderer, Institute of Network

Cultures, 2008, pp. 33-44.

---. “What is Digital Cinema?" Post-Cinema: Theorizing $21^{\text {st }}$-Cenutry Film, edited by Shane

Denson and Julia Leyda, REFRAME Books, 2016, pp. 20-50.

Mares, Peter. Borderline: Australia's Treatment of Refugees and Asylum Seekers. University of New South Wales Press, 2001.

Martin, Adrian. “In So Many Words.” Frames Cinema Journal, vol. 1, 2012.

Martin-Jones, David. Deleuze, Cinema and National Identity: Narrative Time in National

Contexts. Edenborough University Press, 2006.

Masschelein, Anneleen. "A Homeless Concept. Shapes of the Uncanny in TwentiethCentury Theory and Culture." Image and Narrative: Online Magazine of the Visual Narrative, vol. 5, 2003. www.imageandnarrative.be/inarchive/uncanny/ anneleenmasschelein. htm. Accessed 1. Mar. 2020.

Mast, Gerald and Bruce Kawin. A Short History of the Movies. Allyn and Bacon, 2000.

Maunder, Tess interview with Soda_Jerk.”Soda_Jerk," Ocula Magazine, 2018, ocula.com/magazine/conversations/sodajerk/. Accessed 1 Mar. 2020.

Mayer, Geoff and Keith Beattie. The Cinema of Australia and New Zealand. Wallflower Press, 2007.

McCarthy, Noelle. "Soda Jerk - Australian Art Duo's New Film, TERROR NULLIUS." RNZ, 2018, www.rnz.co.nz/national/programmes/saturday/audio/2018654599/sodajerk-australian-art-duo-s-new-film-terror-nullius. Accessed 1 Mar. 2020

McCourt, Tom and Patrick Burkart. "When creators, corporations and consumers collide: Napster and the development of on-line music distribution." Media, Culture \& Society, vol. 25, 2003, pp. 333-350.

McEwan, Paul. "Racist Film: Teaching The Birth of a Nation." Cinema Journal, vol. 47, no. 1, 2007, pp. 98-101.

McGrath, Kenta. "Riot and Revenge: Symmetry and the Cronulla Riot in Abe Forsythe's Down Under." Alphaville: Journal of Film and Screen Media, no. 13, 2017, pp. 1332.

McIntosh, Jonathan. "Building a Critical Culture with Political Remix Video." New Cultural Economy Symposium IV, Linz, 2008, www.youtube.com/watch?v=xwpI9yTnuBQ. Accessed 1 Mar. 2020. 
---. "A History of Subversive Remix Video Before YouTube: Thirty Political Video Mashups Made between World War II and 2005." Transformative Works and Cultures, no. 9, 2012, doi.org/10.3983/twc.2012.0371.

McWhirter, Andrew. "Film Criticism, Film Scholarship and the Video Essay." Screen, vol. 56, no. 3, 2015, pp. 369-377.

Meshes of the Afternoon. Directed by Maya Deren and Alexander Hammid. 1943.

Mielke, Graham. Social Media: Communication, Sharing and Visibility. Routledge, 2016.

Millbank, Adrienne. "The Detention of Boat People.” Current Issues Brief 8 2000-01, Parliament of Australia, 2001.

Milatovic, Maja. "Consuming Wildlife: Representations of Tourism and Retribution in Australian Animal Horror.” Animal Horror Cinema: Genre, History and Criticism, edited by Katarina Gregersdotter, Johan Höglund and Nicklas Hållén, Palgrave, 2015, pp. 76-93.

Miller, Toby, Nitin Govil, John McMurria, Richard Maxwell and Ting Wang. Global Hollywood 2. University of California Press, 2004.

Milner, Ryan M. The World Made Meme: Public Conversations and Participatory Media. MIT Press, 2016.

Mori, Masahiro. “The Uncanny Valley.” IEEE Robotics Automation Magazine, vol. 19, no. 2, 2012, pp. 98-100.

Morley, David. "Finding Out About the World from Telvision News: Some Problems."

Television and Common Knowledge, edited by Jostein Gripstud, 1999, pp. 136-158. A Movie. Directed by Bruce Conner, 1958.

Muriel's Wedding. Directed by P. J. Hogan. House \& Moorhouse Films, 1994.

Mystery Road. Directed Ivan Sen. 2013.

My Tehran for Sale. Directed by Granaz Moussavi. 2009

Nanni, Giordano. The Colonisation of Time: Ritual, Routine and Resistance in the British Empire. Manchester University Press, 2012.

Navas, Eduardo. Remix Theory: The Aesthetics of Sampling. Springer, 2012.

Nelson, Jacqueline K., Maria Hynes, Scott Sharpe, Yin Paradies and Kevin Dunn.

“Witnessing Anti-White 'Racism': White Victimhood and 'Reverse Racism' in Australia.” Journal of Intercultural Studies, vol. 39, no. 3, 2018, pp. 339-358.

Neumark, Norie. "Where Am I? The Terror of Terra Nullius." A Companion to Australian Cinema, edited by Felicity Collins, Jane Landman and Susan Bye, John Wiley and Sons, 2019, pp. 525-536. 
Newall, Steve. "Soda_Jerk talk sample-based, political revenge fable TERROR NULLIUS." Flicks, 2018, www.flicks.co.nz/features/soda-jerk-talk-sample-based-politicalrevenge-fable-terror-nullius/. Accessed 1 Mar. 2020.

Newson, Rhonwyn. "Fraser Anning Doubles Down on Anti-Muslim Comments." Newshub, 2019, www.newshub.co.nz/home/world/2019/03/fraser-anning-doubles-down-onanti-muslim-comments.html. Accessed 1. Mar. 2020.

Nichols, Bill. Introduction to Documentary, 2nd Edition. Indiana University Press, 2010,

---. “Remaking History: Jay Leyda and the Compilation Film.” Film History, vol. 26, no. 4, 2014, pp. 146-156.

Nicholson, Ben. "Benwick Film \& Media Arts Festival 2018.” Notebook, 2018, mubi.com/no tebook/posts/berwick-film-media-arts-festival-2018. Accessed 1 Mar. 2020.

Nicolacopoulos, Toula and George Vassilacopoulos. "Racism, Foreigner Communities and the Onto-pathology of White Australian Subjectivity." Whitening Race: Essays in Social and Cultural Criticism, edited by Aileen Moreton-Robinson, Aboriginal Studies Press, 2004, pp. 32-47.

Night and Fog. Directed by Alain Resnais. Argos Films, 1956.

Night Cries: A Rural Tragedy. Directed by Tracey Moffat. 1990.

Noble, Gregory. “'Where the Bloody Hell are We?' Multicultural Manners in a World of Hyperdiversity." Lines In The Sand: The Cronulla Riots, Multiculturalism and National Belonging, edited by Greg Noble, Institute of Criminology Press, 2006, pp. $1-23$.

North, Dan. "The Silent Screen, 1895-1927: Special/Visual Effects.” Editing and Special/Visual Effects, edited by Charlie Keil and Kristen Whissel, Rutgers University Press, 2016, pp. 37-50.

Northover, Kylie. "Golden Record to Spin Through Outer Space.” The Sydney Morning Herald, 2014, www.smh.com.au/entertainment/music/golden-record-to-spin-throughouter-space-20140106-30dg8.html. Accessed 1 Mar. 2020.

O’Doherty, Brian. "Bruce Conner and His Films.” 1965. Pop, edited by Mark Francis and Hal Foster, Phaidon Press, 2005, p. 239.

Obsessive Becoming. Directed by Daniel Reeves. 1995.

October. Directed by Sergei Eisenstein. Sovkino, 1928.

Olofsson, Christoffer. “Top Five Shorts of 2018.” KinoScope, 2019, read.kinoscope.org/ 
2019/01/04/top-five-shorts-of-2018/. Accessed 1 Mar. 2020.

Orr, Jackie. “Materializing a Cyborg Manifesto.” Women's Studies Quarterly, vol. 20, no. 1/2, 2012, pp. 273-280.

Outback and Beyond. Performed by Grayson Cooke and Mike Cooper. 2012.

Owens, Craig. "The Allegorical Impulse: Toward a Theory of Postmodernism.” October, vol. 12,1980 , pp. $67-86$.

Pauline Hansen: Please Explain! Directed by Anna Broinowski. Special Broadcasting Service, 2016.

Pearlman, Karen and Adelheid Heftberger. "Recognising Women's Work as Creative Work." Apparatus. Film, Media and Digital Cultures of Central and Eastern Europe, vol. 6, 2018, 10.17892/app.2018.0006.124.

Pearson, Megan S. C. A Whedon Manifesto: Superhumans, Inhumans, and Humans in the Posthuman Century, Southern Illinois University at Edwardsville, Ann Arbor, MA thesis, 2014. ProQuest, search.proquest.com/docview/1562776890?accountid=14782.

Perkins, Maureen. “Timeless Cultures: The 'Dreamtime' as Colonial Discourse.” Time and Society, vol. 7, no. 2, 1998, pp. 335-51.

Perry, Nick. Dominion of Signs: Television, Advertising and Other New Zealand Fictions. Auckland University Press, 1994.

Peterson. Directed by Tim Burstall. Hexagon Productions, 1974

Petric, Vlada. "Esther Shub, Cinema is my Life." Quarterly Review of Film Studies, vol. 3, no. 4, 1978, pp. 429-448.

---. "Esther Shub's Unrealised Project. Quarterly Review of Film Studies, vol. 3, no. 4, 1978, pp. 449-456.

Pheasant-Kelly, Fran. "Trauma, Repression and The Babadook: Sexual Identity in the Trump Era." Make America Hate Again: Trump-Era Horror and the Politic of Fear, edited by Victoria McCollum, Routledge, 2019.

The Piano. Directed by Jane Campion. Jan Chapman Films, 1993.

Picnic at Hanging Rock. Directed by Peter Weir. British Empire Films, 1975.

Pihama, Leonie. “Are Films Dangerous? A Maori Woman's Perspective On "The Piano.” Hecate: An Interdisciplinary Journal of Women's Liberation, vol. 20, no. 2, 1994, p. 239.

Plant, Sadie. Zeros and Ones: Digital Women and the New Technoculture. Fourth Estate, 
1997.

Please Like Me. Created by Josh Thomas. Australian Broadcasting Coporation, 2013-2016. Poynting, Scott. "Scouring the Shire." Lines In The Sand: The Cronulla Riots,

Multiculturalism and National Belonging, edited by Greg Noble, Institute of Criminology Press, 2006, pp. 44-58.

Poynting, Scott and Victoria Mason. “Tolerance, Freedom, Justice and Peace'?: Britain, Australia and Anti-Muslim Racism since 11 September 2001." Journal of Intercultural Studies, vol. 27, no. 4, 2006, pp. 365-391.

Presence, Steven. "Reel News in the Digital Age: Framing Britain's Radical VideoActivists." The Routledge Companion to Cinema and Politics, edited by Yannis Tzioumakis and Claire Molloy, Routledge, 2016, pp. 103-111.

Puberty Blues. Created by John Edwards and Imogen Banks. Southern Star Entertainment, 2012-2014.

Puberty Blues. Directed by Bruce Beresford. Umbrella Entertainment, 1981.

Pudovkin, Vsevolod. Film Technique and Film Acting. Translated by Igor Montagu. Bonanza Books, 1949.

Purvis, Emily Marie. "Copyright Law in the Digital Age: Technology Companies Megabyte Back as Australia's Fair Dealing Provisions Lag." University of Western Australia Law Review, vol. 41, no, 2, 2017, pp. 25-35.

Radhakrishnan, R. Theory in an Uneven World. John Wiley \& Sons, 2008.

Rayner, Jonathan. Australian Cinema: An Introduction. Manchester University Press, 2000.

---. "Gothic Definitions: The New Australian "Cinema of Horrors." Antipodes, vol. 25, no. 1, 2011, pp. 91-97.

Redmond, Sean, editor. Liquid Metal: The Science Fiction Film Reader. Columbia University Press, 2005.

Reeve, Donna. "Cyborgs, Cripples and iCrip: Reflections on the Contribution of Haraway to Disability Studies.” Disability and Social Theory: New Developments and Directions, edited by Dan Goodley, Bill Hughes and Lennard Davis, Palgrave Macmillan, 2012, pp. 91-111.

Reid, Mark A. “ A Few Black Keys and Maori Tattoos: Re-Reading Jane Campion's The Piano in PostNegritude Time." Quarterly Review of Film and Video, vol. 17, no. 2, 2000, pp. 107-116. 
RiP!: A Remix Manifesto. Directed by Brett Gaylor, 2008.

Road Games. Directed by Richard Franklin. Essaness Pictures, 1981.

Rogers, Ariel. “Classical Hollywood, 1928-1946: Special/Visual Effects.” North, Dan. "The Silent Screen, 1895-1927: Special/Visual Effects.” Editing and Special/Visual Effects, edited by Charlie Keil and Kristen Whissel, Rutgers University Press, 2016, pp. 68-77.

Romano, Aja. "Why Can’t We Stop Fighting About Cancel Culture.” Vox, 2019, Www.vox.com/culture/2019/12/30/20879720/what-is-cancel-culture-explainedhistory-debate. Accessed 1 Mar. 2020.

Rome Open City. Directed by Roberto Rossellini. Minerva Film, 1945.

Romper Stomper. Directed by Geoffery Wright. Film Victoria, 1992.

Rose-Redwood, CindyAnn and Reuben Rose-Redwood. “'It Definitely Felt Very White':

Race, Gender, and the Performative Politics of Assembly at the Women's March in Victoria, British Columbia." Gender, Place \& Culture, vol. 24, no. 5, 2017, pp. 645654.

Rosen, Robert. The American Historical Review, vol. 95, no. 4, 1990, pp. 1126-1128.

Ross, Loretta. "I'm a Black Feminist. I Think Call-Out Culture Is Toxic.” The New York Times, 2019. www.nytimes.com/2019/08/17/opinion/sunday/cancel-culture-callout.html. Accessed 1 Mar. 2020.

Royle, Nicholas. The Uncanny. Manchester University Press, 2003.

Russo, Julie Levin and Coppa, Francesca. "Fan/Remix Video (a remix)." Transformative Works and Cultures, vol. 9, 2012, doi.org/10.3983/twc.2012.0431.

Sahraoui, Nassima and Caroline Sauter. Thinking In Constellations: Walter Benjamin and the Humanities. Cambridge, 2018.

Said, Edward. "Opponents, Audiences, Constituencies and Community." Postmodern Culture, edited by Hal Foster, Pluto Press, 1985, pp. 136-159.

---. Orientalism. Vintage, 1979.

Saler, Michael. "Profane Illuminations, Delicate and Mysterious Flame: Mass Culture and Uncanny Gnosis.” Uncanny Modernity: Cultural Theories, Modern Anxieties, edited by Jo Collins, Springer, 2008.

The Sapphires. Directed by Wayne Blair. Goalpost Pictures, 2012.

Sarbin, Theodore R. Narrative Psychology: The Storied Nature of Human Conduct. Praeger, 1986.

Schultz, Rosemary, "The Agenda Setting Function of Mass Media, Tampa, John Howard, 
Print Media and Public Opinion: How It All Came Together in Melbourne" Independent Study Project (ISP) Collection, no. 482, 2005.

Schwartz, Joan and Terry Cook. "Archives, Records, and Power: The Making of Modern Memory.” Archival Science, vol. 2, no. 1/2, 2002, pp. 1-19.

Scott, Allen J. On Hollywood: The Place, The Industry. Princeton University Press, 2005.

Scott, Jessie. "Soda_Jerk's Theatre of Ghosts.” ACMI, 2018. www.acmi.net.au/ideas/read/soda_jerks-theatre-ghosts/. Accessed 1 Mar. 2020.

Scott Morrison - I've Always Believed in Miracles Song. Directed by Victor De Meer, 2019. www.youtube.com/watch?v=anAm-Uly3-s. Accessed 1 Mar. 2020.

Searle, Adrian. "Tracey Moffatt Review - Horrible Histories from Australia's Venice Envoy." The Guardian, 2017. www.theguardian.com/artanddesign/2017/may/10/ tracey-moffatt-my-horizon-australia-pavilion-venice-biennale. Accessed 1 Mar. 2020.

The Seashell and the Clergyman. Directed by Germaine Dulac. 1928.

A Secret Country: The First Australians Fight Back. Directed by Alan Lowrey and written by John Pilger. British Central Independent Television, 1985

Semati, Mehdi. "Islamophobia, Culture and Race in the Age of Empire." Cultural Studies, vol. 24, no. 2, 2010, pp. 256-275.

Sharp, Bailey and Ben Juers interview with Soda_Jerk. "Weaponising Frustration and Despair: An Interview with Soda_Jerk," The Lifted Brow, 2018, www.thelifted brow.com/liftedbrow/2018/3/25/weaponising-frustration-and -despair-an-interviewwith-sodajerk. Accessed 1 Mar. 2020.

Sharp, lana (née Shub). "The Fall of the Romanov Dynasty (1927): A Constructivist Paradigm for Neigrovaia Fil'ma." Historical Journal of Film, Radio and Television, vol. 28, no. 2, 2008, pp. 195-217, DOI: 10.1080/01439680802077238.

Shaviro, Steven. "Post-Continuity: An Introduction." Post-Cinema: Theorizing $21^{\text {st }}$-Cenutry Film, edited by Shane Denson and Julia Leyda, REFRAME Books, 2016, pp. 51-64. Shelley, Peter. Australian Horror Films, 1973-2010. McFarland, 2012.

Shub, Esfir. "And Again the Newsreel.” 1929. Esfir Shub: Selected Writings," foreword by Liubov Dyshlyuk and translated by Anastasia Kostina, Feminist Media Histories, vol. 3, no. 2, 2016, pp. 21-24.

---. "From My Experience.” 1927. "Esfir Shub: Selected Writings,” foreword by Liubov Dyshlyuk and translated by Anastasia Kostina, Feminist Media Histories, vol. 3, no. 2, 2016, pp. 17-19.

---. “The Great Road.” 1928. "Esfir Shub: Selected Writings,” foreword by Liubov 
Dyshlyuk and translated by Anastasia Kostina, Feminist Media Histories, vol. 3, no. 2, 2016, p. 21.

---. "The First Word." 1928. "Esfir Shub: Selected Writings," foreword by Liubov Dyshlyuk and translated by Anastasia Kostina, Feminist Media Histories, vol. 3, no. 2, 2016, pp. 19-20.

---. "The Work of Montazhnitsy." 1927. "Esfir Shub on Women in the Editing Room." Foreword and translation by Alla Gadassik, Apparatus: Film, Media and Digital Cultures in Central and Eastern Europe, no. 6, 2018, doi.org/10.17892/app.2018.0006.125.

Smelik, Anneke. "Cinematic Fantasys of Becoming-Cyborg." Film Criticism, the Cold War, and the Blacklist: Reading the Hollywood Reds, edited by Jeff Smith, 2010, pp. 89104.

Smith, Ali. "On Edge." The Ends of Collage, edited by Yuval Etgar, Luxembourg and Dayan, 2017, pp. 233-234.

Sobande, Francesca. "Memes, digital remix culture and (re)mediating British politics and public life." IPPR Progressive Review, vol. 26, no. 2, 2019, pp. 151-160.

Sobchack, Vivian. The Persistence of History: Cinema, Television and the Modern Event. Routledge, 1995.

Soda_Jerk. “The Anarchivist Manifesto.” INCITE Journal of Experimental Media, vol. 6, 2015, pp. 140-145.

---. “TERROR NULLIUS.” Soda_Jerk, 2018, www.sodajerk.com.au/video_work.php? $\mathrm{v}=20180223211319$. Accessed 1 Mar. 2020.

Sofoulis, Zoë. “Cyberquake: Haraway’s Manifesto.” 2002. The Cybercultures Reader: Second Edition, edited by David Bell and Barbara M Kennedy, 2007, pp. 281-323.

Sontag, Susan. Against Interpretation. Farrar, Strauss and Giroux, 1966.

Sorlin, Pierre. The Film in History. Basil Blackwell, 1980.

Spear. Directed by Stephen Page. Cinema Plus, 2015.

Speidel, Suzanne. "Film Form and Narrative." Introduction to Film Studies, Fifth Edition, edited by Jill Nelmes, Routledge, 2011, pp. 79-112.

Spivak, Gayatri Chakravorty and Elizabeth Gross. "Criticism, Feminism and the Institution: An Interview with Gayatri Chakravorty Spivak.” Thesis Eleven, no. 10/11, 1984/5, pp. 175-187.

Squire, Dian. "Ending Allies Through the Eradication of the Ally (Industrial) Complex." Rethinking LGBTQIA Students and Collegiate Contexts: Identity, Policies and 
Campus Climate, edited by Eboni Zamani-Gallaher, Devika Dibya Choudhuri and Jason Taylor, Routledge, 2020, pp. 186-203.

Stadler, Jane et al. Imagined Landscapes: Geovisualizing Australian Spatial Narratives.

Indiana University Press, 2016.

Stam, Robert. Reflexivity in Film and Literature: Don Quixote to Jean-Luc Godard. Columbia University Press, 1985.

---. "The Two Avant-Gardes: Solanas and Getino's Hour of the Furnaces." Documenting the Documentary: Close Readings of Documentary Film and Video, edited by Barry Keith Grant and Jeannette Sloniowski, Wayne State University Press, 2013. Steinberg, Michael P. "The Collector as Allegorist: Goods, Gods and the Objects of History." Walter Benjamin and the Demands of History, edited by Michael P. Steinberg, Cornell University Press, 1996.

Sterritt, David, editor. Jean-Luc Godard Interviews. University Press of Mississippi, 1998. Stratton, Jon. “"Welcome to Paradise': Asylum Seekers, Neoliberalism, Nostalgia and Lucky Miles." Continuum: Journal of Media \& Cultural Studies, vol. 23, no. 5, 2009, pp. 629-645.

---. "What Made 'Mad Max' Popular? The Mythology of a Conservative Fantasy." Art \& Text, no. 9, 1987, pp. 37-56.

Stone, Alison. Third Wave Feminism: A Critical Exploration. Palgrave Macmillan, 2004.

Strike. Directed by Sergei Eisenstien. Goskino Proletkult, 1925.

Sweetie. Directed by Jane Campion. Avenue Pictures Productions, 1989.

Swenberg, Thorbjörn and Erik Erikson. "Effects of Continuity or Discontinuity in Actual Film Editing." Empirical Studies of the Arts, vol. 36, no. 2, 2018, pp. 222-246.

Tascón, Sonia. Human Right Film Festivals: Activism in Context. Palgrave Macmillan, 2015. Tavan, Gwenda. "Long, Slow Death of White Australia." The Sydney Papers, vol. 17, no. 3/4, 2005, pp. 135-139.

Taylor, Affrica. "Australian Bodies, Australian Sands." Lines In The Sand: The Cronulla Riots, Multiculturalism and National Belonging, edited by Greg Noble, Institute of Criminology Press, 2006, pp. 111-127.

Ten Canoes. Directed by Rolf de Heer and Peter Djigirr. Palace Films and Cinemas, 2006. TERROR NULLIUS. Directed by Soda_Jerk, 2018.

Thussu, Daya K. Media on the Move: Global Flow and Contra-Flow. Routledge, 2007. Tinwell, Angela. The Uncanny Valley: In Games and Animation. CRC Press, 2015. Tofts, Darren and Christian McCrea. "What Now?: The Imprecise and Disagreeable 
Aesthetics of Remix." Fibreculture Journal, vol. 15, 2009, www.journal.

fibreculture.org/issue15/index_print.html. Accessed 1 Mar. 2020.

Torchin, Leshu. "Kony 2012: Anatomy of a Campaign Video and a Video Campaign.” The Routledge Companion to Cinema and Politics, edited by Yannis Tzioumakis and

Claire Molloy, Routledge, 2016, pp. 123-134.

A Trip Down Memory Lane. Directed by Arthur Lipsett. 1965.

Turkey Shoot. Directed by Brian Trenchard-Smith. Hemdale, 1982

Turnock, Julie. “The Auteur Renaissance, 1968-1980: Special/Visual Effects.” Editing and Special/Visual Effects, edited by Charlie Keil and Kristen Whissel, Rutgers

University Press, 2016, pp. 116-128.

Ulmer, Gregory L. “The Object of Post-Criticism.” Postmodern Culture, edited by Hal Foster, Pluto Press, 1985, pp. 38-110.

Vaidhyanathan, Siva. Copyrights and Copywrongs The Rise of Intellectual Property and How it Threatens Creativity. New York University Press, 2001.

Veracini, Lorenzo. "Historylessness: Australia as a Settler Colonial Collective."

Postcolonial Studies, vol. 10, no. 3, 2007, pp. 271-285.

Vigil. Directed by Tracey Moffatt. 2017.

Vint, Sherryl, editor. Science Fiction and Cultural Theory: A Reader. Routledge, 2016.

VNS Matrix. "A Cyberfeminist Manifesto for the $21^{\text {st }}$ Century.” 1991, vnsmatrix.net.

Accessed 1 Mar. 2020.

Walkabout. Directed by Nicholas Roeg. Max L. Raab-Si Litvinoff Films, 1970.

Warner, Charles R. "Shocking Histoire(s): Godard, Surrealism, and Historical Montage."

Quarterly Review of Film and Video, vol. 25, no. 1, 2007, pp 1-15.

Wees, William C. Recycled Images: The Art and Politics of Found Footage Films.

Anthology Film Archives, 1993.

Wentworth. Created by Lara Radulovich, David Hannam, and Reg Watson. Fremantle Australia, 2013 - ongoing.

Where Green Ants Dream. Directed by Werner Herzog. Filmverlag der Autoren, 1984.

A White Ghost Sailed In. Directed by Tracey Moffatt. 2017.

White, Hayden. "Historiography and Historiophoty." The American Historical Review, vol. 93, no. 5, 1988, pp. 1193-1199.

---. Metahistory: The Historical Imagination in Nineteenth Century Europe. Johns Hopkin University Press, 1973.

---. "The Modernist Event." The Persistence of History: Cinema, Television and the Modern 
Event, edited by Vivian Sobchack, Routledge, 1995, pp. 17-38.

White, Leanne. “The Man from Snowy River: Australia's Bush Legend and Commercial

Nationalism." Tourism Review International, vol. 13, no. 2, 2009, pp. 139-148.

Williams, James S. "European Culture and Artistic Resistance in Histoire(s) du Cinéma."

---. “Histoire(s) Du Cinéma.” Film Quarterly, vol. 61, no. 3, 2008, pp. 10-16.

Williams, Paul.’Beyond 'Mad Max III:' Race, Empire and Heroism on Post-Apocalyptic

Terrain.” Science Fiction Studies, vol. 32, no. 2, 2005, pp. 301-315.

Willis, Ika. "Slash as Queer Utopia.” Queer Space: Centres and Peripheries Conference,

University of Technology, Sydney, 2007, pp. 1-6.

Wilson, Clint, Felix Guiterrez and Lena Chao. Racism, Sexism, and the Media: The Rise of

Class Communication in Multicultural America. SAGE, 2003.

Wilson, Jason. “'It's OK to be White' is Not a Joke, it's Careless Politicians Helping the Far Right." The Guardian, 2018, www.theguardian.com/commentisfree/2018/oct/16/itsok-to-be-white-is-not-a-joke-its-careless-politicians-helping-the-far-right. Accessed 1 Mar. 2020.

Windschuttle, Keith. The Fabrication of Aboriginal History, Vol. 1, Van Dieman's Land 1803-184. Macleay Press, 2002.

Winn, J. Emmett. "Mad Max, Reaganism and The Road Warrior.” Kinema: A Journal for Film and Audiovisual Media, 1997, pp. 1-11.

Witt, Michael. Jean-Luc Godard, Cinema Historian. Indiana University Press, 2013.

Wolf Creek. Created by Greg McLean. Emu Creek Pictures, 2016-2017.

Wolfram, Eddie. History of Collage: An Anthology of Collage, Assemblage, and Event Structures. Studio Vista, 1975.

Wong, Jack. "Remapping the Constellation of Walter Benjamin's Allegorical Method." American, British and Canadian Studies, vol. 25, no. 1, 2015, pp. 37-59.

Wong, Luke. "Southern Cross tattoos lose their lustre, leaving bearers to cover up." $A B C$ News, 2018, www.abc.net.au/news/2018-01-26/trend-of-covering-up-and-removingsouthern-cross-tattoos/9360746. Accessed 1. Mar. 2020.

Wong, Tim. “TERROR NULLIUS.” New Zealand International Film Festival, 2018, www.nziff.co.nz/2018/auckland/terror-nullius/. Accessed 1. Mar. 2020.

Yeo, Rob. "Cutting Through History: Found Footage in Avant-garde Filmmaking." Cut: Film as Found Object in Contemporary Video, edited by Stefano Basilico, Milwaukee Art Museum, 2004, pp. 13-27.

Yin, Jing. "Beyond Postmodernism: A Non-Western Perspective on Identity." Journal of 
Multicultural Discourses, vol. 13, no. 3, 2018, pp. 193-219.

Young, Robert. Postcolonialism: An Historical Introduction. Wiley Blackwell, 2016.

Zeilinger, Martin. "Sampling as Analysis, Sampling as Symptom.” Sampling Media, edited by David Laderman and Laurel Westrup, Oxford University Press, 2014.

Zielinski, Ger. "On the Production of Heterotopia, and Other Spaces, In and Around Lesbian and Gay Film Festivals." Jumpcut: A Review of Contemporary Media, no. 54, 2012, www.ejumpcut.org/archive/jc54.2012/gerZelinskiFestivals/index.html. Accessed 1 Mar. 2020.

Zorn's Lemma. Directed by Hollis Frampton. 1970. 